\title{
Microbial lipases and their industrial applications: a comprehensive review
}

\author{
Prem Chandra ${ }^{1 *} \mathbb{D}, E^{2}$ espa ${ }^{2}$, Ranjan Singh ${ }^{3}$ and Pankaj Kumar Arora ${ }^{4}$
}

\begin{abstract}
Lipases are very versatile enzymes, and produced the attention of the several industrial processes. Lipase can be achieved from several sources, animal, vegetable, and microbiological. The uses of microbial lipase market is estimated to be USD 425.0 Million in 2018 and it is projected to reach USD 590.2 Million by 2023, growing at a CAGR of $6.8 \%$ from 2018. Microbial lipases (EC 3.1.1.3) catalyze the hydrolysis of long chain triglycerides. The microbial origins of lipase enzymes are logically dynamic and proficient also have an extensive range of industrial uses with the manufacturing of altered molecules. The unique lipase (triacylglycerol acyl hydrolase) enzymes catalyzed the hydrolysis, esterification and alcoholysis reactions. Immobilization has made the use of microbial lipases accomplish its best performance and hence suitable for several reactions and need to enhance aroma to the immobilization processes. Immobilized enzymes depend on the immobilization technique and the carrier type. The choice of the carrier concerns usually the biocompatibility, chemical and thermal stability, and insolubility under reaction conditions, capability of easy rejuvenation and reusability, as well as cost proficiency. Bacillus spp., Achromobacter spp., Alcaligenes spp., Arthrobacter spp., Pseudomonos spp., of bacteria and Penicillium spp., Fusarium spp., Aspergillus spp., of fungi are screened large scale for lipase production. Lipases as multipurpose biological catalyst has given a favorable vision in meeting the needs for several industries such as biodiesel, foods and drinks, leather, textile, detergents, pharmaceuticals and medicals. This review represents a discussion on microbial sources of lipases, immobilization methods increased productivity at market profitability and reduce logistical liability on the environment and user.
\end{abstract}

Keywords: Microbial lipase, Fatty acids, Triglycerides, Protein engineering, Biosensor, Food industry, Candida antarctica lipase B (CALB)

\section{Introduction}

The serine hydrolases are present in abundantly and known as lipase enzyme which belong to triacylglycerol ester hydrolase family (EC 3.1.1.3). They can catalyze the hydrolysis (and synthesis) of long-chain triglycerides to fatty acids, diacylglycerol, monoacylglycerol and glycerol known as carboxylesterases [1, 2]. Besides hydrolysis activity they display interesterification, esterification, aminolysis and alcoholysis activity which are contributed

\footnotetext{
*Correspondence: p.chandrabbau@gmail.com

${ }^{1}$ Food Microbiology \& Toxicology, Department of Microbiology, School for Biomedical and Pharmaceutical Sciences, Babasaheb Bhimrao Ambedkar University (A Central) University, Lucknow, Uttar Pradesh 226025, India

Full list of author information is available at the end of the article
}

in wide range industries $[3,4]$. Lipase synthesizes esters from glycerol and long-chain fatty acids in non-aqueous medium [5]. The microbial lipases are more valuable comparison to derive from plants or animals due to their variety of catalytic activities available, high yield production, and simplicity of genetic manipulation, absence of seasonal fluctuations, regular supply, more stability safer and more convenient and the growth rate of microorganisms very high in economically media [6, 7]. The bacterial isolates offer higher activities such as neutral or alkaline $\mathrm{pH}$ optima and the thermostability associated to yeasts [8]. Bacterial strains such as Pseudomonas alcaligenes, $P$. aeruginosa, $P$. fragi, P. fluorescens BJ-10, Bacillus subtilis, B. nealsonii S2MT and some species of fungi are Penicillium expansum, Trichoderma, Penicillium chrysogenum; 
Aspergillus niger produces lipases in higher quantities [913]. The increasing awareness about animal health and quality of animal produce, and increasing consumption of enzyme-modified cheese (EMC) and enzyme-modified dairy ingredients (EMDI) the lipase market has been extensively increased $[14,15]$. Due to the more benefits of microbial lipases over animal and plant lipases are also motivating the market growth. The request for microbial sources is projected to witness significant growth in the near future, due to their wide range of food processing applications $[16,17]$. The microbial lipase market is projected to dominate due to cleaning agent segment through the forecast period [18]. The growth of industrial microbial lipases in the detergents industry is the innovative key factor to replacing harsh chlorine bleach with lipase and reduced the industrial as well as sewage pollution from fresh water $[19,20]$. The microbial lipases in the form of powder is projected to dominate the microbial lipase markets due to its stability, easy to handle, and easier for packaging and its transportation preferred by the consumers $[21,22]$. These are extensively applicable in several another industries such as dairy, food and beverage, animal feed, cleaning, biofuel, pharmaceuticals, textile cosmetic, perfumery, flavour industry, biocatalytic resolution, esters and amino acid derivatives, fine chemicals production, agrochemicals, biosensor, and bioremediation [23-25]. Additionally, altering in the dietary patterns have led to augmented the consumption of dairy products in the region; increasing in trepidations about superior hygiene, in consciousness of personal hygiene, contagious diseases, and bleaching household industrial surfaces [26]. The manufacturers who operate on a global level and the rising in implementation of lipase enzymes drive the demand for microbial lipases in the region [27, 28].

Between the 2015 and 2020, the market scope of lipase is expected to reach $\$ 590.5$ Million by 2020 globally, at a CAGR of $6.5 \%$. The Asia-Pacific was the largest market for lipase consumption in 2014 [29, 30]. And during the forecast period the Asia-Pacific market is estimated to grow at the highest CAGR. Moreover, the rising prospects in the developing markets such as India, China, and Brazil are expected to enhance the market scope of lipases over the forecast period. Novozymes A/S (Denmark), E. I. du Pont de Nemours and Company (Genencor) (U.S.), Koninklijke DSM N.V. (Netherlands), and Chr. Hansen Holdings A/S (Denmark) are the key industries reported for the consumption of lipases at worldwide (http://www.marketsandmarkets.com, 2020). Due to the specific properties such as enantioselectivity, regioselectivity and broad substrate specificity properties the lipase showing more interest between all the enzymes $[31,32]$. This present review focused on discussing the sources of microorganisms, immobilization methods and their potential applications of lipases including commercially available.

\section{Historical background}

Inside or outside the cells enzymes are proteins and have ability of catalyzing the various chemical and biochemical reactions. They are highly specific natural catalysts to the various types of substrates and operate under insignificant conditions of environmental factor such as temperature, pressure, $\mathrm{pH}$, with high conversion rates [33, 34]. Lipase was first discovered in pancreatic juice as an enzyme by Claude Bernard in 1856, which hydrolysed unsolvable oil droplets and transformed them to soluble products [35]. After that the productions of lipase have been observed in the bacteria Bacillus prodigiosus, $B$. pyocyaneus and B. fluorescens in 1901, and in the current scenario Serratia marcescens, Pseudomonas aeruginosa and Pseudomonas fluorescens species of bacteria have been detected for the production of lipases on large scale [36]. Lipolase was the first commercial recombinant lipase industrialized from the fungus Thermomycesl anugiwnosus and expressed in Aspergillus oryzae in 1994 [37]. Traditionally, lipase has been achieved from the animal pancreas and was made applicable as digestive supplements in the form of crude or in purified grade. It has been extensively used as biocatalytic procedures for the synthesis of several novel chemical compounds [38-40].

\section{Definition of lipases}

Lipases (EC 3.1.1.3) are known as triacylglycerol acylhydrolase which acts on carboxylic ester bonds is the part of hydrolases family [41, 42]. They do not require any cofactor and belongs to the class of serine hydrolases [43]. Triglycerides hydrolyzed into diglycerides, monoglycerides, fatty acids, and glycerol by using the lipases naturally (Fig. 1a). The carboxylic esters bonds can be hydrolyzed by esterases in addition to lipases $[44,45]$.

The hydrolysis of ester bonds at the interface catalyzes by lipases between an unsolvable phase of substrate and aqueous phase where the enzymes keep on liquefied under natural conditions (Fig. 1b). However, Pseudomonas aeruginosa, Candida anatarctica $B$, and Burkholderia glumae possessed a lid but did not show interfacial activation [46, 47]. Esterification, transesterification, interesterification, acidolysis, alcoholysis, and aminolysis conversion reaction takes place by lipases [48, 49].

The presence of a lid and the interfacial activation are not the suitable criteria for to categorize a true lipase, carboxylesterase simply defined that catalyzes the hydrolysis and synthesis of long-chain acylglycerols [50]. 
a

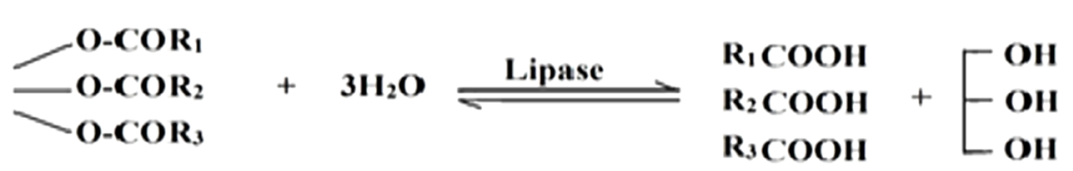

Fatty acid Glycerol

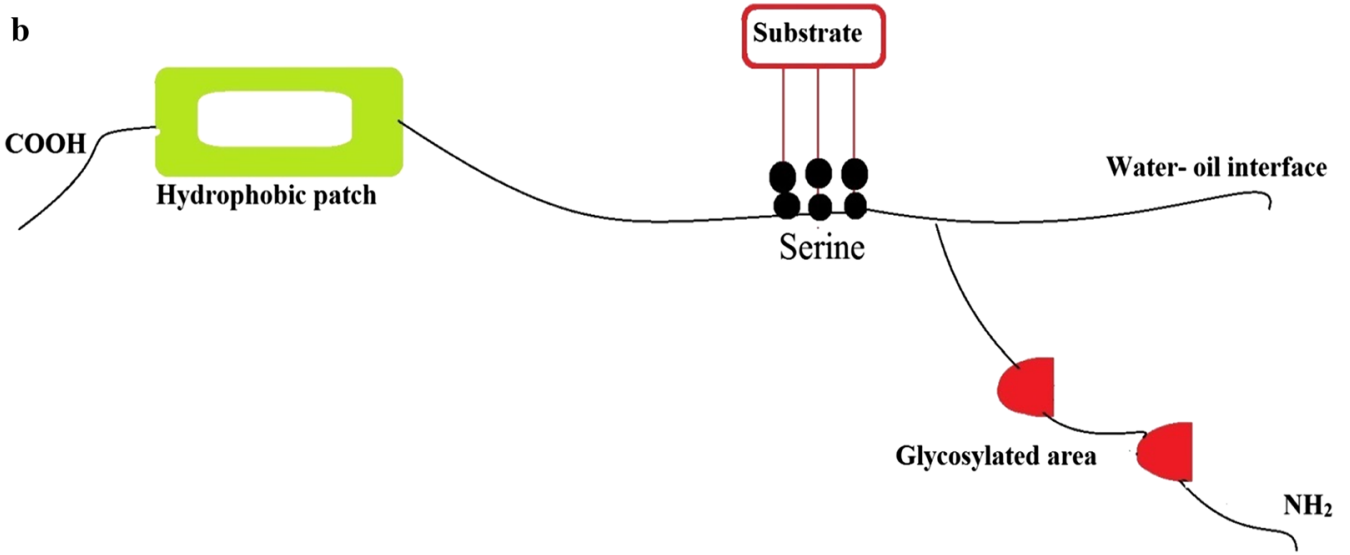

Fig. 1 (a) Hydrolysis of triglyceride converts into glycerol and fatty acid. b Representation of a molecule of lipase with its features

\section{Properties and characteristics of lipases}

The molecular weight of lipases is in the range of $19-60 \mathrm{kDa}$ and reported to be monomeric protein. The position of the fatty acid in the glycerol backbone, chain length of the fatty acid, and its degree of unsaturation are the factors and the physical properties of lipases depend on it $[51,52]$. The sensory and nutritive values of given triglyceride also affected by these features. Several lipases catalyze a number of useful reactions such as esterification due to their activeness in organic solvents $[47,53]$. Lipases displayed $\mathrm{pH}$ dependent activities, generally at neutral $\mathrm{pH} 7.0$ or up to $\mathrm{pH} 4.0$ and 8.0 lipases are stable, Chromobacterium viscosum, A. niger and Rhizophus sp., produced extracellular lipases are active at acidic $\mathrm{pH}$, and $P$. nitroaeducens produced alkaline lipase and active at $\mathrm{pH} 11.0$ [54]. Under certain experimental conditions lipases have capability to reversing the reactions which leads to esterification and interesterification in the absence of water $[55,56]$. For the expression of lipase activities the cofactors are not necessary but calcium is the divalent cation stimulates the activity [57, 58]. Co, $\mathrm{Ni}^{2+}, \mathrm{Hg}^{2+}$ and $\mathrm{Sn}^{2+}$ inhibited the lipase activities drastically and $\mathrm{Zn}^{2+}, \mathrm{Mg}^{2+}$, EDTA and SDS inhibited slightly. The half-life values determined temperature stability profiles of lipases and lower temperature shows more stability $[59,60]$. According to the region-specificity lipases divided into two groups and revealed with acyl glycerol substrate. Without display of regiospecificity only fatty acids are discharged from all three positions of glycerols in the first group of lipases [61-63]. The fatty acids regio-specifically discharged from the 1,3 positions of acylglycerols in the second group of lipase. Triacylglycerol hydrolysed by lipases and constructed 2-monoacylglycerol and free fatty acids 1, 2-(2, 3)-diacylglycerols. In $A$. arrhizus, $R$. delemar, $C$. cylindracea and $P$. aeruginosa the partial stereo-specificity have been detected in the hydrolysis of triacylglycerols [64-66]. These enzymes may be used to extract optically pure esters and alcohols due to these properties. At low water activity using the organic media offers an exceptional prospect over variation of the solvent [67]. So, varying the properties of the solvents an enzyme's specificity may be transformed. Any solvent may utilize a substantial influence on the catalytic properties of an enzyme due to the possession of soft structures and delicate $[68,69]$.

\section{Kinetic model of lipolysis}

At the substrate/water interface lipolysis arises so the Michaelis-Menten model cannot be described it. In a homogeneous phase which is effective only for biocatalysis in which enzyme and substrate are soluble [70, 71]. At an interface to describe the kinetics of lipolysis simple models has been proposed and be made up of two consecutive equilibrium $[72,73]$. The alterable adsorption of enzyme to the interface $\left(\mathrm{E} \leftrightarrow \mathrm{E}^{*}\right)$ happens in the first equilibrium phase, a single substrate molecule $(\mathrm{S})$ 
binds by the adsorbed enzyme $\left(E^{*}\right)$ in the formation of $\left(E^{*} S\right)$ complex as a result in the second phase of equilibrium [74, 75]. For the enzyme-substrate complex to the Michaelis- Menten equilibrium this latter equilibrium is equivalent. Ending with the discharge of the products and renovation of the enzyme in the $\left(\mathrm{E}^{*}\right)$ form, the subsequent catalytic steps take place once the $\left(E^{*} S\right)$ complex is formed [76, 77]. The adsorbed lipase in the vicinity of substrate concentration at the interface is at the surface concentration instead of volumetric concentration conventional in the atmosphere [78, 79]. The rejuvenated lipase remnant adsorbed to the interface and is only unrestricted after a number of catalytic cycles in this model (Fig. 2).

The activity of lipase is a utility of interfacial conformation: the enzyme can be denatured as well as triggered or neutralized and the interface is a suitable spot for restraining lipolysis. The directly interaction of lipase inhibitor with the enzyme and obstructs the activity of lipase. On the other hand, via the adsorption to the interphase or to the substrate molecules few compounds can postpone the lipolytic reaction [80-82].

Lipase inhibitors are grouped into two categories:

(a) Synthetic lipase inhibitors (including phosphonates, boronic acids and fats analogues) and

(b) Natural compounds ( $\beta$-lactones and several botanical foodstuffs-plant extracts and metabolites, chiefly polyphenols, saponins as well as peptides and particular nutritive fibers). Lipases are essential enzymes for lipid absorption, so the absorption of fat or obesity controlled by the lipase inhibition. $\beta$ - lactones including orlistat are the natural compounds, have the ability to inhibit the lipase activity $[83,84]$. Over $80 \%$ of total dietary fats the pancreatic lipase is responsible for the hydrolysis. In several countries for the treatment of obesity orlistat is the registered drug [85].

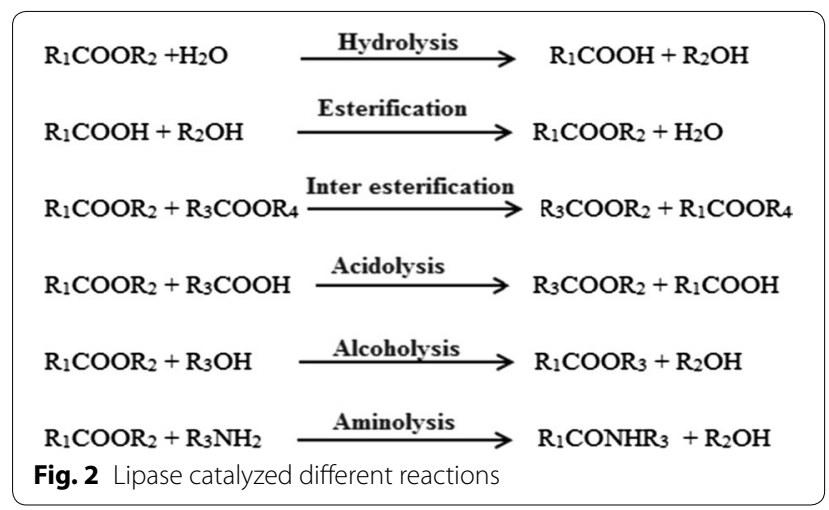

\section{Lipase inhibitors from microbial sources}

From microorganisms several metabolic products have potent pancreatic lipase (PL) inhibitory activity. The several bacterial, fungal and other marine species continued search of effective antiobesity agent screened to find new compounds with PL inhibitory activity [86, 87].

\section{Lipstatin}

The digestive activity of pancreatic lipases controls by the Lipstatin is a $\beta$-lactone molecule which also controls the absorption of fat in the small intestine. Lipstatin was first isolated from Streptomyces toxytricini is a precursor for tetrahydrolipstatin (also known as orlistat, Xenical, and Alli), the only FDA-approved antiobesity medication for long-term use is a very potent inhibitor of PL [88, 89]. Lipase inhibitory activity was lost on opening of $\beta$-lactone ring. The catalytic hydrogenation product of lipstatin is crystalline tetrahydrolipstatin and generally known as orlistat is currently on the market as an antiobesity agent $[90,91]$.

\section{Panclicins}

Streptomyces sp. NR 0619 produced Panclicins is another class of potent PL inhibitors. N-formylalanyloxy or $\mathrm{N}$-formylglycyloxy substituent are two alkyl chains are found in Panclicins too contains b-lactone structures [80]. Panclicins A and B are alanine type while panclicins $\mathrm{C}, \mathrm{D}$ and $\mathrm{E}$ are glycine type of compounds. The inhibitory activity was recognized to the amino acid moiety, alanine-containing compounds being two to three folds weaker than glycine-containing compounds [92].

\section{Valilactone}

Valilactone first isolated from Streptomyces albolongus MG147-CF2 strain from shaken culture and jar fermentation. Valilactone potently inhibited hog PL with an IC50 of $0.14 \mathrm{ng} / \mathrm{ml}$. It also influenced inhibitory activity of esterase from hog liver with an IC50 value of $0.029 \mathrm{mg} / \mathrm{ml}$ [93].

\section{Ebelactones}

Ebelactone A and B are two ebelactones were isolated from the fermentation broth of Actinomycetes strain G7-Gl, closely related to Streptomyces aburaviensis. Both A and B revealed PL inhibitory activity with IC50 values of against hog PL are $3 \mathrm{ng} / \mathrm{ml}$ and $0.8 \mathrm{ng} / \mathrm{ml}$, respectively [94].

\section{Esterastin}

Esterastin was isolated from actinomycetes Streptomyces lavendulae MD4-C1 strain from the fermentation 
broth. Competitively Esterastin introverted the hog pancreas lipase with IC50 value of $0.2 \mathrm{ng} / \mathrm{ml}$ [95].

\section{Caulerpenyne}

Caulerpenyne extracted and purified from an extract of Caulerpa taxifolia competitively introverted the activity of lipase with IC50 values of $2 \mathrm{mM}$ and $13 \mathrm{mM}$, using creamed triolein and disseminated 4-methylumbelliferyl oleate as substrates, individually [96, 97]. The inhibitory activity of caulerpenyne was independent of substrate concentration suggesting direct interaction but dependent on the lipase concentration with the lipase protein, slightly than interacting with the substrate. Oral supervision of corn oil with caulerpenyne to rats demonstrated a reduced and hindered peak plasma triacylglycerol concentration, signifying its potential as a lipid absorption inhibitor $[98,99]$.

\section{Vibralactone}

Vibralactone secreted from Boreostereum virens microfungi is a scarce fused $\beta$-lactone-type metabolite, covalently but reversibly transforms the active site serine of the enzyme via acylation by the blactone. The IC50 of the vibralactone was resolute to be $0.4 \mathrm{mg} / \mathrm{ml}[94,100]$.

\section{Percyquinin}

Percyquinin obtained from the cultures of Basidiomycetes Stereum complicatum ST 001837 [101], inhibited PL with an IC50 of $2 \mathrm{~mm}$, is another $\beta$-lactone metabolite. In one study on $\beta$-lactone class of compounds, the stereochemistry $(2 S, 3 S)$ of the $\beta$-lactone ring was found to impart specificity for the PL, while (2R, 3R) stereochemistry was accountable for inhibition of HMG-CoA synthase [80].

\section{Sources for microbial lipases}

Microbial lipases found universal in nature and are commercially substantial due to the low manufacturing cost superior stability and more availability than animal and plant lipases [102]. Naturally or recombinant microbial lipases are generally used in diverse bioengineering applications [103]. A wide diversity of microbial resources provides by nature, microbes have more adaptation abilities and inhospitable atmospheres like Dead Sea, Antarctica, Alkaline lakes, Hot springs, volcanic vents and contaminated soils, which provides extraordinary potential for the lipases production with specific features $[104,105]$. An enormous spin-off with esteem to the enantioselectivity hydrolysis and the formation of carboxyl esters has produced ready availability. The marine microfloras have more capabilities for the formation of enzymes and proteins active compounds. Mostly lipase fashioned extracellularly secretion from fungi and bacteria $[106,107]$.
In numerous biocatalytic procedures Candida antarctica lipase B (CALB) is the most habitually used enzyme and have a more amount of patents. Candida rugosa lipase (CRL) is another scientifically significant lipase from the yeast, which is a mixture of different isoforms and is commercially accessible and this grounding is known as "Generally Recognized As Safe" (GRAS) and used in the food industry [108]. PLA1s and PLA2s from Fusarium oxysporum, T. lanuginosus, A. niger and Trichoderma reesei between the yeast and fungal phospholipases are used in the degumming of vegetable oils and commercialized. While mostly used in the food industry are PLA1s, PLA2s and PLBs extracted from $A$. oryzae and A. niger [103, 109]. Due to their high transphosphatidylation and hydrolytic activities PLDs isolated from Actinomycete strains are commercially available and used in several industrialized procedures [110]. Mostly the bacterial genera for the production of lipases and phospholipases have been reconnoitered are Pseudomonas, Bacillus and Streptomyces, followed by Burkholderia, Chromobacterium, Achromobacter, Alcaligenes and Arthrobacter [111]. Some lipases producing microorganisms reveal new sources and applications of industrial enzymes as shown in Table 1.

\section{Bacterial lipases}

Lipase has been detected initially in 1901, B. prodigiosus and B. fluorescens, presently Serratia marcescens and $P$. fluorescens observed today's best lipase producing bacteria subsequently [112-115]. The glycoproteins and lipoproteins are bacterial lipases. In most of the bacteria the enzyme production is affected by the certain polysaccharides have been observed [116-118]. Some bacterial lipases are thermo-stable and most of the bacterial lipases are reported as constitutive and nonspecific in their substrate specificity $[119,120]$. Achromobacter sp., Alcaligenes sp., Arthrobacter sp., Pseudomonas sp., Staphylococcus sp. and Chromobacterium sp. have been exploited for the manufacturing of lipases between the bacteria [121].

\section{Fungal lipases}

Since 1950 's fungal lipases have been studied, due to their affluence in thermal and $\mathrm{pH}$ stability, substrate specificity, and activity in organic solvents and downstream processing these lipases have been exploited [122]. The contemporary period machinery favors the procedure of batch fermentation and low cost extraction methods so the fungal lipases have assistances over bacteria. Major filamentous genera of fungi included are Rhizopus, Aspergillus, Penicillium, Mucor, Ashbya, Geotrichum, Beauveria, Humicola, Rhizomucor, Fusarium, Acremonium, Alternaria, Eurotrium and Ophiostoma for the production of 
Table 1 Microbial source of Lipase and their industrial application

\begin{tabular}{|c|c|c|}
\hline Microbial Sources & Applications & References \\
\hline \multicolumn{3}{|l|}{ Fungal species } \\
\hline Fusarium solani NFCCL 4084 & Halophilic lipase for biodiesel production & {$[470]$} \\
\hline Yarrowia lipolytica & $\begin{array}{l}\text { Degrades very efficiently hydrophobic and unusual substrates such } \\
\text { as n-alkanes, oils, fats, and fatty acids as low-cost carbon sources }\end{array}$ & {$[670]$} \\
\hline Aspergillus oryzae & $\begin{array}{l}\text { Saturated fatty acids synthesized, faster cheese ripening, flavour } \\
\text { customized cheese }\end{array}$ & {$[671]$} \\
\hline Rhizomucor javanicus (meih) & Non-hydrogenated solid fats & {$[672]$} \\
\hline Rhizomucor miehei & Cocoa-butter equivalents & {$[673]$} \\
\hline Geotrichum candidum and C. antarctica & $\begin{array}{l}\text { Through biocatalytic processes preparation of chiral intermediates } \\
\text { which synthesized the pharmaceutical compounds related to the } \\
\text { elimination of bad cholesterol for the treatment of the Alzhei- } \\
\text { mer's disease }\end{array}$ & {$[674]$} \\
\hline Candida antarctica & Oils and fats enriched, removal of size lubricants, denim finishing & {$[675]$} \\
\hline Candida rugosa & Human Milk fat substitute & {$[676]$} \\
\hline Candida lipolytica & Cheese ripening, Fatty acid production & {$[670]$} \\
\hline \multirow[t]{2}{*}{ Penicillium camembertii } & Production of glycerolglycolipids & {$[672]$} \\
\hline & Synthesis of saturated triacyl glycerides & {$[677,678]$} \\
\hline Trichoderma lanuginosus & Produced a lipase containing detergent ${ }^{\prime}$ LipoPrime ${ }^{\circledR \prime}$ & {$[16]$} \\
\hline Penicillium roquefortii & Production of characteristic flavor of blue cheese in dairy products & [679]. \\
\hline Aspergillus niger & $\begin{array}{l}\text { Faster cheese ripening, flavor customized cheese, Dough stability } \\
\text { and conditioning }\end{array}$ & {$[680]$} \\
\hline Meyerozyma guilliermondii & Promising feed lipase using cheese whey & {$[681]$} \\
\hline A. niger GZUF36 & Potential of the enzyme in the synthesis of functional oils & {$[526]$} \\
\hline Aspergillus flavus & $\begin{array}{l}\text { Fat stain elimination; Synthesis of pharmaceuticals, polymers, } \\
\text { biodiesels, biosurfactants }\end{array}$ & [682] \\
\hline Candida antarctica & $\begin{array}{l}\text { Pitch control in paper and pulp industry, Polycondensation, ring } \\
\text { opening polymerization of lactones, carbonates in polymer }\end{array}$ & {$[674]$} \\
\hline Rhizomucor meihei & $\begin{array}{l}\text { As a biocatalyst in personal care products such as skin and sun-tan } \\
\text { creams, bath oils etc }\end{array}$ & [683] \\
\hline Rhizomucor meihei & Surfactants for baking industry, dairy products, Noodles & {$[684]$} \\
\hline Rhizomucor miehei & $\begin{array}{l}\text { Oils and fats enriched, cocoa butter substitutes, synthesis of bioac- } \\
\text { tive molecules }\end{array}$ & {$[685]$} \\
\hline Candida tropicalis, Aspergillus oryzae & Degradation of crude oil hydrocarbons & {$[686]$} \\
\hline Penicillium abeanum & Use for docosahexaenoic acid enrichment of tuna oil & {$[687]$} \\
\hline Rhizopus nodosus & Leather processing and dehairing and fat removal & {$[688]$} \\
\hline Candida rugosa & Activated sludge treatment, aerobic waste treatment & {$[689]$} \\
\hline P. chrysogenum & Food industry waste treatment & {$[690]$} \\
\hline Rhizomucor meihei & Surfactants for baking industry, Dairy products, Noodles & {$[684]$} \\
\hline P. chrysogenum & Food industry waste treatment & {$[690]$} \\
\hline Thermomyces lanuginose & Non-hydrogenated solid fats & {$[691]$} \\
\hline M. miehei & $\begin{array}{l}\text { Used as aroma and fragrance in the food, beverage, and pharma- } \\
\text { ceutical industries }\end{array}$ & [692] \\
\hline C. parapsilosis & Hydroxamic acids (food additive) & {$[534]$} \\
\hline M. miehei, C. antarctica & Synthesis of short chain flavour thio-ester in solvent free medium & {$[643]$} \\
\hline M. miehei, Rhizopus arrhizus & Production of flavour esters & [693] \\
\hline \multicolumn{3}{|l|}{ Bacterial species } \\
\hline $\begin{array}{l}\text { Achromobacter sp. HEGN 014, Virgibacillus pantothenticus HEGN } \\
114\end{array}$ & Treatment of oily wastewater & {$[694]$} \\
\hline Pseudomonas mendocina & Dishwashing/laundry Removal of fat strain & [622] \\
\hline Acinetobacter radioresistens; Bacillus sp. FH5 & Used in detergent industry & {$[695]$} \\
\hline Staphylococcus pasteuri & Using in oil degradation & {$[696]$} \\
\hline P. fluorescens & $\begin{array}{l}\text { Enantioselective transesterification of a racemate }(R, S) \text {-4-methyl-1- } \\
\text { heptyn-4-en-3-ol, a component of the insecticide S-2852 }\end{array}$ & {$[697]$} \\
\hline
\end{tabular}


Table 1 (continued)

\begin{tabular}{|c|c|c|}
\hline Microbial Sources & Applications & References \\
\hline Staphylococcus warneri and S. xylosus & The production of flavour esters & [693] \\
\hline Bacillus sp. & Used in leather processing & [698] \\
\hline Brevundimonas sp. QPT-2 & Involved in enantioselective degradation of AOPP herbicides & [699] \\
\hline Micrococcus sp. & $\begin{array}{l}\text { Commonly used detergents, enhance the removal of oily stains } \\
\text { from various types of fabrics }\end{array}$ & [448] \\
\hline Bacillus cereus HSS & Waste water treatment & [626] \\
\hline Marinobacter lipolyticus & Organic Solvent-Tolerant Lipolytic enzyme & [700] \\
\hline Haloarcula sp. G41 & Organic solvent-tolerant lipase for biodiesel production & [701] \\
\hline Bacillus subtilis & Baking industry for bread making & [702] \\
\hline Geobacillus stearothermophilus & Enhanced stability in methanol & [449] \\
\hline Pseudomonas aeruginosa HFE733 & $\begin{array}{l}\text { Biodegradation of oil and organics (determination as chemical } \\
\text { oxygen demand (COD), biodegradation of food wastewater from } \\
\text { restaurants }\end{array}$ & [703] \\
\hline Pseudomonas sp. & Food processing and oil manufacture & [704] \\
\hline Natronococcus sp. & Application in biocatalysis & [701] \\
\hline P. alcaligenes M-1 & $\begin{array}{l}\text { Alkaline lipases, able to removing fatty stains when used in a wash- } \\
\text { ing machine }\end{array}$ & [705] \\
\hline Pseudomonas plantarii & $\begin{array}{l}\text { Solvay Enzyme Products, Applicable for is a nonionic and/or anionic } \\
\text { detergent formulation }\end{array}$ & [706] \\
\hline Chromobacterium viscosum & $\begin{array}{l}\text { Detergent formulations containing alkaline lipase used in laundry } \\
\text { detergent "Top" }\end{array}$ & [707] \\
\hline Acinetobacter sp. & $\begin{array}{l}\text { Degrading } 60-65 \% \text { of the fatty material in the waste water man- } \\
\text { agement }\end{array}$ & [708] \\
\hline Bacillus thermocatenulatus & Used in medical industry & [641] \\
\hline $\begin{array}{l}\text { Lactobacillus casei, Lactobacillus paracasei, Lactobacillus rhamnosus, } \\
\text { and Lactobacillus plantarum. }\end{array}$ & Cheese Industry for improvement of flavor & [709] \\
\hline Penicillium roquefortii & Cheese Industry for cheese ripening & [710] \\
\hline Staphylococcus warneri, S. xylosus & Production of flavour esters & [711] \\
\hline Pseudomonas cepacia & Biodiesel fuel production & [712] \\
\hline Pseudomonas sp. & $\begin{array}{l}\text { Formation of (-)-15-deoxyspergualin 23) in drug industry as antitu- } \\
\text { mor antibiotic and immunosuppressive agent }\end{array}$ & [713] \\
\hline
\end{tabular}

lipases [123, 124]. Other species such as Candida rugosa, Candida antarctica, T. lanuginosus, Rhizomucor miehei, Pseudomonas, Mucor and Geotrichum. Colletotrichum gloesporioides produced 27,700 U/l of lipase are the most productive strain identified from the Brazilian savanna soil by using enrichment culture techniques $[125,126]$. $A$. niger, C. rugosa, H. lanuginosa, M. miehei, R. arrhi$z u s, R$. delemar, $R$. japonicus, $R$. niveus and $R$. oryzae are the principal manufacturers of these commercial lipases [127-129].

\section{Purification of lipases}

To get consistency of lipase from a large number of bacteria and fungi various novel purification technologies are available [130]. Generally, several steps are contains for the purification of lipases contingent upon the purity estimated for food application. The extracellular microbial lipases from the culture broth eliminated by the centrifugation or filtration in the fermentation process and cells are became freed [131, 132]. The ammonium sulphate precipitation, ultrafiltration or extraction with organic solvents is concentrated the cell-free culture broth [133]. The gel filtration and affinity chromatography like several combination of numerous chromatographic approaches purified about of the $80 \%$ using precipitation steps, and then $60 \%$ ammonium sulphate and 35\% ethanol. A homogenous product produces is the final step of gel filtration [134].

The novel purification machineries such as the (i) membrane separation procedures, (ii) immuno purification, (iii) hydrophobic interaction chromatography using epoxyactivated spacer arm as a ligand and polyethylene glycol restrained on Sepharose, (iv) polyvinyl alcohol polymers as column chromatography stationary phases, and (v) aqueous two phase systems are frequently engaged after these pre-purification steps $[135,136]$. The enzyme recovery and fold purification outcomes are found acceptable using of hydrophobic interaction chromatography [137, 138]. An 
acid resilient lipase has been filtered from crude profitable arrangements by size exclusion on Bio-gel-p-100 and ion exchange on Mono-Q., From A. niger fungi. Using the chromatography on hydroxyapatite, octyl-Sepharose and sephacryl S-200 the lipase was purified to homogeneity from $R$. japonicus NR400 [139].

\section{Substrates for lipase}

A chiral alcohol moiety possesses by the glycerides which is the natural substrate for lipases. The lipases were mostly valuable for the resolution or asymmetrization of esters bearing a chiral alcohol moiety was assumed [140-143].

\section{Methods for lipase assay}

Due to the wide substrate specificity of lipases a number of assay protocols are engaged for lipase assay. At the lipid water interface the determination of lipase activity is the analytical of free lipase [144]. Using various physiochemical approaches the determination activities can be carried as with all reactions catalyzed by enzymes and observing the vanishing of the substrate or by the product release [145]. For the determining of the hydrolytic activity several methods are presented such as Titrimetry, Spectroscopy (Photometry, Fluorimetry and Infrared, Chromatography, Radio activity, Interfacial tensiometry, Turbidimetry, Conductimetry, Immunochemistry, and Microscopy [146, 147]. The triacylglycerol hydrolysis reaction catalyzed by lipases generally can be written as:
Multi-fold benefits such as increase in thermal and ionic stability are applicable using immobilized lipases which upturns its proficiency. When the enzyme is immobilized it is easier to control reaction parameters like flow rate and substrates convenience [154, 155]. For immobilization include large surface area, low cost, reusability, good chemical, mechanical and thermal stability, and insolubility the desirable characteristics of solid supports used. According to the interface among the enzyme and support the enzyme immobilization approaches can be classified like physical and chemical procedures [156]. The interactions among the enzymes and support are by weaker bonds like hydrogen bonds, Van derWalls exchanges, which create these interactions adjustable in the physical method. For the interface among the enzyme and support are stronger by covalent bonds the procedure created irrecoverable in chemical methods [157, 158].

\section{Physical methods \\ Adsorption}

In the physical approaches of immobilization adsorption procedure, the enzymes immobilized by Van der Waals bonds, hydrophobic interactions, hydrogen bonds, and ionic bonds [159]. On the surface of the support the enzyme becomes adsorbed (bound), and the substrates used mostly for this procedure are cation and anion exchange resins, activated carbon, silica gel, alumina,

$$
\begin{array}{r}
\text { Triacylglycerols } \rightarrow \text { Diacylglycerols }+ \text { Free fatty acids } \rightarrow \text { Monoacylglycerols }+ \text { Free fatty acids } \\
\rightarrow \text { Glycerols }+ \text { Free fatty acids }
\end{array}
$$

The activity of lipases can be examined by the monitoring of release of either free fatty acids or glycerol from triacylglycerols or fatty acid ester displays by this reaction [148]. The titrimetery assay using olive oil as a substrate is the mostly used lipase assay protocol due to its simplicity, correctness and reproducibility [149, 150]. Another spectrophotometric assay based on techniques which purify the colour to fatty acids releasing after the hydrolysis of triacylglycerols $[151,152]$. The release of $1 \mu$ mole of free fatty acid from combined olive oil or triolein or tributyrin per minute at specified temperature and $\mathrm{pH}$ values which relates a lipase activity unit. The units of lipolytic activity per microgram of extra cellular protein expressed the Specific activity of lipases [153].

\section{Immobilization of lipases}

Recyclability, enzyme stability and activity of expensive lipases improve due to the immobilization process. It can easily control the process of enzymatic reaction purity of the products and for its reusability feature [36]. controlled pore glass, ceramics, natural materials like cellulose and agarose, additionally to specific industrialized deposits [160]. The procedure of absorption is modest, low cost and takes two phases to comprehensive it; in the first dispersion of the enzyme happens through the conveyors surface, and then conveyor adsorption. Adsorption is controlled by the diffusion for lipase since the support binding is quicker than its diffusion [161]. The immobilization occurs naturally and the process is executed under slight conditions, subsequently, without affecting its catalytic activity there is no change or slightly change in the structure of enzyme [36].

\section{Encapsulation and entrapment}

In fiber or gel of synthetic polymeric or natural sustenance these approaches include captivity or casing the enzymes. In the one step these methods provides easy contact between enzymes and substrate along with increased mechanical stability are effective and low cost [162]. In the second step, encapsulation and entrapment 
decrease mass transferal of substrate to enzyme because of small matrix pores size, but the large apertures to permit leaking enzymes from the carriers [36]. Enzyme deactivation during the procedure of immobilization is another disadvantage, during use abrasion support material, and small loading capacity. So, this difficulty may be resolved by cross-linking mediator addition [160].

\section{Confinement}

Confinement also known as imprisonment in the immobilization of enzymes the unification of the enzyme is the part of a reactive mixture to be polymerized, generally the porous matrix is formed around the biocatalyst to be immobilized in this procedure [163]. The polymer matrix encircles the enzyme confining it in its structure and the substrates and produces diffuse through the support as the polymerization profits, while the enzymes linger immobilized within the provision [158, 164]. The immobilization technique in captivity is simple and fast comparatively being one of the approaches of relaxed use in insignificant procedures, and very appropriate in the manufacture of biosensors, because there is limited chance of conformational changes of the enzymatic structure, thus its catalytic action permitting, besides the prospect by less cost arrays $[165,166]$. However, the effort in monitoring the size of the pores of the support can principal to the leaching of enzymes and also restrictions in developing the diffusion of substrates and yields inside the support, besides the striving in upgrade are the main problem in immobilization [167]. The enzyme activity is highly dependent on the type of immobilization demonstration. These outcomes designated that the immobilized lipase not only showed good recovery of activity but also significant stability, better reuse, and flexibility to use than free lipase by entrapment and adsorption [168].

\section{Chemical methods \\ Covalent binding}

The lipases are immobilized to support of chemical bonds in the covalent variety in this immobilization process. These bonds arise from chemical reactions like glutamic acid residues, lysine, cysteine, and aspartic acid among these carrier ingredients and the side chain amino acids of the enzymes and hydroxylamine, carboxylic, imidazole, and phenolics functional groups are found for the development of covalent bonds additionally [169]. Covalent immobilization delivers enzymatic stability and high add-on of the lipases to support, ensuring rigidity in its structure because it is a strong chemical bond [170]. The structure of the enzyme can maintain by this rigidity and unaffected against denaturing agents like organic solvents, heat, extreme $\mathrm{pH}$, and others. Though, the active site of the enzyme changes by the covalent bond producing its inactivation [171]. For this to materialize through activation reactions the surface of the support is modified as long as the improvement of more forceful functional groups for interface with the group's enzyme. Consequently, the selection of support containing a more concentration of reactive groups to permit the enzymesupport binding is very imperative [172].

\section{Cross-linking}

The crosslinking used to increase the stability of enzymes is a technique of enzymatic immobilization, for the enzyme to bind which does not involve support. Using a reagent called crosslinking agent or crosslinker the immobilization process is carried out, which form intramolecular and intermolecular crosslinks with specific groups of amino acids present on the surface of the solubilized enzyme consequently formed crosslinked enzymes [160, 173]. To protect the enzyme from the external environment is the main function of crosslinking agents. Enzymes obtained by crystallization, atomization, and aggregation leads by crosslinking approaches [174]. The immobilization of the enzyme arises subsequent in the development of Cross-Linked (soluble) Enzyme (CLE), Cross-Linked Enzyme Crystals (CLEC), Crosslinked Enzyme Aggregates (CLEA), and CrossLinked Spraydrying Enzyme (CSDE) when these enzymes are placed in a medium containing a cross-linking agent $[175,176]$. Due to the elimination of solid support; besides being an adaptable process are highly catalyzed enzymatic activities, high stability, and low cost of production is the main advantage of cross-linking process, it is possible to get more healthy and stable enzymes for industrial uses $[177,178]$.

\section{Cross-linked enzyme}

Enzymatic cross-linking to be recognized was the first process, but the other differences of the techniqes looked are enzymatic crosslinked enzyme crystals, crosslinked enzymatic aggregates, and atomized crosslinked enzymes. CLE that arises by crosslinking among the dissolved enzymes and the crosslinker agent is an immobilization technique [179].

\section{Cross-linked enzyme crystals}

A crosslinking agent is added into the solution containing the crystallized enzyme using an immobilization technique known as CLECs. The conformational structure of the enzyme, as well as its catalytic activity may modify this procedure [180]. The immobilization process of the crystallized enzyme monitors from its addition to the crosslinking agent, generally which is a two-dimensional solid surface; the enzyme stabilization arises that means 
forming a three-dimensional structure of intermolecular and intramolecular crosslinks that perform as a barrier evading its solubilization in the medium [181], to alterations in the reaction medium production it more resistant, temperature, $\mathrm{pH}$, permitting storage for long periods (up to years), and consenting its recycle easing the parting of the medium; due to the high enzyme concentration moreover all these benefits, when compared to immobilized or soluble enzymes CLECs present higher volume catalytic activity [164, 182]. Though, CLEC have needed of that the enzyme be crystallized, it is necessary that it is highly purified but to crystallize the enzyme, which is a very costly process, assembling the immobilization procedure sophisticated and expensive [183].

\section{Cross-linked enzyme aggregates}

The CLE procedure has their catalytic activity reduced if the enzymes immobilized, because they are solubilize in the solution, discussed previously. To achieve the crystallized enzyme in the CLEC procedure, to be immobilized which must be purified highly, the procedure formed very costly and complex $[184,185]$. So, the CLEAs appeared as a substitute to the procedures defined in the literature already. The precipitating agents like salts, acids, organic solvents addition by the precipitated enzymes using the protein precipitation procedure $[179,186]$, and in the mixture holding the enzyme without distressing its active three-dimensional structure. As a result, the lacking need for it to have the topmost clarity and obtaining the desired enzyme, and reducing the cost of immobilization and time [187].

\section{Cross-linked spray-dried enzyme}

With a crosslinking agent blending spray-dried enzymes the cross-linked spray-dried enzymes (CSDEs) are produced. In this method, a polymer (carrier particles) a solution/suspension containing the enzyme is fed into a spray dryer; to escape deterioration of enzymes due to disclosure to high temperatures these particles are used during drying [184]. To a medium containing the crosslinking agent the enzymes are added so that crosslinking occurs after drying. To control various parameters it is technically possible, like as particle size of the enzyme, due to the deactivation of the enzyme that occurs during the spray drying the application may be limited [188].

\section{Industrial applications of lipases Application in food industry Lipase in dairy industry}

For the hydrolysis of milk fat, to modify the fatty acid chain lengths and to boost the flavour of cheeses lipases are widely used in the dairy industry $[189,190]$.
Currently, it is also applicable in the speeding up the ripening of cheese and lipolysis of fat, butter and cream. By the action of lipases on milk fat various products particularly soft cheeses with specific flavour characteristics generated with free fatty acids $[191,192]$. For the production of cheese from M. miehei, A. niger, A. oryzae etc. the engineered industry developed a whole range of microbial lipases [156, 193]. Using the individual microbial lipases or their mixtures for the preparations of a good quality range of cheeses produced [194]. At raised temperature in the presence of enzyme when cheese is incubated Enzyme Modified Cheese (EMC) is manufactured and in order to harvest a concentrated flavour using lipase catalysis [195]. In comparison to normal cheese in EMC the concentration of fat is 10 times higher and used as an ingredient in other products like dips, sauces, soups and snack $[196,197]$. Acetoacetate, $\beta$-keto acids, flavour esters, methyl ketones and lactones flavour ingredients are synthesized due to the free fatty acids by the initiating of simple chemical reactions $[198,199]$. In vitamin A and $\mathrm{E}$ esters the lipase catalyzed hydrolysis and alcoholysis of ester bonds. To the oxidation prone vitamins A and $E$ the Supercritical Fluid Extraction (SFE) technique are used for the research of immobilized $C$. antarctica [200-202]. For the determination of vitamins D2/D3, $\mathrm{K} 53$ and $\beta$-carotene in milk powder and infant formulations the SFE technology should be applicable. Several cheese types, such as cheddar, provolone and ras cheeses the gastric lipases are applied to hasten the ripening and improvement of flavour [203]. The rate of fatty acid deliverance augments after the addition of lipase which also hastens the growth of flavour [204, 205]. The liberation of fatty acids significantly increased with the adding of calf lipase and aggregates the ripening temperature (from $7^{\circ}$ to $53{ }^{\circ} \mathrm{C}$ ) [206, 207]. Liberated fatty acid profiles of the enhanced procedure were undistinguishable to the control and the entire amounts of short-chain liberated fatty acids (C4 to C6) were significant for the improvement of cheddar cheese flavour during maturing revealed in the observations [208, 209]. Remains the lipase to be active after maturing and can cause the improvement of strong rancid flavour his is the disadvantage. A highly soluble proteins and free fatty acids and displayed better flavour within 3 months of ripening in the cheddar cheese industrialization when a cock-tail of fungal protease and lipase were used [210, 211]. During the ripening of a high level of enzyme may result in too much enzymatic reaction communicate an undesired specific and decrease the productivity [212, 213]. For faster cheese ripening decreases bitterness and losses in productivity the liposome technology adopted [214]. By cell lysis the bacterial intracellular enzymes are unrestricted and subsidize to flavour through lipolysis and other enzymatic actions [215]. 
Cell free extracts microcapsules in milk fat can be added to takeout milk clotting. With intact capsules formed cheeses contains more enzymatic end products significantly than the acquired by enzyme addition directly $[216,217]$. By encapsulating in a high melting fraction of fat the capsule stability can be upgraded. In cheese the inherent milk lipase made from unpasteurized milk which affects the substantial lipolytic action [218, 219]. In Blue-vein and Camembert cheeses are lipolytic and produce lipases using the culture and secondary microflora such as $P$. roqueforti and $P$. camembertii, respectively [220, 221]. Paramesan, Provolone, and Romano are Italian cheese to intensify their flavour after adding the lipases generally $[222,223]$. There is a steady increase in the concentration of progressive fatty acids and total soluble nitrogen during nitrogen $[224,225]$. Triggering the development of cheese flavour lipases releases the fatty acids from triglycerides. In dairy foods the overview of conjugated linoleic acid (CLA) has been complete possible by the immobilization of lipases [226]. Both lipases and proteases accelerate ripening of cheeses individually as well as a "cocktail". As such the enzymes may be added or encapsulated [227, 228]. A series of enzymatic reactions proceeded very gradually during the cheese ripening, transforming the fresh, automatically worked curd to the anticipated final ripe cheese texture and flavour [229]. Lipases, proteases and lactase enzymes hydrolyze lipids, proteins and lactose, respectively in order to elevate the level of flavour moieties and/or flavour mainframes [230, 231].

\section{Lipase in fat and oil industry}

In food processing manufacturing the oil and fats amendment is one of the prime areas which demands economically green technologies and it is very significant constituents of foods [232, 233]. Changing the location of fatty acid chains lipases permit us to amend the assets of lipids in the glycerides and interchanging one or other of these with new ones [234, 235]. Relatively economical and less appropriate lipid can be improved to a higher value fat in this way. The hydrolysis, esterification and inter esterification of oils and fats catalyzed by the fat $[236,237]$. Esterification and inter esterification are used to get value added products between the lipolytic transformation of oils and fats like specialty fats and partial glycerides using the positional and fatty acid detailed lipases, and have superior industrial prospective than fatty acid production in bulk through hydrolysis [238, 239]. For fat and oil hydrolysis an immobilized lipase membrane reactor assembled which produced products and that involve less downstream processing so reduced the overall cost of processing [240, 241]. Highly selective microbial phospholipases is a recently industrialized environmental friendly procedure for the removal of phospholipids in vegetable oils (de-gumming) [242, 243].

To production of a food grade, cost effective, immobilized 1, 3-regioselective (lipozyme TL $1 \mathrm{M}$ ) lipase using granulation to immobilize lipases, targeted for the production of frying fats and for the inter esterification of commodity oils reductions and lard components [244, 245]. To produce modified acylglycerols lipases catalyzed interesterification of fats and oils it cannot be acquired by predictable chemical interesterification [246, 247]. For the esterification of functionalized phenols and production of lipophilic antioxidants using immobilized lipases from C. antarctica (CAL-B), C. cylindracea Ay30, $H$. lanuginosa, Pseudomonas sp. and G. candidum to be used in sunflower oil [248]. Lipases used in the pure form, in the immobilized form or in the cell bound form on the hydrolysis of fats and oil observed in the many studies [249, 250]. In 2002, Australia New Zealand Food Authority (ANZFA) the use of triacylglycerol lipase achieved from hereditarily modified $A$. oryzae as a processing aid in the oils and fats productiveness for oil de-gumming, and in the food industry to progress emulsifying possessions was scientifically accepted [251]. Based on the granulation of silica a new procedure for immobilizing lipases has intensely shortened the development and let down the procedure cost. For the manufacture of commodity fats and oils with no content of trans-fatty acids such inventive methods are now extensively employed $[252,253]$.

A continuous packed bed rector for the design and operation was established for the interesterification of soybean oil having $22.7 \%$ oleoyl and $54.3 \%$ linoleoyl moieties as molar acyl in hexane consuming an immobilized Sn-1, 3-specific lipase (Lipozyme IM) from $M$. miehei with oleic acid [254, 255]. The loss of catalytic activity of Lipozyme IM in soybean oil reduced the rate of change in oleoyl and linoleoyl moiety arrangements in soybean oil decreased. The lipase catalyzed acidolysis of soybean oil with oleic acid to increase oleic acid content in an organic solvent $[256,257]$. The degumming step can be conceded out with a phospholipase in the physical refining of vegetable oils. By the introduction of a microbial phospholipase (Lecitase Novo) the economy of enzymatic degumming has been improved expressively $[258,259]$. Glycerolysis of commercial oils and fats catalyzed using Novozym 435 (C. antarctica lipase) to form monoacylglycerides (MGs) was examined using a tetra ammonium established ionic liquid as the reaction medium [260]. Nearly $100 \%$ alteration of triglycerides in this ionic liquid produced a $90 \%$ of monoglycerides were accomplished which were significantly higher as associated to the productivity in normal solvents [261]. For the retailoring of vegetable oils microbial lipases may be 
exploited. The nutritionally important structured triacylglycerols such as coco butter substitutes, low caloric triacylglycerols, and PUFA and oleic oil-enriched oils may be upgraded using cheap oils [262, 263]. By using directed interesterification normally the fat and oil alterations are carried out chemically and known as non-specific and energy intensive. Lipase intervened alterations occupy a noticeable place in oil industry for tailoring structuredlipids since enzymatic alterations are specific and can be carried out at moderate reaction conditions [264, 265].

A structured lipid (SL) from natural vegetable oils synthesized and contains EFAs and natural antioxidants [266]. To produce oils and fats containing nutritionally important polyunsaturated fatty acids (PUFAs) enzymatic interesterification can be used known as eicospentaenoic and docosahexaenoic acids. The interesterification of triglycerides using immobilized lipase was not commercially viable due to the high cost and the processing $[267,268]$.

\section{Lipase RM and lipase TL for cocoa butter analogues}

The vegetable oils origins such as palm, rapeseed, canola, and sunflower used by food producers regulates the physical properties of fats and oils since every oil has several types of fatty acids in the 1, 2, 3 positions of triacylglycerides a diverse scattering [269, 270]. Exploiting the microbial lipase that are 1, 3 regio-specific [6], used in the production of cocoa butter-type triacylglycerols principally and catalyzed interesterification using lipase [271]. Using 1, 3 regio-specific lipases the interesterification has been used to enrich low-cost fats like palm-oil fractions into 1, (3) palmitoyl, 2-oleoyl, 3 (1) stearoylglycerol and 1(3) stearoyl, 2-oleoyl, 3(1) stearoylglycerol, which have enormous presentation as confection fats [272, 273]. Crystallization possessions as well as melting features are formed in chocolate using 30\% cocoa butter. Cocoa butter has a tendency to be very expensive so an additional source from fat assortments was industrialized which requires an original mixing of palm mid fraction and stearate ester; monitored by desiccation and enzymatic lipase reactions [274, 275]. The distillation and solvent fractionation are essential for the compulsory product formation in further processing. In marketable manufacturing of cocoa butter this procedure has been used comprehensively equivalent by Loders Croklaan of the Uniliver Group in Wormerver, Netherlands [276]. Due to steric deterrent lipase is sn-1, 3 specific characteristically do not interchange acyl groups at the 2 position are produced from Mucor miehei, Rhizopus arhizus, Aspergillus niger, and Thermomyces lanuginosus, though some intramolecular transesterification of diacylglycerol intermediates can occur over prolonged reaction times $[277,278]$. The production of a cocoa butter equivalent the enzymatic transesterification was initially assessed that activate the sn-1, 3 specificity of a diversity of fungal lipases [279, 280].

\section{Lipases used in cosmetics and personal care products}

The cosmetic market globally share may surpass USD 680 billion by 2024, using related to hair care, skin care, perfume, personal hygiene, oral products. For the advanced cosmetic merchandises may drive the growth of industry. Lack of regulatory policies may hinder supply dynamics and put pressure on lipase market price trend [281,282]. The manufacturing of isopropyl myristate, isopropyl palmitate and 2- ethylhexylpalmitate for the application as a palliative in particular maintenance products like dermal and sun-tan ointments, bath oils etc. prepared by Unichem International (Spain) [283]. An essential fragrance component in the perfume industry rose oxide formulated from several microbial sources with lipases and Transesterification of 3, 7-dimethyl- 4, 7- octadien1-ol. The immobilized lipase of Rhizomucor meihei was used as a biocatalyst [284, 285]. In place of the conventional acid catalyst the used enzyme provides needful lowest downstream refining and plentiful advanced value claimed by company. In personal care products wax esters (esters of fatty acids and fatty alcohols) have related uses and are also being enzymatically manufactured (Croda Universal Ltd.), and in a batch bioreactor the company uses C. cylindracea lipase [286]. Normally, the production cost is marginally higher than that of the conventional techniques according to the manufacturer, and the upgraded quality of final product justified cost. In makeups and pharmaceuticals like skin care products the abundant commercial potential of retinoids (Vitamin A and their derivatives) are found. In the catalytic reaction of immobilized lipase the water-soluble retinol derivatives were prepared [287-289]. And the lipases also used for the hair stressing provisions, and as a constituent of topical antiobese emulsions or as oral administration. They are also used for the cleaning, moderating, aroma, and coloring in personal care of cosmetic sector [290, 291]. The lipases show activities in surfactants and in aroma production and used in cosmetics and perfumeries also. In the presence of lipase a patent Nippon Oil and Fats obtained from for the preparation of propylene glycerol mono fatty acid ester and also used as emulsifier and a pearling agent in cosmetics and foods [292, 293]. Novozym 435, derived from Candida antartica is a nonspecific lipase and determined for the enzymatic combination of isopropyl myristate most suitably [294, 295].

\section{Lipases used in tea processing}

Tea is the most popular beverage and manufactured from the Camellia sinensis L. in the world. But the process of 
manufacturing is different for each one such as unfermented is green tea, semi-fermented is oolong tea, well fermented tea is known as black tea [296]. Tea that is commercially available is prepared from the bud of the plant and apical two leaves of Camellia sinensis (L). To complete tea depends on the effect of oxidative and hydrolytic enzymes present endogenously in the green leaf the renovation of fresh tea leaf. The tea leaves processing can be done either by the orthodox process or the Cut-Tear-Curl (CTC) process. The orthodox method, though very extravagant, produces tea of high quality that is light and aromatic. The main feature of the CTC process is that it is much simpler but results in teas with more cuppage and lesser aroma. For these motives, the CTC teas are more economical than the orthodox ones. If the flavour of CTC teas can be enhanced to the level of orthodox teas, it would be a favourable cooperation between superiority and economy [297]. Enzymatic breakdown of membrane lipids initiate the development of volatile products during the manufacturing of black tea with specific flavour properties accentuate the significance of lipid in flavour improvement $[298,299]$. The quality of black tea is depending upon dryness, mechanical breaking and enzymatic fermentation to which tea leaves are exposed. The level of polyunsaturated fatty acids detected by the reduction in total lipid content which enhanced by Rhizomucor miehei lipase [300, 301].

\section{Lipase used as biosensors in food industry}

Two important part of biosensor with their unique properties are combined as physico-chemical transducer is used as measurable signal and the second compartment is biological origin for the providing specific analysis $[302,303]$. One of the parts of biological origin entitled is the Lipase. And a common substrate tributyrin designated for the origins of various lipases. Several bacteria Bacillus subtilis and Chromobacterium viscosum and fungus Rhizomucor miehei, R. oryzae, Fusarium solani hydrolases tributyrin to dibutyrin and butyrate are mentioned for the lipases [304, 305].

For the quantitative determination of triacylglycerol the immobilized lipases are used as biosensor due their accuracy and efficiency. Lipases are essential in the food industry specifically in fats and oils, soft drinks, drug industries, beverages, and also in medical diagnosis [306]. Using the lipase enzymes as biosensor in the analytically and quantifically methods the triacylglycerol breakdowns into the glycerol. For the determination of organophosphorous pesticides using the lipase hydrolysis a surface acoustic wave impedance biosensor developed [307, 308]. And it is also used for the analysis of Dichlorvos insecticide residues in vegetables. Blending with glucose oxidase the lipases may be immobilized onto $\mathrm{pH}$ /oxygen electrodes, and functions as lipid biosensors also used for the analysis of triglycerides and blood cholesterol samples [309, 310]. Presently, the chromatographic and spectroscopic methods are inadequate for the quantification and the determination of pesticidal residues in water and food grains. The estimation and the detection of the triglycerides is a clinically significant parameter and which is correlated to the disorder of heart related problems [311-313]. Another biosensor industrialized for the analysis of methyl-parathion and tributyrin was potentiometric biosensor based on C. rugosa lipase. The purified lipase C. rugosa was immobilized on glass electrode and cross-linked with glutaraldehyde [314, 315]. The compound 4-nitrophenyl laurate hydrolysed into 4-nitrophenol and laurate, 4-nitrophenyl oleate into 4-nitrophenol and oleate, 4-nitrophenol palmitate into 4-nitrophenol and palmitate, 4-nitrophenyl propionate into 4-nitrophenol and propionate, $\alpha$-naphthyl acetate into $\alpha$-naphthol and acetate, methyl acetate into methanol and acetate, methyl butyrate into methanol and butyrate, methyl laurate into methanol and laurate, methyl palmitate into methanol and palmitate, methyl propionate into methanol and propionate, and methyl stearate to methanol and stearate by Micrococcus sp. was verified [316-318]. The overview of Electrochemical and Optical assays-based on lipase biosensor are specified in following Table 2.

\section{Nanotechnology in enzyme biosensors}

In biosensor planning a significant role played by the nanotechnology, less than $100 \mathrm{~nm}$ smaller dimensions which involves in the study of manipulation, creation, and use of materials, devices. Incorporating enzymes with nanomaterials the electrochemical biosensors are new ingredients with synergistic possessions initiated from the apparatuses of the hybrid combinations [319-321]. A new generation of bioelectronics devices with high sensitivity and stability has an excellent scenario based on nanotechnology biosensors. To achieve direct wiring of enzymes to electrode surface using nanoscale materials this promotes electrochemical reaction, commanding nanobarcode for biomaterials, and signal amplifying of biorecognition event. Carbon nanotubes (CNT) and gold are regularly used nanomaterial for enzyme biosensors [322, 323]. Gold showed more catalytic ability for several organic reactions. So, to catalyze biochemical reactions to design biosensors metal nanoparticles have been used. Additionally, in the reaction medium the nanoparticles perform as predictable identical catalysts, but after the reaction can be easily recovered [324-326]. CNT rolled up into a nanoscale are graphite sheets, having diameters range among fractions of nanometers and tens of nanometers and lengths up to numerous centimeters with both 
Table 2 Electrochemical assays at lipase based Biosensor

\begin{tabular}{|c|c|c|c|c|}
\hline Source of used lipase & Analyte & Principle of lipase use in assay & Detection limit & References \\
\hline \multicolumn{5}{|c|}{ Electrochemical assays at lipase based biosensor } \\
\hline Candida rugosa (Fungi) & $\begin{array}{l}\text { Methyl parathion } \\
\text { (p-nitrophenyl pesticides) }\end{array}$ & $\begin{array}{l}\text { On a glass pH electrode lipase was } \\
\text { mobilized and transformed which } \\
\text { reduced the } \mathrm{pH} \text {; methyl-paraoxon } \\
\text { inhibit reaction }\end{array}$ & $93 \mu \mathrm{mol} / /$ & {$[714]$} \\
\hline Burkholderia cepacia Lipase (Bacterium) & $\begin{array}{l}\text { Methyl parathion, } \\
\text { (p-nitrophenyl) }\end{array}$ & $\begin{array}{l}\text { Lipase was immobilized on zeolitic nan- } \\
\text { oparticles and then into chitosan on a } \\
\text { glassy carbon electrode, pesticides like } \\
\text { methyl parathion were hydrolyzed to } \\
\text { p-nitrophenyl that was electrochemi- } \\
\text { cally oxidized in the next ste }\end{array}$ & $0.1-38 \mu \mathrm{M} / \mathrm{I}$ & {$[715]$} \\
\hline Candida rugosa (Fungi) & Diazinon & $\begin{array}{l}\text { Lipase converted diazinon to diethyl } \\
\text { phosphorothioic acid and 2-isopropyl- } \\
\text { 4-methyl-6- hydroxypyrimidine. which } \\
\text { caused a change in the impedance of } \\
\text { the medium }\end{array}$ & 10 nmol/l (fungal lipase) & {$[306]$} \\
\hline Candida rugosa (Fungi) & $\begin{array}{l}\text { Chlorfenvinphos, } \\
\text { Malathion }\end{array}$ & $\begin{array}{l}\text { Lipase converted p- nitrophenyl acetate } \\
\text { to p- nitrophenol and acetic acid, } \\
\text { p- nitrophenol was oxidized and } \\
\text { a current at } 0.024 \mathrm{~V} \text { was recorded, } \\
\text { analyzed inhibited lipase and stopped } \\
\text { the reaction. }\end{array}$ & $\begin{array}{l}84.5 \mu \mathrm{mol} / \mathrm{l} \text { for } \\
\text { chlorfenvinphos } \\
\text { and } 282 \mu \mathrm{mol} / \mathrm{l} \\
\text { for malathion }\end{array}$ & {$[716]$} \\
\hline \multicolumn{5}{|l|}{ Optical assays-based on lipase biosensor } \\
\hline $\begin{array}{l}\text { Candida antarctica, } \\
\text { Yarrowia lipolytica and fungus }\end{array}$ & Lipase itself & $\begin{array}{l}\text { p-nitrophenyl butyrate } \\
\text { hydrolysis to butyric acid and } \\
\text { p-nitrophenol, coloration caused by } \\
\text { p-nitrophenol was measured }\end{array}$ & $0.05 \mathrm{U} / \mathrm{ml}$ & {$[717]$} \\
\hline $\begin{array}{l}\text { Candida antarctica, } \\
\text { Mucor miehei, } \\
\text { Thermomyces lanuginosus (Fungus) } \\
\text { and bacteria Pseudomonas } \\
\text { cepacia and P. fluorescens }\end{array}$ & Lipase itself & $\begin{array}{l}\text { Butyryl 4-methyl umbelliferone (Bu- } \\
\text { 4-Mu) and methanol in tert-butanol } \\
\text { were trans-esterified in the presence of } \\
\text { lipase, production of 4-methylumbel- } \\
\text { liferone was measured fluorometre }\end{array}$ & Not available & {$[718]$} \\
\hline
\end{tabular}

their ends generally covered by fullerene-like arrangements [327, 328].

\section{Immobilized enzymes in the food industry}

In several methods the enzyme is immobilized such as adsorption, entrapment, and covalent binding on several supports. Immobilization creates thermostability of the enzyme and prevents the loss of enzyme activity. The technical circumstantial behind enzyme immobilization for superior catalysis is multifarious [181]. In addition to the easiness of handling and the use of two main targetted profits is (a) easy split-up of enzyme from the products, (b) reuse of the enzyme [160]. Easy split-up of the enzyme from the product simpilifies enzyme use and supports a dependable and effectual reaction tools. The reuse of enzymes delivers cost benefits which are often an important requirement for establishing an enzyme catalysed procedure in the first place. The immobilized enzyme arrangements possessions are administered by both properties the enzyme and the carrier material [329].

\section{Lipase CalB for vitamin C esters}

L-Ascorbic acid (Vitamin C) acting as a free radical scavenger react with oxygen consequently removing it in a closed system is the foremost water-soluble usual antioxidant [330, 331]. Vitamin $C$ is insoluble in oils and fats compared to esters of L-ascorbic acid are soluble in fats with long-chain fatty acids (E-304) are active as antioxidants in foods rich in lipids [332, 333]. Ascorbic acid reacting with sulphuric acid produced ascorbyl palmitate and stearate monitored by re-esterification with consistent fatty acid, and successively distilled by re-crystallization. The need for tedious merchandise isolation, less productions due to non-regioselectivity reactions and the use of strong acids has some shortcomings due to this chemical process [334]. From Candida antarctica (CalB) the immobilized lipase B described by biocatalytic methods as biocatalyst and free fatty acids or activated esters such as acyl donors (Fig. 3). The conversion of biocatalytic can do levels of approximately $95 \%$ alteration contingent on operational temperature, the productivity of the side product (water) removal, and length of the fatty acid [335-337]. 
<smiles>O=C1OC(C(O)CO)C(O)=C1O</smiles>

Vitamin C

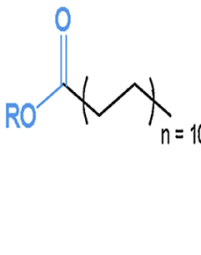

Fatty acid ester

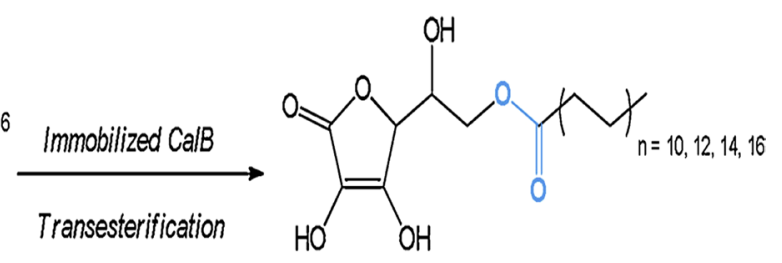

Fatty acid ester of vitamin C

Fig. 3 Manufacture of vitamin C fatty acid ester by transesterification catalyzed by immobilized CalB [344]

Comparatively with the current chemical procedures the enzymatic synthesis offers selected benefits like lower reaction temperatures, cleaner product and decreased downstream processing $[68,338]$. The production of ascorbyl esters mostly is still achieved by chemical synthesis so this biocatalyzed procedure is stagnant in its original improvement period [339, 340]. The enzymatic procedure and the high costs of the restrained enzymes linked to the chemical catalysts due to the long reaction time requirement [341, 342].

\section{Lipase in human milk fat substitutes}

Several lipids such as oleic (30-35\%), palmitic (20-30\%), linoleic (7-14\%) and stearic acids (5.7-8\%) are found in Human milk fat (HMF) [343]. Palmitic acid is the major saturated fatty acid in HMF contrasting in vegetable oils and in cow's milk fat commonly esterified at the sn-2 position of the TAGs while the unsaturated fatty acids are at the external positions [343, 344]. HMF fatty acid profile has a vital effect in infants on its digestibility and intestinal absorption. With free fatty acids (FFA) from different sources the sn-1, 3 lipase-catalyzed acidolysis of tripalmitin, butterfat, palm oil, palm stearin or lard (rich in palmitic acid in sn-2 position) the Human Milk Fat Substitutes (HMFS) have been obtained [343, 345]. Through the acidolysis between lard and soybean fatty acids catalyzed by the sn-1,3 selective lipase from $R h i$ zomucor miehei (Lipozyme ${ }^{\circledR} \mathrm{RM}$ ) using IOI Loders Croklaan, by biocatalytic processes the commercial Betapol ${ }^{\circledR}$ product is industrialized [245, 346].

\section{Lipase used in egg processing}

A variety of properties such as foaming, gelation, emulsifying in batters and mayonnaise and enhanced texture of baked goods eggs provides practical constituents to the food industry [347, 348]. The emulsifying properties of the egg lipids improved by the lipases for the better performance and the addition rate of lesser egg yolk in managed food recipes, like dressings and mayonnaiselike products, so the egg lipids are accountable for the emulsifying possessions [349, 350]. In the Russian and East European countries is concentrated one-third of the market for emulsified dressings. Nestlé, Kraft and Unilever are the global players and highly industrialized market [351]. The emulsified dressings of egg yolk are assessed at 3 millions of metric tons per year globally for the production in their process and consumed approximately 150000 metric tons per year [352, 353]. Egg yolk is composed of $50 \%$ water, $32 \%$ lipids and $16 \%$ protein a complex oil-water emulsion, in which $80 \%$ lipids is phoshatidylcholine $(\mathrm{PC})$ and approximately, 1/3 of the lipids are phospholipids [354, 355]. And it also contains phosphatidylethanolamine (Fig. 4).

\section{Lipase in bakery products, confectionery and cheese flavourings}

For the hydrolysis of milk fat in the dairy industry lipases are expansively used. In current uses of lipases are the flavour improvements of cheeses, the cheese ripening hastening, the cheese like products manufacturing, and the butterfat, cream lipolysis [356]. By the action of lipases on milk fat provides many dairy products from free fatty acids with their specific flavour features particularly the soft cheeses [357]. The short chain (mainly C4 and C6) fatty acids released primarily with the addition of lipases which leads the improvement of a sharp, tasty flavour, while the announcement of medium chain (C12, C14) fatty acids have a habit of to report a soapy taste to the

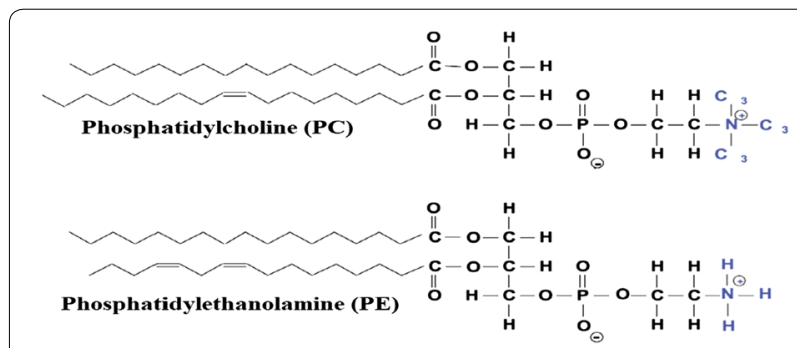

Fig. 4 The emulsion stability increased of egg yolk phospholipids into lyso-phospholipids by the enzymatic conversion [669] 
product $[220,358]$. Additionally, the free fatty acids participate in simple chemical reactions and the transformed by the microbial inhabitants of the cheese $[359,360]$. The acetoacetate, beta-keto acids, methyl ketones, flavour esters and lactones flavour gradient are manufactured by their initiations [361]. In the production of enzyme modified cheeses (EMC) lipases plays a significant role [362]. In the presence of enzymes EMC incubated at raised temperature in appropriate to harvest an intense flavour for the use as an essential in new merchandises such as dips, sauces, dressings, soups, snacks, etc. Mucor meihei (Piccnate, Gist-Brocades; Palatase M, Novo Nordisk), A. niger and A. oryzae (Palatase A, Novo Nordisk; Lipase AP, Amano; Flavour AGE, Chr. Hansen) and several others a whole range of microbial lipase preparations has been industrialized for the cheese engineering industry [363, 364]. In coffee whiteners the enhancement of flavour to yield the creamy flavour, and buttery texture of toffees and caramel lipases has been used. Lipase enzyme produced from Pencillium roqueforti developed blue cheese flavour $[365,366]$. C. antarctica lipase fraction B (CAL-B) can be involved as a strong biocatalyst in the esterification reactions due to the high transformations accomplished in the synthesis of short-chain flavour esters in an organic solvent, though this enzyme showed diffident enantioselectivity with chiral short-chain carboxylic acids [367, 368]. In the existence of beef extract/ butter oil and lipases the fermentation of Candida utilis monitored by spray drying manufactured yeast which had a beefy/blue cheese like flavour [369, 370]. In the manufacturing of better-flavored alcoholic beverages this improved yeast can be used. A. niger, R. oryzae, C. cylindracea are produced lipases and used in bakery products [371], which expedites bakeries to extend shelf-life of breads, increase and control the non-enzymatic browning, increase loiter volume and progress the fragment structure [372, 373].

\section{Lipase used in wine}

The color, taste and aromatic properties of wine contributed a complex mixture of thousands of compounds [374]. Much attention has been received on wine aroma in current years and several sensory compounds recognized [375]. The ethyl esters have received pronounced attention due to its great influence on taste between these compounds [376, 377], and the ethyl acetate ester is most collective compound represent in wines. Though, the other esters like ethyl decanoate, ethyl 2-methyl-propionate, ethyl 3-methyl-propionate, ethyl 3-methylbutanoate, ethyl cinnamate, methyl-butyl acetate, 2-phenyl-ethyl acetate and hexyl acetate, 2-ethyl hidroxpropionato, diethyl butanediato, ethyl butanoate, ethyl hexanoate, octanoate $[378,379]$. During the aging process of the beverage those formed enzymatically between an alcohol and an acid formed by chemical esterification are classified in two groups [380, 381]. Stability in the presence of ethanol, sodium metabisulfate, malic, tartaric, citric and lactic acid and high activity on $\mathrm{pH} 5-7$ together with the specific properties of esterases and lipases used for the production of ethyl acetate, ethyl butanoate, ethyl hexanoate and ethyl octanotate [382, 383]. Escherichia coli BL21 genetically improved by insertion of gene encoding the lipase/esterase enzyme consequential from Lactobacillus plantarum WCFS estimated for the characteristics of lipase/esterase production [384]. The microorganisms produced enzymes and presented a high potential for the application in wine production procedure and showed high activity at low $\mathrm{pH}$ and stability in the presence of ethanol, sodium metabisulfite and tartaric, lactic and citric acids $[385,386]$. During the processing of papaya wine the effect of sequential inoculation of yeasts, Williopsis saturnus var. mrakii NCYC2251 and Saccharomyces cerevisiae var. bayanus R2 evaluated on ester production [387].

\section{Lipase used in dietetics}

There are increasing the demand for low caloric fats and fat replacers due to the risk associated with high fat intake so the awareness increased of consumers in current scenario [388]. Todays the fatty acid contains majority of reduced caloric fats and fat substitutes available, and these are not present in edible oils and fats naturally but match the chemistry and functions of the natural fats $[389,390]$. But the disadvantage of such products is the deficiency of nutritionally significant essential fatty acids (EFA) [391]. The structured triglycerols formed a positional analysis and showed a proliferation for the primary positions paralleled to the secondary positions in preference of the lipase action [392, 393]. In the Sn-2 position the targeted structured triglycerols with palmitoyl moieties and in the Sn-1, 3 positions of medium chain acyl moieties should be beneficial for infant nutrient and clinical in food formulation as well as parental sustenance uses [394, 395]. Lipase isolated from $R$. miehei was used as the biocatalyst for the acidolysis are commercially immobilized Sn-1, 3-specific lipase, Lipozyme RM IM. The incorporation level increased with reaction time for both oleic and stearic acids $[396,397]$. The SLs produced have potential use in infant formulae and stated for the collaboration among industry and academia for increasing the successful commercialization of enzymatic processes [398]. Infant formula production with more absorbs TAGs with modification of vegetable oils [233]. The Poly Unsaturated Fatty Acids (PUFAs) and Medium Chain Fatty Acids (MCFA) in the same positions and 
amounts composed amounts as those found in human milk [399, 400]. The structured lipids (SLs) having palmitic, oleic, stearic and linoleic acids, similar to human milk fat (HMF), were manufactured by enzymatic acidolysis between tripalmitin, hazelnut oil fatty acids and stearic acid [401, 402]. Staphylococcus epidermidis is the gram-positive bacterium the lipase treated formulas incapacitated it $[312,403]$. The lipid fraction of infant formulations is not only a source of nutrients they also worked as the antiviral and antibacterial activity incubation with lipases shows in current studies [404, 405].

\section{Lipase in meat and fish industry}

To remove excess fat in the meat manufacturing and fish industry to produce the lean meat the lipase are also used. It is also used to enhance its flavour for the fermentation of meat products [406], and to expand the superiority of fermented sausages. For the hydrolysis of fish oil and aggregate the unsaturated fatty acid (n-3 PUFA) the microbial lipases are also used [407]. A fish processing by-products diversity contains growth factors contribution decent prospective as culture media, as displayed by the highest level of lipase activity formed by several microbial strains. With the use of fish wastes for microbial lipase manufacture associated with a major concern is the presence of lipids [408]. Using Staphylococcus epidermidis CMST Pi2 a defatted fish meat improvement allowable a maximum lipase manufactureing [409]. So, that there is a convinced need for improving the microbial lipase manufactureing taking into contemplation of several factors particularly the composition of fish waste and microbial strain nutrient necessities [410].

In the beginning at the times of scarcity the dry-curing was used as a meat preservation process; due to the spread use of refrigeration technology while today it has lost their importance. Though, the process has been reformed and amended in order to obtain a palatable and gorgeous meat product [411, 412]. Adipose tissue lipids and muscles are also ingredient to intense lipolysis, manufacturing free fatty acids by the lipases action that, in another stage, is renovated to volatiles as a consequence of oxidation [413]. Dry-cured hams are strongly affected the sensory profiles of by these enzymatic reactions [414]. Additionally, the muscle enzymes activity level is depend on the properties of raw ham significantly, such as crossbreeding age and the environmental factor of process like temperature, time, water activity, redox potential, and salt content $[415,416]$. Therefore, the muscle enzyme system controls lipases and proteases generally, are vital for the normalization of the processing and/or improvement of flavor eminence of dry-cured ham [417-419].

\section{Other applications of lipases}

In the formation of biopolymers the bacterial lipases are also applied. To produce solvent tolerant lipase used for the synthesis of ethyl butyrate ester in non-aqueous environment the B. multivorans V2 was observed [420, 421]. In the presence of Pseudomonas lipase by alcoholysis of cod liver oil the Omega-3 polyunsaturated fatty acids are prepared. Pseudomonas sp. produced lipase and can be used for the production of isopulegol compounds has fragrance like citrus and spearmint flavor occurred by b-pinene [422].

\section{Agriculture applications}

\section{CalB lipase as herbicide for dimethenamids- $P$}

By the enzyme inhibition of fatty acid biosynthesis a selective group of herbicides which are active against targeted plant species [423]. A number of active the aryloxy-substituted phenoxypropionate with a chiral center possess a common chemical structure (Fig. 5). A chief part of the herbicidal activity resides in only one of the enantiomers was identified similarly in pharmacological molecules.compounds within this group.

At position 2 the R-configuration is the most active so there has been substantial power from enterprises to improve the economical paths to manufacturing particular enantiomers. Instead of a racemate using a single enantiomer reduced the cost of producers and for the

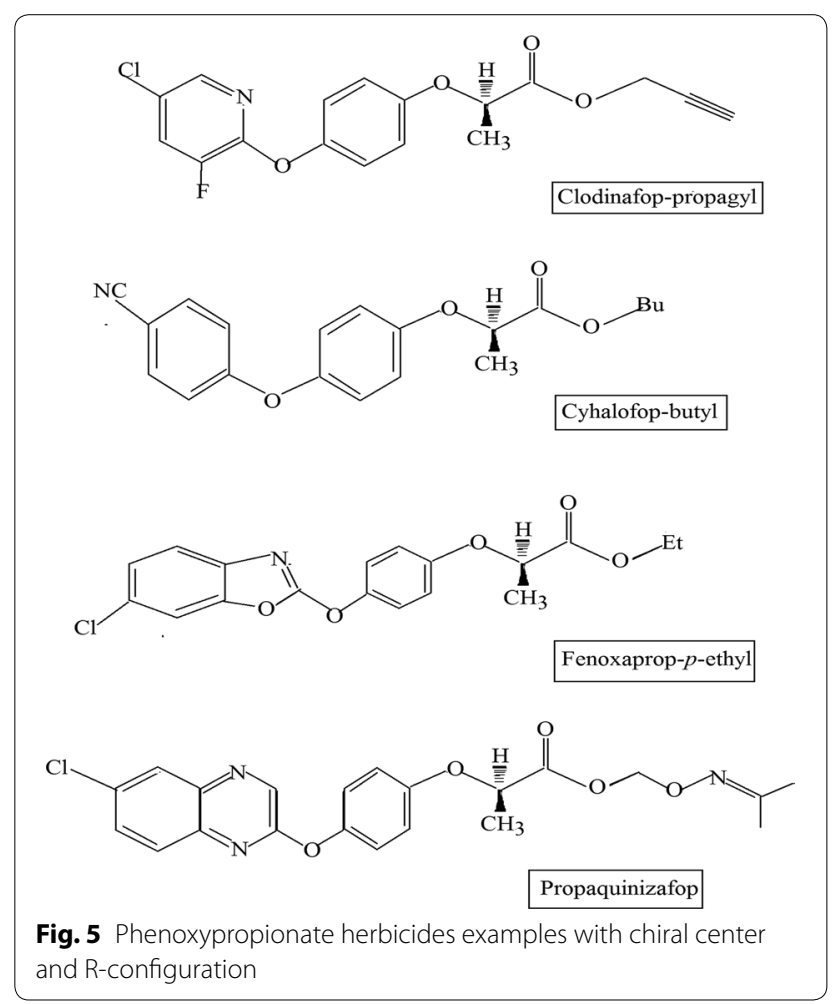


formers and also reduced the environmental influence [424, 425]. So, the biocatalysis substantiated to be an exceptional apparatus to succeed such enantioselectivity. The compounds Metolachlor and Dimethenamid were industrialized as a racemic mixture initially. Subsequent their innovation, it was recognized that a foremost quantity of the herbicidal movement be present in individually one enantiomers [426, 427].

The dynamic ingredient in Dual Magnum ${ }^{\circledR}$ (for the use of maize a chief grass herbicides), in the case of (S)Metolachlor (Fig. 6), an imine hydrogenation with the enantiomerically pure ligand "xyliphos", consumed in the manufacturing process of chemical and iridium catalyst system catalyzed it $[428,429]$. These process of dimethenamid industrialized by Sandoz 1996, sold to BASF, and the route to the single enantiomer DimethenamidP developed successfully (Fig. 7), a selective acylation of

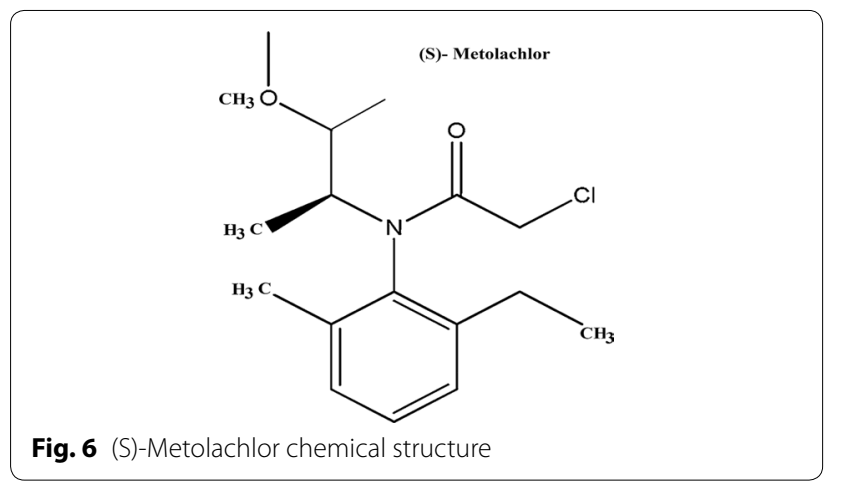

(S)-1-methoxy-2-aminopropane with ethyl 2- methoxyacetate involves or immobilized lipase CalB catalyzed a longer chain ester [344].

The molecule chirality lies in the 1-methoxy-2-aminopropane part of the structure in the case of dimethenamid [430]. Without addition of organic solvent using neat reagents the reaction takes place at $20-60{ }^{\circ} \mathrm{C}$ and accomplishes transformations of $>60 \%$ with (S)-amine ee $>99 \%$ using immobilized CalB (Novozym 435 or L2 from Chirazyme), however the undesirable ( $\mathrm{R})$ - amide is reprocessed further [431]. Due to the extraction or distillation process the undesirable ( $\mathrm{R}$ )-amide and alcohol by-product can be upgraded the desired (S)-amine. To obtain the Dimethenamid-P the improved (S) amine is further reacted [432]. By the using immobilized lipase this process was further simplified and in the process can be separated easily and for racemic resolution cycles further used [356, 433]. By BASF and others in form of (R)-amide the process was also advanced allowing the reuse the unwanted enantiomer. BASF sold Dimethenamid-P as commercial product under the brand name of Outlook ${ }^{\mathrm{TM}}$. Small-seeded broadleaf weeds such as water hemp, pigweed and nightshade and other grasses the growth was retarded by this product $[311,434]$.

\section{Applications of lipases in environment cleaning Lipase in waste water or effluent treatment}

Both aerobic and anaerobic approaches lipases are comprehensively applied in the treatment of wastewater. One of the most important aerobic treatment devices formed

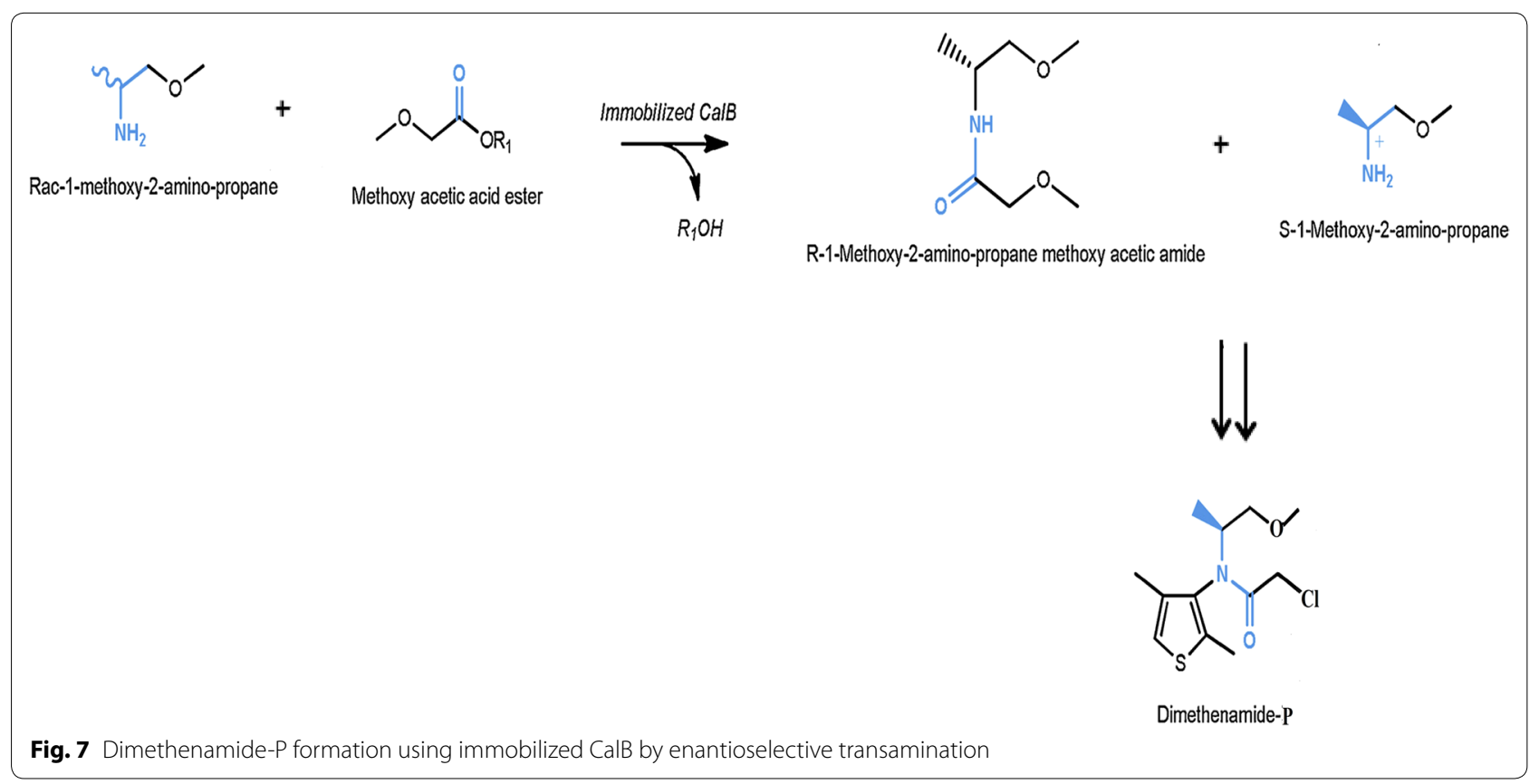


known as activated sludge process, the thin layers of fats from the surface of aerated tanks to permit oxygen transport constantly removes includes maintenance of biomass [435]. Lipases used from C. rugosa, Pseudomonas, Bacillus, Acinetobacter etc. [436] can be easily digested the impurities of skimmed fat-rich. Lipases are widely useful in the industrial wastewaters treatment such as, food waste, dairy waste, and grease from wool, manure and waste water from oil mills employing the anaerobic processes [437, 438]. The waste water effluents of food processing, tannery, automobile industries, and restaurant and fast-food outlets treated from lipase producing bacteria and seeding them. The regular performance of anaerobic digesters assisted using lipases [311, 439, 440]. In the wastewater treatment plants the treatment of fats using enzymatic approaches mainly triglycerides can be hydrolyzed up to $90 \%$ filth and further improved using immobilizing lipase synthesizing bacteria [441]. The genetic engineering approaches of microorganisms in the treatment of effluents also successfully applied [442].

\section{Lipase in bioremediation}

To decontaminate samples from oil spills, oil-wet soils, industrial wastes and wastewater tinged with lipids the process employed is known as bioremediation [443]. Without the prior treatment of the effluent which enters into the natural environment may be hazardous. Staphylococcus pasteurii COM-4A, Bacillus subtilis COM-B6, Arthrobacter sp. are the lipase-producing organisms to curb the contaminants effectively have been reported $[444,445]$. The species of Pseudomonas assisted as accessible apparatuses for microbial remediation such as $P$. aeruginosa have been particularly useful. To optimize the lipase manufacturing as well as oil hydrolysis process the Statistical methods have been adopted. Bacillus spp. pool isolated from matured contaminated soil of petroleum and B. stearothermophilus isolated from slaughter house waste hold for promising bioremediation [446]. Under acidic conditions Burkholderia sp. and Raoultella planticola bacterial genera having capabilities to degrade edible oil [447]. For the treatment of high strength Oil and Gas wastewater other bacterial consortia have been articulated as potential inoculum involved of $P$. aeruginosa, Bacillus sp., Halomonas sp., Citricoccus alkalitolerans and Acinetobacter caloaceticus revealed in another studies [448-450]. And other one comprised of B. subtilis, B. licheniformis, B. amyloliquifaciens, S. marsescens, P. aeruginosa, and S. aureus [12].

Lipolytic activities have also been practically applied for bioremediation using fungal culture is Geotrichum candidum applied in olive mill wastewater treatment and solid culture of $P$. chrysogenum sapplied in bioremediation of waste cooking oil characterize this statement. In the treatment of waste water Y. lipolytica has found massive uses [10, 128, 451]. The Antarctic basidiomycetous yeast Mrakia blollopis SK-4 has been productive in the low-temperature remediation of milk fat curdle [452]. In Oil and Gas biodegradation symbiosis of Yeast-bacteria is also valuable as shown in the association between lipase-secreting Burkholderia arboris and glycerol-assimilating C. cylindracea [453]. Quizalofop-p-ethyl (QPE; ethyl(R)-2-[4-(6-chloroquinoxalin-2-yloxy) phenoxy] propionate) is a member of the aryloxyphenoxypropionate (AOPP) group of herbicides is a post-emergence effectively controls grass weeds and is often detected in the environment degraded Pseudomonas sp. J-2 was isolated from acclimated activated sludge [454].

\section{Lipase in biodegradation of oil}

In cold environments the biodegradation of petroleum hydrocarbons such as Alpine soils able to degrade these contaminants is a result of indigenous cold-adapted microorganisms [455]. P. putida GPo1 alkB; Acinetobacter spp. alkM; Rhodococcus spp. alkB1, and Rhodococcus spp. alkB2 in the degradation of n-alkanes, P. putida xylE in aromatic hydrocarbons, $P$. putida ndoB and Mycobacterium sp. strain PYR-1 nidA in the polycyclic aromatic hydrocarbons the seven genotypes determined form the 12 samples taken from the oil-contaminated sites [456, 457]. Bacterial monocultures showed positive response in bio-augmented clean-up of waste water effluent polluted with hydrocarbons and organic polymers using hydrolytic enzymes isolated from lubricant-contaminated effluent from an electric power station $[458,459]$. In freshly polluted unfertilized and fertilized soils monitored the activity of microbial lipase is a valuable display of diesel oil biodegradation. In the coastal environment the fungal species can be used to destroy the oil spills which may improve ecorestoration as well as in the enzymatic oil processing in industries [460]. Several microbes such as B. aliphaticum, Edwardsiella tarda, Bacterium aliphaticum, Bacillus megaterium, Bacillus cereus, Pseudomonas maltiphilia, Fusarium vertiaculloide, Botryodiphodia thiobroma, Fusiarum oxysporum, Cryptococcus neofomas, Aspergillus niger and Candida tropicalis have been reported for the production of lipase enzymes and have potential to degrade crude oil [10].

\section{Lipase in pulp and paper industry}

Lignocellulosic biomass in enormous quantities processes in pulp paper industry every year. For the manufacturing of pulp this machinery is highly diverse and several prospects occur for the presentation of microbial enzymes [461]. In the paper industry enzymes have found some uses but these have been confined mainly to areas such as alterations of raw starch. For waste paper 
deinking lipase can increase the pulping rate of pulp, intensity and whiteness decreases chemical usage, pollution level of waste water, prolong equipment life, conserve energy and time and decrease the composite cost [462]. To a deinking arrangement for ethylene oxidepropylene oxide adduct stearate upgraded whiteness of paper and reduced enduring ink spots using lipase from Pseudomonas sp. KWI-56 [463]. The monitoring approach of enzymatic pitch has been in use in a largescale paper-making process as a routine operation since early 1990s using lipases [464].

\section{Lipase in leather degreasing}

For removing the fat lipases distinguish a more ecologically sound technique. Lipases permit tensides to be substituted entirely for bovine hides [34, 465]. The use of solvents is very common and these can also be substituted with lipases and surfactants which contain up to $40 \%$ fat for sheepskins [466]. For sheepskins if the surfactants are used they may be harmful to the environment and are usually not as effective [467]. Small animal skins and hides from intensively fed cattle the degreasing is a necessary stage in the processing of fatty raw ingredients [468]. Volatile organic compound (VOC) emissions are harmful in environmental concern generated from using organic solvents and surfactants conventional methods. In moderate fat content the fats and grease removes from skins and hides by lipase enzymes [469]. In skin and hide degreasing both alkaline stable and acid active lipases can be used. Triglyceride hydrolysed to glycerol and frees fatty acids using lipases [470]. The degradation of fat cell membranes and sebaceous gland components the alkaline stable proteases are used to encourage and to improve the process. For using lipases deliming and bating are the most suitable processing stages [471, 472]. Acid active lipases have been stored in a pickled state can be used to treat skins. The uniform colour and a cleaner appearance are the main improvement of using lipases [473]. Production of hydrophobic (waterproof) leather upgraded using lipases, leather manufacturers have commented that 'fogging' is reduced for car upholstery [334]. Fat dispersion and production of water-resistant and low-fogging leathers are the two advantages over the solvents or surfactant proposed the tanner by lipases. During soaking and/or liming the alkaline lipases are applied in combination with the relevant protease preferred [474]. Between the other possessions, making the fat manageable to the lipase the protease will open up the membranes surrounding the fat cell $[475,476]$. The breakdown foodstuffs emulsify the intact fat and the fat becomes more mobile, then which will distribute itself through the covering so that in several cases a suitable degreasing with surfactants will not be compulsory [477]. The lipases (acid) can also be applied for instance pickled skin or wool and fur, or semi acid for wet blue Wool in an acid process [478]. The combination of an acid lipase and an acid protease enzyme the example are Novozyme, Denmark markets NovoCor ABL and NovoCor ADL, NovoLime for acid bating of fur and wool; for enzyme-assisted liming of hides and skins a protease/lipase blend; an acid lipase for degreasing of hides and skins are NovoCor AD $[479,480]$. Lime and mixtures of sodium sulphide to dissolve hair present on the skins for the treatment of animal skins has used conventionally in the leather engineering industry but this approach is unpleasant and polluting both [481]. The liming is not efficient in chemical processes where the elimination of remaining fats and protein fragments are allied with the hide and the hair. To utilize a mixture of lipases it has become common practice for this purpose and also known as technical jargon as the bating process [482, 483]. The hair on the skins becomes slackens and the enzymes removes, which can then be clarified off. Using the traditional approaches compared to leather manufacturing the end product is of a higher quality. For the degreasing of suede clothing leathers from wooled sheep skins the lipase was used from Rhizopus nodosus [484, 485].

\section{Lipase in plastic biodegradation}

To curtail the environmental complications widely used of biodegradable plastics as a clean and green technology processes though there are biodestructible plastics are used interchangeably despite their transformations [486, 487]. The extent and rate of degradation is the main difference between the biodestructible and biodegradable plastics, where the former necessitates further management unlike the latter. The comprehensive destructibility of plastics is based on the capability of lipases to cut down polycaprolactone (aliphatic polyester); to promote their rate of degradation can be diversified with plastics observed in Fermentation Research Institute Tsukuba, Japan [488]. Lipase producing species of bacteria are applicable to biodegradation of Polyurethanes (PUR) are Pseudomonas protegens BC2-12, P. protegens CHA0, P. protegens Pf-5, P. fluorescens A506 and Pf0-1, P. chlororaphis [489]. To act on PUR one of the first enzymes identified was the PueB lipase from Pseudomonas chlororaphis. Pseudomonas sp. genus of Gram-negative betaproteobacteria has been linked with PUR activities most regularly [490]. At least one additional enzyme active on PUR codes for organisms and labelled as PueA, the secreted hydrolases degraded PUR and the degradation is tightly regulated. From Pseudomonas pelagia (PpelaLip) a putative lipase recognized as prospective enzymes performing on polyesters in broad-spectrum using an in 
silico genome mining approach [491]. Polyurethane was degraded significantly by Pseudomonas sp. The production of high amounts of extracellular lipases in $P$. aeruginosa was reported to facilitate the degradation of aromatic-aliphatic polyesters and polyesteramides [492].

\section{Lipase in polymer degradation}

Lipase isolated from the Thermomyces laguginosus (TLL) is a prominently thermostable basophilic enzyme and have capability in both immobilized and soluble form [493, 494]. In the current scenario the most significant ecological complications are the degradation of polymers. Several lipases were performed the catalysis of the side chain of poly (vinyl acetate) in toluene at $60{ }^{\circ} \mathrm{C}[495,496]$. The hydrolysis of longer side chains are in order hog-pancreas lipase $>$ Novozyme $435>$ TLL > Candida rugosa lipase whereas in the reverse order the short chains are hydrolyzed. On the biodegradation of poly (-caprolactone) the effect of several solvents is another example [497]. Using two different lipases Novozyme 435 and TLL the reaction was implemented at $45{ }^{\circ} \mathrm{C}$, while with viscosity the rate of degradation reduced and the polarity of the solvents increased [498, 499]. In non-aqueous solvents the inactivation rate was greater using TLL than Novozyme 435 . The polymers at an optimal value concentration of $8.7 \mathrm{wt}$. \% of water in acetone both are the enzymes exhibited the maximum degradation [500]. TLL degraded another polymer was Poly (bisphenolA carbonate). At various temperatures $\left(26-70{ }^{\circ} \mathrm{C}\right)$ the reaction was executed in solution by altered lipases in various solvents Candida rugosa, hog-pancreas, TLL and Novozyme 435 [501]. For hog-pancreas lipase and other lipases the optimal temperatures were 50 and $60{ }^{\circ} \mathrm{C}$. The degradability activity overall of the lipases was TLL $>$ Candida rugosa $>$ Novozyme $435>$ hog pancreas order [502]. The viscosity and polarity of the solvents effect was the same as exhibited in the degradation of poly-caprolactone. From Thermobifida fusca and Fusarium solani TLL and cutinases hydrolyzed poly (ethylene terephthalate) textiles and films and bis (benzoyloxyethyl) terephthalate endo-wise is another example [503]. A seven-fold increase of hydrolysis products released from 3PET was determined in the presence of Triton X-100 due to interfacial activation of the lipase. Semi-crystalline poly (ethylene terephthalate) films and fabrics increased hydrolysis rates were observed for both lipase and cutinase in the presence of the plasticizer $N, N$-diethyl-2-phenylacetamide [502, 503]. Enzymes from Penicillium citrinum, Thermobifida fusca, Fusarium solani pisi and TLL treated with the linear aromatic polyester poly (trimethylene terephthalate). The highest amounts of hydrolysis products cutinase from the polymer were found to release from T. fusca, and capable to hydrolyse and open a cyclic dimer [504]. So in the degradation of several polymers that pretense an actual ecological complication TLL was found very applicable $[505,506]$.

\section{Lipase in detergents manufacturing}

The chemical constituents of detergents caused ecological contamination and to hazardous for the fauna and flora so the lipases are used as a substitute of these unsafe constituents [507, 508]. From the muddy substrates the lipid molecules removed lipase based detergents which preferred for long life of cleaned fabric and active at the ambient temperature $[509,510]$. So, currently most of the industries producing enzymatically based detergents. Pseudomonas ADT3 produced lipase was found valuable in detergent [511]. The removal of corn oil stains from un-dyed cotton fabric takes place when lipase mixed with the detergent and extracted from Bacillus sonorensis $[512,513]$. At low temperature to wash the cloths in laundry the cold active lipases are useful as additives in detergent preparations [514] and in organic mixture of chiral intermediary. Pseudomonas aeruginosa strain BUP2 produced an alkaline and thermotolerant lipase used in the detergent industry efficiently with high specific activity [515]. Commonly used in detergents the lipase producing microbes are Bacillus flexus XJU-1, Bacillus licheniformis, Bacillus licheniformis VSG1, Bacillus pumilus SG2, Bacillus subtilis JPBW-9, Geobacillus sp., Pseudomonas aeruginosa sanai and Serratia marcescens DEPTK2 [516, 517]. P. mendocina (Lumafast) and Pseudomonas glumae bacteria produced lipases with high temperature optima for commercial detergent formulations are used [518]. P. mendocina and Pseudomonas alcaligenes produced lipases known as Lumafast and Lipomax, respectively, by Genencor International, AU-KBC Research Center, Life Sciences, Anna University, Chennai, India (http:// www.au-kbc.org/beta/ bioproj2/uses.htm) [519-521]. An alkaline lipase produced bacteria $P$. alcaligenes $\mathrm{M}-1$, have capability to removing the fatty stains using in washing machine [522]. Solvay Enzyme Products, Inc. 1992-0129/1990-07-25, extracted from Pseudomonas plantarii is a nonionic and/or anionic detergent formulation patented in a European Patent Office (EPO) [523]. Lipolase introduced by Novo Nordisk In 1994 was the first commercial lipase which was extracted from Trichoderma lanuginosus and expressed in A. oryzae [524, 525]. Lipo Prime $^{\circledR}$ is a lipase containing detergent also produced by them. Trichosporon asahii MSR 54 produced an alkaline lipase and developed a presoak formulation which applicable for the removal of oil stains at ambient temperature [526]. 


\section{Lipase in resolution of racemic mixtures formation}

To resolve the racemic mixtures and to synthesize the chiral building blocks lipases can be used for pharmaceuticals, agrochemicals and pesticides [527]. In nonpolar organic solvents some lipases retains their movement [528, 529]. In the hydrolysis of water-insoluble esters they can be used through stereospecific hydrolysis in the resolution of racemic mixtures [530]. Enantio selective hydrolysis or esterification, have been developed the resolution of stereoisomers $[468,531]$. In the efficacy of many drugs chirality is a key factor; so in the pharmaceutical chemistry the production of single enantiomers of drug intermediates has become increasingly [532, 533]. For the preparation of bulk drug ingredients and agricultural products the chiral intermediates and fine chemicals are in great claim from the pharmacological and agrochemical manufacturing [534]. The vast prospective of microorganisms there has been an increasing wakefulness and enzymes for the conversion of artificial compounds with more chemo-, regio- and enantioselectivity [535]. The process of enantioselectivity esterification with alcohols lipase from C. antarctica (Novozyme (R) 435) has been used for the kinetic resolution of racemic flurbiprofen [536, 537]. RS-beta-(aminomethyl)-4-chlorobenzene propanoic acid applied in the remedy of pain and as a muscle relaxant chemically known as baclofen and produces two isomers. For resolving racemic mixture lipase extracted from C. cylindracea has been used as a catalyst [538]. Stereoselective acetylation of racemic 7-[N, $N$-bis-(benzyloxy-carbonyl) $\quad N$-(guanidinoheptanoyl)]alphahydroxy-glycine 24 to corresponding S-(-)-acetate 25 was demonstrated catalysed by lipase [539]. For the total chemical synthesis of (-) -15-deoxyspergualin 23 an immunosuppressive agent and antitumor antibiotic and $\mathrm{S}$ - (-)-acetate 25 is a key intermediate $[540,541]$.

To prepare chiral intermediates for pharmaceuticals biocatalytic processes were used and includes the subsequent methods [542, 543]. A key chiral intermediate is (S) [1-(acetoxyl)-4-(3-phenyl) butyl] phosphonic acid diethyl ester 21 and essential for total compound mixture of BMS-188494 (an anticholesterol drug) [544]. Stereoselective acetylation of racemic [1- (hydroxy)-4-(3-phenyl) butyl] phosphonic acid diethyl ester 22 using G. candidum lipase prepared BMS-188494 (an anticholesterol drug) using a chiral intermediate [545, 546]. Lipase B from $C$. antarctica was revealed the enzymatic determination of racemic 2-pentanol and 2-heptanol [547, 548]. For the production of anti-Alzheimer's drug required a chiral intermediate known as S- (+) - 2-pentanol. Under a license from the Massachusetts Institute of Technology a company Chemie Linz Co. (Austria) manufactured phenoxypropionate herbicides is being carried out on a $100-\mathrm{kg}$ scale by the resolution of 2-halopropionic acids
[549]. For the manufacturing of optically active intermediates on a kilo-gramme scale several pharmaceutical companies used lipases world-wide [334]. In the UK, Enzymatix companies offer a whole variety of intermediates prepared via lipase mediated resolution specialize in biotransformation $[58,550]$. Polyfunctional organic compounds of regioselective modifications are another area of intensifying lipase solicitation [551]. Castanospermine is a favorable drug for the curing of AIDS magnificently prepared by using lipase in regioselective modification [552].

\section{Applications of lipase in pharmaceuticals and medical industry Lipase in pharmaceuticals}

A thermo-stable lipase has capabilities to catalyzing in bioenergy, pharmaceutical manufacturing and for transesterification of palm oil to FAMEs also resistant to organic solvents obtained from Acinetobacter baylyi [553, 554]. Furthermore, lipases are also applicable for the curing of hair loss and skin scalp disease [555]. For the industrial production of aryl aliphatic glycolipids, citronellol laurate from citronellol and lauric acid, and ethyl esterification of docosahexaenoic acid to ethyl docosahexaenoate the cold active lipases are used [556]. A very less quantity of enzymes exhibited positional specificity but Bacillus lipases showed selectivity to the fatty acid chain length of an ester [557]. In pharmaceutical industries for the synthesis of enantiopure compounds Bacillus lipases can be used due to these properties [558]. Using Staphylococcus lipase the antioxidant properties such as tyrosol acetate, propyl gallate and eugenol benzoate are manufactured [559]. In the case of tuberculosis (TB) detection lipase can be used for the diagnostic purposes. Mycobacterium tuberculosis lipase is used to check the infection with high specificity and sensitivity detection [560].

In blood serum the level of lipase for the detection of acute pancreatitis and their wound the level of lipase can be used. Due to using the overdose of alcohol or bile duct obstruction caused pancreatitis [561, 562]. As a constituent of topical anti-obese creams lipases are used in manufacturing of hair waving and also used for the curing of malignant tumors as digestive aids because lipases are initiate as activators of tumor necrosis factor (TNF) [131, 563]. Lovastatin drug reduce the serum cholesterol level and manufactured from Candida rugosa lipase [564]. The diltiazem hydrochloride is a widely used for the vasodilation of coronary and manufactured from $S$. marcescens lipase using a key intermediate 3-phenylglycidic acid ester by asymmetric hydrolysis [565]. For the manufacturing of (2R, 3S)-3-(4-methoxyphenyl) methyl glycidate (a key intermediate for diltiazem) and 3, 4-dihydroxylphenyl alanine (DOPA, for curing of Parkinson's 
disease) microbial lipases (EC 1.10.3.2) are used [566]. Lipases (EC 3.1.1.3) enzymes are used in the organic synthesis and also for optically active alcohols, acids, esters, and lactones [567].

\section{Lipase CalB for Odanacatib}

Generally, Lipase (EC 3.1.1.3) isolated from Candida antarctica (CalB) are commonly used as catalyst for the manufacturing of personal care products, active pharmacological and food constituents due to their regio-, chemo- and enantioselectivity [568]. Due to its broad selectivity and high acceptance to organic solvents and temperature CalB finds several uses in industrialized procedures in immobilized form $[569,570]$. Merck introduced in 2011, using immobilized CalB for the manufacturing of Odanacatib. Odanacatib discovered in 2008, is a potent cathepsin $\mathrm{K}$ inhibitor and was estimated for the curing of osteoporosis in women after menopause and at present it is withdrawn [571, 572]. The ethanolysis of azlactone is the complete ring opening vital step the procedure reported by Merck [573]. Using the high substrate concentration ( $200 \mathrm{~g} / \mathrm{l}$ of azlactone) in a continuous plug flow reactor at $60{ }^{\circ} \mathrm{C}$ in methyl tert-butyl ether (MTBE), after reaction catalyzed the immobilized CalB gives $95 \%$ conversion of the desired (S)- $\gamma$-fluoroleucine ethyl ester [574, 575], (Fig. 8).

For the process due to the key success the usage of several carriers than the one that is normally working for CalB immobilization [576], which allowed 99.9\% decline in price when matched to expending the industrially obtainable Novozym 435 (CalB immobilized on a divinyl-benzene/methacrylate carrier) [577, 578]. The stability and movement was improved expressively when immobilizing CalB on an octadecyl functionalized methacrylate resin equated to Novozym 435 preparation which is commercially available [579]. To the optimal interaction of the hydrophobic octadecyl groups with lipases this was renowned. In the immobilization of transaminase the octadecyl functionalized carrier also shows good performance $[284,580]$.

\section{Lipase CalB for Sofosbuvir}

A chronic liver disease Hepatitis $\mathrm{C}$ is an infectious disease affected by Hepatitis $\mathrm{C}$ virus (HCV), within the Flaviviridae family and a member of the hepacivirus genera worldwide [581]. It is an asymptomatic infection which traumatized to liver and finally, to cirrhosis and the symptom apparent after many years generally $[582,583]$. The cirrhosis of liver exhibited into liver failure oesophageal, gastric varices and finally cancer. The direct contact with infected blood the $\mathrm{HCV}$ is predominantly transferred [584, 585]. The high mutagenicity of $\mathrm{HCV}$ and the existence of several genotypes and subtypes is the result of emerging upgraded approaches of treating hepatitis $\mathrm{C}$ [586].

Several chemical steps are required for the production of Sofosbuvir which is an enormous compound, for the enantioselective hydrolysis of an acetate ester into the chiral alcohol into the procedure immobilized CalB is used in the patent from Gilead [587]. Divinyl benzene/ methacrylate polymer (Novozym 435) was used in MTBE on CalB immobilization with aqueous $0.1 \mathrm{M}$ phosphate

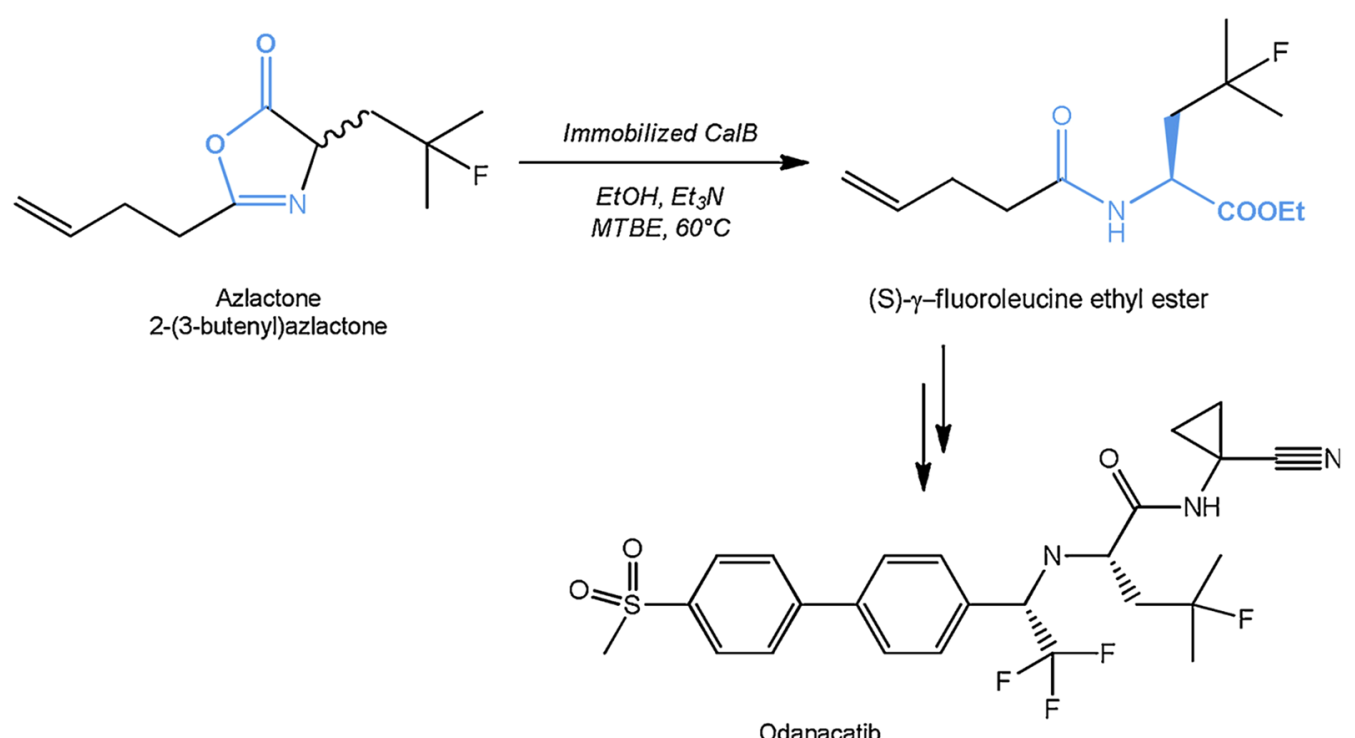

Odanacatib

Fig. 8 Lactone opening and esterification by immobilized CalB in organic solvent to produce chiral intermediate of drug Odanacatib 
buffer $\mathrm{pH} 7$ soaking at a temperature of $10{ }^{\circ} \mathrm{C}$ and the racemate conversion to the favorite enantiomer is almost $40 \%$ [588]. An intermediate manufacturing of sofosbuvir another biocatalytic process was reported in 2014 by Chemelectiva-HC-Pharma [311]. The use of immobilized lipase CalB the process also involves but the catalyzed reaction excitingly is on a diverse position of the molecule $[589,590]$. Indeed, in polar protic organic solvent to give the corresponding alcohol at $60{ }^{\circ} \mathrm{C}$ the immobilized $\mathrm{CalB}$ is used for a regioselective mono-deacetylation of sofosbuvir intermediate.

\section{Lipase in diagnostic tool}

In the medical sector lipases are significant drug targets or marker enzymes. Their presence or increasing levels can indicate certain infection or disease and can be used as diagnostic tools [591]. To generate glycerol lipases are used in the enzymatic determination of serum triglycerides and consequently analysed using the enzyme interconnected colorimetric reactions [592]. The acute pancreatitis and pancreatic injury detection the level of lipases in blood serum can be used as a diagnostic tool [593]. The serum amylase and lipase levels are used to confirm the analysis of acute pancreatitis but the ultrasonography, computed tomography and endoscopic retrograde cholangiopancreatography are the most accurate laboratory indicators for pancreatitis at serum trypsin level [594]. Using lipases some new improvements in the diagnosing pancreatitis have been produced. Serum lipase activity is not specific for pancreatitis or exocrine pancreatic insufficiency (EPI) because several cell types secrete lipases [595]. For exocrine pancreatic function the concentration of serum pancreatic lipase immunoreactivity (PLI) is highly specific and sensitive for pancreatitis [596]. A newly developed Feline Pancreatic Lipase Immunoreactivity (FPLI) serum test and primary results recommend that for the diagnosis of feline pancreatitis this test is more sensitive comparison to another diagnostic tool [597]. A wide variety of virulence-related genes are found in drinking water possess of Aeromonas bacteria that recommends the examining importance of several isolates as possible in order to improved appreciate the health hazard present in bacteria [598]. In municipally treated drinking water the indication of Aeromonas bacteria represents the potentially pathogenic Aeromonas bacteria on the bases of virulence factor characterization. Propionibacterium acnes lipase examined for the skin diseases and Unsei-in [599]. In axillary seborrheic dermatitis (ASD) the butyric acid production was more than in other dermatitis, and that in acne vulgaris (AV) was more comparison to controls [600]. In acne vulgaris (AV) the Propionibacterium acnes lipase is the pathogenic factor and in ASD the fatty acid production by lipase may be pathogenic factor [601]. An opportunistic pathogen $P$. aeruginosa have capabilities to produce and secrete several virulence factors contributing to the pathogenicity of $P$. aeruginosa regarded as biological properties [602]. The pathogenic bacteria like $P$. acnes, Corynebacterium acnes and Staphylococcus aureus lipases has also been initiate to have the influence on skin rash in acne patients [603].

\section{Lipoprotein lipase (LPL) activators as anti-obesity drugs}

A number of physiological procedures containing homeostasis also secrete an adipocytokine called LPL controlled by adipose tissues [604]. The fatty acids separating (triglycerides derivative) modified by adipose tissues among the metabolism of plasma cholesterol, several tissues and successive intracellular procedures related and dependent on accessibility of lipid [605]. TAGs are deposited in adipose tissues and skeletal muscles are produced by adipocytes. Between the muscle and adipose tissues the partitioning of plasma TG disrupted due to the inequities in LPL activity and their availability, this may also lead to and obesity and insulin resistance [606, 607]. An enhancement in LPL activity has been regularly recognized in obese individuals [608]. The effect of LPL activity and fat deposition correlated in the transgenic mice which were carried out for examinations [609]. To controls in adipose and heart tissues and smooth muscles of transgenic mice the LPL activities were found to be higher compared to control mice observation [610]. Though, there was no alteration in fat accumulation quantity of which showed that obesity was not brought due to advanced LPL activity [611]. The triacylglycerols from lipid droplets of adipocytes hydrolysed by the hormone sensitive lipases (HSL) and advised the elevation in transgenic mice [612]. In the modulating of overall weight gain the HSL is dominant directed by it. So, it may advise that the physiological modulation of LPL activity can be utilized for the control or the causes of the metabolic disorders [613]. As contrasting to adipose tissues the LPL execute the oxidation of fat in skeletal muscles mainly. In the skeletal muscles of transgenic mice hinders dietinduced obesity [271]. Diet encouraged over-expression of human LPL hinders the diet-induced obesity in the skeletal muscles of transgenic mice $[614,615]$. The ratio of carbohydrate: fat oxidation remains unperturbed indicated in the observation of constant Respiratory Quotient (RQ; moles of $\mathrm{CO}_{2}$ production per mole of Oxygen consumed) [616]. A relationship between the RQ and body weight revealed in previously published analysis. In smooth muscles of Pima Indians the RQ is inversely relative to LPL activity $[617,618]$. LPL activator NO-1886 reduces $\mathrm{RQ}$ with long-term treatment and decreases accumulated fats fed with elevated levels of fructose in diabetic rats [619]. For lipid- and non-lipid-associated 
obesity as a therapy associated to non-specific anti-obesity drugs the specific LPL activators may substantiate much valuable with respect to skeletal muscle or tissues [620, 621].

\section{Potential use of lipases in treatment cancer}

Due to reducing physical activity in routine life and in taking high calories may responsible for the risk of liver, colon breast, pancreas, and prostate cancers [622, 623]. Consequently, the intensities of triglycerides (TG) in the serum displayed and may be influenced the colorectal and pancreatic cancers or precancerous lesions. The hydrolysis of plasma TG catalyzed by the lipoprotein lipases (LPL) is also recognized [624]. It is predicted that in human the short arm of chromosome 8 which bear a putative tumor suppressor gene deleted to initiate or promote hepatocellular carcinoma is reported. Using the FISH analysis it is proved in evidence the LPL- deficiency promotes the prostate cancer $[329,625]$. Other cancer susceptible genes also deleted with the short arm of human chromosome which is responsible for breast cancer 2(DBC2), liver cancer 1 (DLC1), mitochondrial tumor suppressor1 (MTUS1) [626]. Therefore, on this chromosome the LPL gene deletion moves the proximal cancer related genes in interrogation and their joint effect in the promotion of carcinogenesis are reported [627]. Patients suffer a loss of skeletal muscle and adipose tissues associated with cachexia (weakness and wasting of the body due to severe chronic illness) are the several forms of cancer, the lipid metabolism and triglyceride hydrolysis is associated with cachexia [628, 629]. LPL acts on monoglycerides (MG) and triglycerides (TG) which shows a key role in lipids and lipoprotein metabolism. LPL modulators such as tumour necrosis factor (TNF)- $\alpha$, Interleukins (IL-1, IL-6) induce by cachexia which obstructs the activity of LPL foremost to a stark cut in the accumulation of fatty tissues [628]. To progress the LPL activity to control the cachexia in cancer patients these outcomes overlay the approach for further research [630].

\section{Lipases in medical devices}

Docosahexaenoic acid (DHA) and eicosapentaenoic acid (EPA) fatty acids (FA) are significant in growth and development, fat malabsorption can lead to decreased caloric intake deficiencies of fatty acids (FA) and caused cystic fibrosis and exocrine pancreatic insufficiency [631]. Cystic fibrosis patient used pancreatic enzyme replacement therapy in conjunction with meals to increase the absorption of fat and other nutrients [632]. The enteral nutrition allows them to meet growth and weight goals thousands of cystic fibrosis patients used in USA [633]. Due to the poor stability of hydrolyzed fats the formulas available contain triglycerides rather than fatty acids.
Alcresta Therapeutics developed a single-use cylindrical cartridge in collaboration with Chiral Vision with a closed chamber by frits comprising digestive immobilized enzyme that links in-line with the enteral feeding set [634]. On a methacrylic polymer (EC 3.1.1.3) the cartridge contains covalently immobilized lipase isolated from Chromobacterium viscosum, Pseudomonas fluorescens, Burkholderia cepacia, or Rhizopus oryzae on polymeric beads that hydrolyses up to $90 \%$ of the fats passed through the cartridge in the enteral formula [385, 635]. Since the device increases the life prospect of the patients and help to fat absorption augmentation consequently improving chronic lung disease and cognitive ability with a reduction time for parenteral nutrition [636].

\section{Application of lipase in bioenergy/biodiesel production}

Due to increasing the environmental pollution issues such as climate changes, greenhouse gases and increasing the prices of fossil fuels have encouraged the examination into the improvement of biofuel/biodiesel technology from sustainable resources [637]. So, the application of lipolytic enzymes not only helps to alleviation the enormous amount of lipid waste substances in a sustainable and ecofriendly way but also challenges the energy safety matters and which could substitute for fossil fuels [638]. Due to the outstanding bio physiochemical features of lipases (triacylglycerol acylhydrolases, EC 3.1.1.3) revealed very substantial biocatalysts. The attention is increased due to biocatalysts on the bases of biotechnological applications [639]. The shortest generation time for lipase enzyme production generally the microorganisms are preferred. Other benefits of microorganisms are high productivity of substrate conversion into product, environmental conditions versatility, and simplicity of genetic operation and in harvesting situations [640]. Lipases have capabilities to catalyze the same reaction using from different sources, but the microbial lipases are mostly used for biodiesel production like Aspergillus niger, Candida antarctica, Candida rugosa, Chromobacterium viscosum, Mucor miehei, Lactobacillus plantarum, Pseudomonas cepacia, Pseudomonas fluorescens, Photobacterium lipolyticum, Rhizopus oryzae, Streptomyces sp., and Thermomyces lanuginose, Burkholderia cepacia, Bacillus subtilis Q1 KX712301 [293, 641]. Candida rugosa yeast is mostly used for lipase production. Currently, Streptomyces sp. was explored as an effective lipase generating microbe for biodiesel manufacturing and found appropriate in the field of biodiesel [642]. The cost of biodiesel production greatly reduces using waste and non-edible vegetable oil, and measured a significant step in decreasing environmental pollution and recycling waste oil [643]. The short-chain alcohol tolerant abilities of lipase and higher thermostability form very suitable 
for usage in the production of biodiesel. Candida antarctica lipase in immobilized form catalyzed methanolysis of soybean oil for the production of biodiesel $[644,645]$.

Currently, over the other lipases in terms of energy saving the cold-active/adapted lipases have been found to be attractive for the production of biodiesel, subsequently the synthesis of biodiesel by other lipases was applied at elevated temperatures [325, 370]. Mostly the cold-active/adapted lipases characterized and identified are bacteria and only few fungal isolates have been also reported are Aspergillus nidulans [214], Geotrichum sp. [646], and Penicillium expansum. Immobilized lipase from Pseudomonas fluorescens is the most dynamic biocatalyst, followed by Pseudomonas cepacia immobilized lipase [647]. Aspergillus awamori BTMFW032 a marine fungus isolated from seawater was detected to harvest an extracellular lipase and biodiesel production [648]. For biodiesel production only microbial lipases are the material of practical importance, because these are produced in industrial scale $[649,650]$.

The greatest extensively used in biodiesel production are free lipases between the commercially available lipases from $P$. fluorescens (Lipase AsK, Amano), $B$. cepacia (Lipase PS, Amano), and T. lanuginosus (Lipase LA201 and Lipopan 50BG, Novozymes), and immobilized lipases from T. lanuginosus (Lipozyme TL IM, Novozymes) and R. miehei (Lipozyme RM IM, Novozymes) [651, 652].

In $A$. niger CALB expressed and immobilized onto an acrylic macroporous resin between recombinant lipases that is known as Novozym 435 (Novozymes) commercially lipase widely used for the production of biodiesel $[77,303]$. In conventional biodiesel production this recombinant lipase has been successfully used, as well as using isopropanolysis of soybean oil in biodiesel production, the synthesis of biodiesel and glycerol carbonate simultaneously from corn oil as the acyl acceptor using dimethyl carbonate, and production of so-called “Ecodiesel” [353, 653].

\section{Application lipase in textile industry}

For degreasing the textile raw materials and increasing the performance lipases are mainly used in the textile industry [654]. The studies of physical and chemical changes of the treated wool fiber and the commercialization of lipase have been observed [655]. On the surface of wool fiber the fatty acids are found discarded treated with anhydrous alkaline lipase and also augmented the quality of wool [656]. The dewaxing effect of silk fibers with lipase and dewaxing and degumming on silk fiber simultaneously the effects of lipase and protease with proper uses and doses have been assessed the better qualities of fiber such as rate of weight loss [657], dyeing, wettability, microstructure, gloss and other properties comparison to without uses of lipases [658]. Additionally, the desizing process of cotton fabric, amylase and lipase can also be decreasing the degree of pollution of the wastewater and degrading the starch into water-soluble compounds [659].

\section{Safety evaluation of lipases}

In agreement with the provisions and conditions of use provided for in Article 7(2) of Regulation (EC) No $1332 / 2008$ on food enzymes [660]. For the valuation of safety and the consent process of food additives, food enzymes and food flavourings Regulation (EC) No. $1331 / 2008$, recognized the European Union (EU) procedures [661]. In Union list only food enzymes involved may be placed on the market as such and used in foods [578]. Microbial lipases used in food applications do not display any toxicity so it is significant in nature. Testing involves for the evaluation of safety on the bases of acute, sub-acute and sub chronic oral toxicity and mutagenic potential [662]. Lipase G produced from P. camembertii was categorized as a nonpathogenic and as nontoxic for the enzyme production employee, operators and the consumer, which is used in the food industry as a processing aid [663]. Under organized fermentation environments lipase derived from $R$. oryzae used as a food additive and the toxic assessment identified for safety concern [664, 665]. P. pastoris used in the manufacture of food enzymes preparation also fulfill accepted safety criteria for the use in the degumming of edible vegetable oil against BD16449 phospholipase C. R. miehei lipase at high levels expressed in $A$. oryzae exhibited significant effects upon body weight and energy metabolism [484]. From $R$. oryzae Lipase $\mathrm{D}$ used for interesterification of edible fats and oils and selective hydrolysis of triglycerides, no adverse effects have been seen when used as designated in the processing of dietary fatty acids and glycerides of fatty acid [127]. C. rugosa lipase enzymes engaged in the production of flavours are considered as safe to workers and consumers [141, 666]. Trichoderma reesei RF10625 is a genetically modified strain produced triacylglycerol acylhydrolase (EC 3.1.1.3) food enzyme used in baking and cereal-based processes $[13,578]$. The enzyme is free from viable cells of the production organism and recombinant DNA and genetic alterations do not give rise to safety concerns [577, 667, 668].

\section{Conclusions and future perspective}

For lipolytic enzymes lipids and other compounds suitable as substrates through the food processing released into the environment, due to the obstruction edible oil, dairy industry thus creating problems in the biochemical processes and decrease the activity of biomass due 
to commencement. Microorganisms have capabilities to biodegrade the lipid waste in mild conditions efficiently producing lipolytic enzymes compared to the classical lipid degradation processes leading to environmental sustainability. The hydrolysis of ester bond-containing synthetic plastic, pesticide, insecticide and parabens are the one emerging aspect in current scenario and also applied for the production of bioenergy and energy saving to sustain the global hazardous wastes. Another important aspect is the production of high value-added products using less energy consuming enzymatic catalysis connected with microbial lipases. For the designing of therapeutic and diagnostic aids lipases have become broader and are evolving rapidly as prime candidates currently. For the pharmaceutical and medicinal applications lipase enzymes used as modulators such as activators and inhibitors specifically for handling of lifestyle diseases such as obesity. In the present time modulators have a huge impact on therapeutics and would be further augmented in the imminent future. So the using of these lipases prominently enhances many various biotechnology-based productions.

\begin{abstract}
Abbreviations
AV: Acne vulgaris; CALB: Candida antarctica lipase B; CRL: Candida rugosa lipase; CLA: Conjugated linoleic acid; CLEA: Cross linked enzyme aggregates; CLE: Cross-linked enzyme; CLEC: Cross-linked enzyme Crystals; CSDE: Crosslinked spraydrying enzyme; CTC: Cut-Tear-Curl; DHA: Docosahexaenoic acid; EMC: Enzyme-modified cheese; EMDI: Enzyme-modified dairy ingredients; GRAS: Generally Recognized As Safe; HCV: Hepatitis C virus; HSL: Hormone sensitive lipases; HMF: Human milk fat; HMFS: Human Milk Fat Substitutes; LPL: Lipoprotein lipase; PL: Pancreatic lipase; PLI: Pancreatic lipase immunoreactivity; PUFAs: Polyunsaturated fatty acids; PUR: Polyurethanes; TNF: Tumor necrosis factor; VOC: Volatile organic compound.
\end{abstract}

\section{Acknowledgements}

Not applicable.

\section{Authors' contributions}

Prem Chandra collected the literature, study and wrote the manuscript; Enespa revised thoroughly corrected the whole manuscript, Ranjan Singh and Pankaj Kumar Arora read and prepared for the final submission.

\section{Funding agency}

The authors declare that there is no funding agency.

\section{Availability of data and materials}

The datasets used and/or analyzed during the preparation of manuscript are available from the corresponding author on reasonable request.

\section{Ethics approval}

Not applicable.

\section{Consent for publication}

Not applicable.

\section{Competing interests}

The authors declare that they have no competing interests.

\section{Author details}

${ }^{1}$ Food Microbiology \& Toxicology, Department of Microbiology, School for Biomedical and Pharmaceutical Sciences, Babasaheb Bhimrao Ambedkar
University (A Central) University, Lucknow, Uttar Pradesh 226025, India. 2 Department of Plant Pathology, School for Agriculture, SMPDC, University of Lucknow, Lucknow 226007, U.P., India. ${ }^{3}$ Department of Environmental Science, School for Environmental Science, Babasaheb Bhimrao Ambedkar University (A Central) University, Lucknow, U.P., India. ${ }^{4}$ Department of Microbiology, School for Biomedical and Pharmaceutical Sciences, Babasaheb Bhimrao Ambedkar University (A Central) University, Lucknow, U.P., India.

Received: 18 June 2020 Accepted: 17 Auqust 2020

Published online: 26 August 2020

References

1. Moraleda-Muñoz A, Shimkets LJ. Lipolytic enzymes in Myxococcus xanthus. J Bacteriol. 2007;189(8):3072-80.

2. Javed S, Azeem F, Hussain S, Rasul I, Siddique MH, Riaz M, Afzal M, Kouser A, Nadeem H. Bacterial lipases: a review on purification and characterization. Prog Biophys Mol Biol. 2018;132:23-34.

3. Rajendran A, Palanisamy A, Thangavelu V. Lipase catalyzed ester synthesis for food processing industries. Brazil Arch Biol Technol. 2009;52(1):207-19.

4. Karadzic I, Masui A, Zivkovic LI, Fujiwara N. Purification and characterization of an alkaline lipase from Pseudomonas aeruginosa isolated from putrid mineral cutting oil as component of metalworking fluid. J Biosci Bioeng. 2006;102(2):82-9.

5. Ergan F, Trani M, Andre G. Production of glycerides from glycerol and fatty acid by immobilized lipases in non-aqueous media. Biotechnol Bioeng. 1990;35(2):195-200

6. Reetz MT. Biocatalysis in organic chemistry and biotechnology: past, present, and future. J Am Chem Soci. 2013:135(34):12480-96.

7. Mendes AA, Oliveira PC, de Castro HF. Properties and biotechnological applications of porcine pancreatic lipase. J Mol Catal B: Enzym. 2012;78:119-34.

8. Wang Y, Srivastava KC, Shen GJ, Wang HY. Thermostable alkaline lipase from a newly isolated thermophilic Bacillus, strain A30-1 (ATCC 53841). J Ferment Bioeng. 1995;79(5):433-8.

9. Tang L, Su M, Yan J, Xie S, Zhang W. Lid hinge region of Penicillium expansum lipase affects enzyme activity and interfacial activation. Process Biochem. 2015;50(8):1218-23.

10. Dwivedi SK, Enespa. In vitro cellulase activity of two wilt causing soil fusaria (Fusarium solani and F. oxysporum f. sp. lycopersici) and efficacy of some pesticides against the said fusaria. J Appl Hort. 2015;17(1):58-65.

11. Salameh MD, Wiegel J. Lipases from extremophiles and potential for industrial applications. Adv Appl Microb. 2007:61:253-83.

12. Phulpoto IA, Yu Z, Bowen H, Ndayisenga F, Jinmei L, Liang H, Qazi MA. Production and characterization of surfactin-like biosurfactant produced by novel strain Bacillus nealsonii S2MT and its potential for oil contaminated soil remediation. Microb Cell Fact. 2020;19:145.

13. Skoczinski P, Volkenborn K, Fulton A, Bhadauriya A, Nutschel C, Gohlke $\mathrm{H}$, Knapp A, Jaeger KE. Contribution of single amino acid and codon substitutions to the production and secretion of a lipase by Bacillus subtilis. Microb Cell Fact. 2017;16(1):160.

14. Freitas L, Bueno T, Perez VH, Santos JC, de Castro HF. Enzymatic hydrolysis of soybean oil using lipase from different sources to yield concentrated of polyunsaturated fatty acids. World J Microb Biotechnol. 2007;23(12):1725-31.

15. Bora L, Kalita MC. Production of thermostable alkaline lipase on vegetable oils from a thermophilic Bacillus sp. DH4, characterization and its potential applications as detergent additive. J Chem Technol Biotechnol Int Res Proc Environ Clean Technol. 2008;83(5):688-93.

16. Adrio JL, Demain AL. Microbial enzymes: tools for biotechnological processes. Biomolecules. 2014:4(1):117-39.

17. Terry LA, White SF, Tigwell $L$. The application of biosensors to fresh produce and the wider food industry. J Agric Food Chem. 2005;53(5):1309-16.

18. Sarrouh B, Santos TM, Miyoshi A, Dias R, Azevedo V. Up-to-date insight on industrial enzymes applications and global market. J Bioprocess Biotechnol. 2012;S4:002. https://doi.org/10.4172/2155-9821.S4-002. 
19. Elbrahim N, Ma K. Industrial applications of thermostable enzymes from extremophilic microorganisms. Curr Biochem Eng. 2017;4(2):75-98.

20. Hauthal HG. Types and typical ingredients of detergents., Handbook of Detergents, Part CBoca Raton: CRC Press; 2016. p. 19-118.

21. Varnam A, Sutherland JP. Milk and milk products: technology, chemistry and microbiology, vol. 1. Berlin: Springer; 2001.

22. Bano K, Kuddus M, Zaheer MR, Zia Q, Khan MF, Gupta A, Aliev G. Microbial enzymatic degradation of biodegradable plastics. Curr Pharma Biotechnol. 2017;18(5):429-40.

23. Vanleeuw E, Winderickx S, Thevissen K, Lagrain B, Dusselier M, Cammue BP, Sels BF. Substrate-specificity of Candida rugosa lipase and its industrial application. ACS Sustain Chem Eng. 2019;7(19):15828-44.

24. Badgujar KC, Bhanage BM. Lipase immobilization on hyroxypropyl methyl cellulose support and its applications for chemoselective synthesis of $\beta$-amino ester compounds. Process Biochem. 2016;51(10):1420-33.

25. Sadaf A, Grewal J, Jain I, Kumari A, Khare SK. Stability and structure of Penicillium chrysogenum lipase in the presence of organic solvents. Prep Biochem Biotechnol. 2018;48(10):977-82.

26. Bloomfield SF, Rook GA, Scott EA, Shanahan F, Stanwell-Smith R, Turner P. Time to abandon the hygiene hypothesis: new perspectives on allergic disease, the human microbiome, infectious disease prevention and the role of targeted hygiene. Perspect Public Health. 2016;136(4):213-24.

27. Liu X, Kokare C. Microbial enzymes of use in industry. In: Biotechnology of microbial enzymes. Acad Press; 2017, p. 267-98.

28. Poeta P, Albino AD, Gilberto I, Vanessa S, Rui B, Carlos SN. Selection, engineering, and expression of microbial enzymes. In: Enzymes in human and animal nutrition. Acad Press; 2018, p. 1-29.

29. Özgen FF, Vardar-Yel N, Roth OS, Shahbaz LS, Vardar-Schara G. Surface residues serine 69 and arginine 194 of metagenome-derived lipase influence catalytic activity. Biochem Eng J. 2020;154:107442.

30. Ávila SN, Gutarra ML, Fernandez-Lafuente R, Cavalcanti ED, Freire DM. Multipurpose fixed-bed bioreactor to simplify lipase production by solid-state fermentation and application in biocatalysis. Biochem Eng $\mathrm{J}$. 2019;144:1-7.

31. Lokha Y, Arana-Peña S, Rios NS, Mendez-Sanchez C, Gonçalves LR, Lopez-Gallego F, Fernandez-Lafuente R. Modulating the properties of the lipase from Thermomyces lanuginosus immobilized on octyl agarose beads by altering the immobilization conditions. Enzym Microbial Technol. 2020;133:109461.

32. Zhong L, Feng Y, Wang G, Wang Z, Bilal M, Lv H, Jia S, Cui J. Production and use of immobilized lipases in/on nanomaterials: a review from the waste to biodiesel production. Int J Biol Macromol. 2020;152:207-22.

33. Pamies O, Bäckvall JE. Combination of enzymes and metal catalysts. A powerful approach in asymmetric catalysis. Chem Rev. 2003;103(8):3247-62.

34. Huang Y, Ren J, Qu X. Nanozymes: classification, catalytic mechanisms, activity regulation, and applications. Chem Rev. 2019;119(6):4357-412.

35. Challa S, Dutta T, Neelapu NRR. Fungal white biotechnology applications for food security: opportunities and challenges. In: Recent advancement in white biotechnology through fungi. Cham: Springer; 2019, p. 119-48.

36. Homaei AA, Sariri R, Vianello F, Stevanato R. Enzyme immobilization: an update. J Chem Biol. 2013;6(4):185-205.

37. Blamey JM, Fischer F, Meyer HP, Sarmiento F, Zinn M. Enzymatic biocatalysis in chemical transformations: a promising and emerging field in green chemistry practice. In: Biotech Microb Enzym. Academic Press; 2017, p. 347-403.

38. Prasad S, Roy I. Converting enzymes into tools of industrial importance. Recent Patent Biotech. 2018;12(1):33-56.

39. Casas-Godoy L, Duquesne S, Bordes F, Sandoval G, Marty A. Lipases: an overview. In: Sandoval G, editor. Lipases and phospholipases. Methods in molecular biology, vol. 861. Totowa: Humana Press; 2012.

40. Angkawidjaja C, Kanaya S. Family I. 3 lipase: bacterial lipases secreted by the type I secretion system. Cell Mol Life Sci CMLS. 2006:63(23):2804-17.

41. Fetzner S, Steiner RA. Cofactor-independent oxidases and oxygenases. Appl Microb Biotech. 2010;86(3):791-804.

42. Kapoor M, Gupta MN. Lipase promiscuity and its biochemical applications. Process Biochem. 2012;47(4):555-69.
43. Beisson F, Tiss A, Rivière C, Verger R. Methods for lipase detection and assay: a critical review. Eur J Lipid Sci Technol. 2000;102(2):133-53.

44. Pascoal A, Estevinho LM, Martins IM, Choupina AB. Novel sources and functions of microbial lipases and their role in the infection mechanisms. Physiol Mol Plant Pathol. 2018;104:119-26.

45. Almeida JM, Martini VP, lulek J, Alnoch RC, Moure VR, Müller-Santos M, Krieger N. Biochemical characterization and application of a new lipase and its cognate foldase obtained from a metagenomic library derived from fat-contaminated soil. Int J Biol Macromol. 2019;137:442-54.

46. Stergiou PY, Foukis A, Filippou M, Koukouritaki M, Parapouli M, Theodorou LG, Papamichael EM. Advances in lipase-catalyzed esterification reactions. Biotechnol Adv. 2013;31(8):1846-59.

47. Damaso MCT, Salum TFC, Terzi SD, Couri S. Assay methods for lipase activity. In: Vermelho AB, Couri S, editors. Methods to determine enzymatic activity. Bentham: Rio de Janeiro; 2013. p. 161-94.

48. Borchert E, Selvin J, Kiran SG, Jackson SA, O'Gara F, Dobson AD. A novel cold active esterase from a deep sea sponge Stelletta normani metagenomic library. Front Mar Sci. 2017;4:287.

49. Jiao Y, Tang J, Wang Y, Koral TL. Radio-frequency applications for food processing and safety. Ann Rev Food Sci Technol. 2018;9:105-27.

50. Lei C, Guo B, Cheng Z, Goda K. Optical time-stretch imaging: principles and applications. Appl Phys Rev. 2016;3(1):011102.

51. Carpen A, Bonomi F, lametti S, Marengo M. Effects of starch addition on the activity and specificity of food-grade lipases. Biotechnol Appl Biochem. 2019;66(4):607-16.

52. Tong $X$, Busk PK, Lange L. Characterization of a new sn-1, 3-regioselective triacylglycerol lipase from Malbranchea cinnamomea. Biotechnol Appl Biochem. 2016;63(4):471-8.

53. Veríssimo LAA, Mól PCG, Soares WCL, Minim VPR, Hespanhol MC, Minim LA. Development of a bioreactor based on lipase entrapped in a monolithic cryogel for esterification and interesterification reactions. Revista Mexicana de Ing Química. 2018;17(1):177-87.

54. Silveira EA, Moreno-Perez S, Basso A, Serban S, Mamede RP, Tardioli PW, Guisan JM. Modulation of the regioselectivity of Thermomyces lanuginosus lipase via biocatalyst engineering for the Ethanolysis of oil in fully anhydrous medium. BMC Biotechnol. 2017;17(1):88.

55. Rmili F, Achouri N, Smichi N, Krayem N, Bayoudh A, Gargouri Y, Fendri A. Purification and biochemical characterization of an organic solventtolerant and detergent-stable lipase from Staphylococcus capitis. Biotechnol Prog. 2019;35(4):e2833.

56. Ekinci AP, Dinçer B, Baltaş N, Adıgüzel A. Partial purification and characterization of lipase from Geobacillus stearothermophilus AH22. J Enzym Inhibit Med Chem. 2016;31(2):325-31.

57. Melani NB, Tambourgi EB, Silveira E. Lipases: from production to applications. Sep Purif Rev. 2020;49(2):143-58.

58. Priyanka P, Tan Y, Kinsella GK, Henehan GT, Ryan BJ. Solvent stable microbial lipases: current understanding and biotechnological applications. Biotechnol Lett. 2019;41(2):203-20.

59. Itoh N, Iwata C, Toda H. Molecular cloning and characterization of a flavonoid-O-methyltransferase with broad substrate specificity and regioselectivity from Citrus depressa. BMC Plant Biol. 2016;16(1):180.

60. Castro LFC, Tocher DR, Monroig O. Long-chain polyunsaturated fatty acid biosynthesis in chordates: insights into the evolution of Fads and Elovl gene repertoire. Prog Lipid Res. 2016;62:25-40.

61. Gaschler MM, Stockwell BR. Lipid peroxidation in cell death. Biochem Biophys Res Commun. 2017;482(3):419-25.

62. Dinanta Utama Q, Sitanggang AB, Adawiyah DR, Hariyadi P. Lipasecatalyzed interesterification for the synthesis of medium-longmedium (MLM) structured lipids - a review. Food Technol Biotechnol. 2019;57(3):305-18

63. Vafaei N, Eskin MNA, Rempel CB, Michael NAE, Curtis BR, Peter JHJ, Martin GS. Interesterification of soybean oil with propylene glycol in supercritical carbon dioxide and analysis by NMR spectroscopy. Appl Biochem Biotechnol. 2020;191:905-20.

64. Nurhasanah S, Munarso SJ, Wulandari N, Hariyadi P. Physical characteristics of structured lipid synthesized by lipase catalyzed interesterification of coconut and palm oils. Pertanika J Sci Technol. 2020;28(1):19-31.

65. Brault G, Shareck F, Hurtubise Y, Lépine F, Doucet N. Short-chain flavor ester synthesis in organic media by an E. coli whole-cell biocatalyst expressing a newly characterized heterologous lipase. PLOS ONE. 2014:9(3):e91872. 
66. Jiang Y, Loos K. Enzymatic synthesis of bio based polyesters and polyamides. Polymers. 2016;8(7):243.

67. Yan Y, Li X, Wang G, Gui X, Li G, Su F, Liu T. Biotechnological preparation of biodiesel and its high-valued derivatives. Rev Appl Energy. 2014;113:1614-31.

68. Robinson PK. Enzymes: principles and biotechnological applications. Essay Biochem. 2015;59:1-41.

69. Eş I, Vieira JDG, Amaral AC. Principles, techniques, and applications of biocatalyst immobilization for industrial application. Appl Microb Biotechnol. 2015;99(5):2065-82.

70. Sarkar A, Zhang S, Holmes M, Ettelaie R. Colloidal aspects of digestion of Pickering emulsions: experiments and theoretical models of lipid digestion kinetics. Adv Coll Interf Sci. 2019;263:195-211.

71. Mat DJ, Le Feunteun S, Michon C, Souchon I. In vitro digestion of foods using $\mathrm{pH}$-stat and the INFOGEST protocol: impact of matrix structure on digestion kinetics of macronutrients, proteins and lipids. Food Res Int. 2016;88:226-33.

72. Hitaishi VP, Clement R, Bourassin N, Baaden M, De Poulpiquet A, Sacquin-Mora S, Lojou E. Controlling redox enzyme orientation at planar electrodes. Catalyst. 2018;8(5):192.

73. Psarra E, König U, Ueda Y, Bellmann C, Janke A, Bittrich E, Uhlmann P. Nanostructured biointerfaces: nanoarchitectonics of thermoresponsive polymer brushes impact protein adsorption and cell adhesion. ACS Appl Mat Interface. 2015;7(23):12516-29.

74. Khodayari A, Zomorrodi AR, Liao JC, Maranas CD. A kinetic model of Escherichia coli core metabolism satisfying multiple sets of mutant flux data. Metabol Eng. 2014;25:50-62.

75. Wong MKL, Krycer JR, Burchfield JG, James DE, Kuncic Z. A generalised enzyme kinetic model for predicting the behaviour of complex biochemical systems. FEBS Open Biol. 2015;5:226-39.

76. Bansode SR, Rathod VK. An investigation of lipase catalysed sonochemical synthesis: a review. Ultrasonics Sonochem. 2017;38:503-29.

77. Amini Z, llham Z, Ong HC, Mazaheri H, Chen WH. State of the art and prospective of lipase-catalyzed transesterification reaction for biodiesel production. Energy Conver Manag. 2017;141:339-53.

78. Hanefeld U, Gardossi L, Magner E. Understanding enzyme immobilisation. Chem Soc Rev. 2009;38(2):453-68.

79. Küchler A, Yoshimoto M, Luginbühl S, Mavelli F, Walde P. Enzymatic reactions in confined environments. Nat Nanotechnol. 2016;11(5):409.

80. Birari RB, Bhutani KK. Pancreatic lipase inhibitors from natural sources: unexplored potential. Drug Discov Today. 2007;12(19-20):879-89.

81. BuchholzT, Melzig MF. Polyphenolic compounds as pancreatic lipase inhibitors. Planta Medica. 2015;81(10):771-83.

82. Xiao S, Yu R, Ai N, Fan X. Rapid screening natural-origin lipase inhibitors from hypolipidemic decoctions by ultrafiltration combined with liquid chromatography-mass spectrometry. J Pharma Biomed Anal. 2015;104:67-74

83. de la Garza AL, Milagro FI, Boque N, Campion J, Martinez JA. Natural inhibitors of pancreatic lipase as new players in obesity treatment. Planta Med. 2011;77(8):773-85.

84. Bialecka-Florjanczyk E, Fabiszewska AU, Krzyczkowska J, Kurylowicz A. Synthetic and natural lipase inhibitors. Mini-Rev Med Chem. 2018:18:672.

85. Drent ML, Van der Veen EA. Lipase inhibition: a novel concept in the treatment of obesity. Int J Obesity Relat Metab Disord. 1993;17(4):241-4

86. Lunagariya NA, Patel NK, Jagtap SC, Bhutani KK. Inhibitors of pancreatic lipase: state of the art and clinical perspectives. EXCLI J. 2014;13:897.

87. Sánchez A, Vázquez A. Bioactive peptides: a review. Food Qual Saf. 2017;1 (1):29-46.

88. Schuhr CA, Eisenreich W, Goese M, Stohler P, Weber W, Kupfer E, Bacher A. Biosynthetic precursors of the lipase inhibitor lipstatin. J Organ Chem. 2002;67(7):2257-62.

89. Eisenreich W, Kupfer E, Stohler P, Weber W, Bacher A. Biosynthetic origin of a branched chain analogue of the lipase inhibitor, lipstatin. J Med Chem. 2003:46(19):4209-12.

90. Bai T, Zhang D, Lin S, Long Q, Wang Y, Ou H, Kang Q, Deng Z, Liu W, Tao M. Operon for biosynthesis of lipstatin, the beta-lactone inhibitor of human pancreatic lipase. Appl Environ Microbiol. 2014;80(24):7473-83.

91. Ma G, Zancanella M, Oyola Y, Richardson RD, Smith JW, Romo D. Total synthesis and comparative analysis of orlistat, valilactone, and a transposed orlistat derivative: inhibitors of fatty acid synthase. Organ Lett. 2006;8(20):4497-500.

92. Park SY, Kang HO, Jang HS, Lee JK, Koo BT, Yum DY. Identification of extracellular $\mathrm{N}$-acylhomoserine lactone acylase from a Streptomyces sp. and its application to quorum quenching. Appl Environ Microbiol. 2005;71(5):2632-41.

93. Ser HL, Law JW, Chaiyakunapruk N, Jacob SA, Palanisamy UD, Chan KG, Goh BH, Lee LH. Fermentation conditions that affect clavulanic acid production in Streptomyces clavuligerus: a systematic review. Front Microbiol. 2016;7:522

94. Liu DZ, Wang F, Liao TG, Tang JG, Steglich W, Zhu HJ, Liu JK. Vibralactone: a lipase inhibitor with an unusual fused $\beta$-lactone produced by cultures of the basidiomycete Boreostereum vibrans. Organ Lett. 2006;8(25):5749-52.

95. Hayakawa M, Yoshida Y, limura Y. Selective isolation of bioactive soil actinomycetes belonging to the Streptomyces violaceusniger phenotypic cluster. J Appl Microbiol. 2004;96(5):973-81.

96. Movahhedin N, Barar J, Azad FF, Barzegari A, Nazemiyeh H. Phytochemistry and biologic activities of Caulerpa peltata native to Oman Sea. Iran J Pharma Res: IJPR. 2014;13(2):515.

97. Valls R, Artaud J, Amade P, Vincente N, Piovetti L. Determination of caulerpenyne, a toxin from the green alga Caulerpa taxifolia (Caulerpaceae). J Chromat A. 1994;663(1):114-8.

98. Shen WJ, Sridhar K, Bernlohr DA, Kraemer FB. Interaction of rat hormone-sensitive lipase with adipocyte lipid-binding protein. Proc Natl Acad Sci. 1999;96(10):5528-32.

99. Ellis GS, Lanza-Jacoby SU, Gow AN, Kendrick ZV. Effects of estradiol on lipoprotein lipase activity and lipid availability in exercised male rats. J Appl Physiol. 1994;77(1):209-15.

100. Duan KT, Li ZH, Yu X, Yuan QX, Wang WX, Li J, Chen HP, Feng T, Liu $J K$. Vibralactone derivatives containing $\gamma, \delta$, $\varepsilon$-lactone cores from cultures of the basidiomycete Boreostereum vibrans. Fitoterapia. 2018;128:7-11.

101. Hopmann C, Kurz M, Mueller G, Toti L, inventors; Aventis Pharma Deutschland $\mathrm{GmbH}$, assignee. Percyquinnin, a process for its production and its use as a pharmaceutical. United States patent US 6,596,518; 2003.

102. Borrelli GM, Trono D. Recombinant lipases and phospholipases and their use as biocatalysts for industrial applications. Int J Mol Sci. 2015;16(9):20774-840.

103. Mayordomo I, Randez-Gil F, Prieto JA. Isolation, purification, and characterization of a cold-active lipase from Aspergillus nidulans. J Agric Food Chem. 2000;48(1):105-9.

104. Elend C, Schmeisser C, Hoebenreich H, Steele HL, Streit WR. Isolation and characterization of a metagenome-derived and cold-active lipase with high stereospecificity for (R)-ibuprofen esters. J Biotechnol. 2007;130(4):370-7.

105. Sánchez-Porro C, Martin S, Mellado E, Ventosa A. Diversity of moderately halophilic bacteria producing extracellular hydrolytic enzymes. J Appl Microbiol. 2003;94(2):295-300.

106. Boutaiba S, Bhatnagar T, Hacene H, Mitchell DA, Baratti JC. Preliminary characterisation of a lipolytic activity from an extremely halophilic archaeon, Natronococcus sp. J Mol Catal B: Enzym. 2006:41(1-2):21-6.

107. Moura MV, da Silva GP, de Oliveira Machado AC, Torres FA, Freire DM, Almeida RV. Displaying lipase B from Candida antarctica in Pichia pastoris using the yeast surface display approach: prospection of a new anchor and characterization of the whole cell biocatalyst. PLoS ONE. 2015;10(10):e0141454.

108. De Maria L, Vind J, Oxenbøll KM, Svendsen A, Patkar S. Phospholipases and their industrial applications. Appl Microbiol Biotechnol. 2007;74(2):290-300.

109. Magarvey NA, Keller JM, Bernan V, Dworkin M, Sherman DH. Isolation and characterization of novel marine-derived actinomycete taxa rich in bioactive metabolites. Appl Environ Microbiol. 2004;70(12):7520-9.

110. Munsch-Alatossava P, Käkelä R, Ibarra D, Youbi-Idrissi M, Alatossava T. Phospholipolysis caused by different types of bacterial phospholipases during cold storage of bovine raw milk is prevented by $\mathrm{N}_{2}$ gas flushing. Front Microbiol. 2018;9:1307.

111. Geoffry K, Achur RN. Optimization of novel halophilic lipase production by Fusarium solani strain NFCCL 4084 using palm oil mill effluent. J Genet Eng Biotechnol. 2018;16(2):327-34. 
112. Mobarak-Qamsari E, Kasra-Kermanshahi R, Moosavi-Nejad Z. Isolation and identification of a novel, lipase-producing bacterium, Pseudomnas aeruginosa KM110. Iran J Microbiol. 2011;3(2):92.

113. Veerapagu M, Sankara A, Jeya K, Alagendran S. Isolation and identification of a novel lipase producing bacteria from oil spilled soil. Int J Innov Res Sci Eng Technol. 2014;3(5):111-9.

114. Corper HJ, Sweany HC. The enzymes of the tubercle Bacillus. J Bacteriol. 1918;3(2):129.

115. Ghosh PK, Saxena RK, Gupta R, Yadav RP, Davidson S. Microbial lipases: production and applications. Sci Prog. 1996;1933:119-57.

116. Hiol A, Jonzo MD, Druet D, Comeau L. Production, purification and characterization of an extracellular lipase from Mucor hiemalis $\mathrm{f}$. hiemalis. Enzym Microbial Technol. 1999;25(1-2):80-7.

117. Winkler UK, Stuckmann M. Glycogen, hyaluronate, and some other polysaccharides greatly enhance the formation of exolipase by Serratia marcescens. J Bacterial. 1979;138(3):663-70.

118. Muthazhagan K, Thangaraj M. Production and partial characterization of lipase by Bacillus sp. isolated from vellar estuary sediment. IJSIT. 2014;3:639-53.

119. Arpigny $\mathrm{J}$, Jaeger KE. Bacterial lipolytic enzymes: classification and properties. Biochem J. 1999;343(1):177-83.

120. Tembhurkar VR, Kulkarni MB, Peshwe SA. Optimization of lipase production by Pseudomonas spp. in submerged batch process in shake flask culture. Sci Res Rep. 2012;2(1):46-50.

121. Sardessai YN, Bhosle S. Industrial potential of organic solvent tolerant bacteria. Biotech Prog. 2004;20(3):655-60.

122. Iftikhar T, Niaz M, Zia MA. Production of extracellular lipases by Rhizopus oligosporus in a stirred fermentor. Braz J Microbiol. 2010;41(4):1124-32.

123. Costa TM, Hermann KL, Garcia-Roman M, Valle RDCSC, Tavares LBB. Lipase production by Aspergillus niger grown in different agroindustrial wastes by solid-state fermentation. Brazil J Chem Eng. 2012;34(2):419-27.

124. Basheer SM, Chellappan S, Beena PS, Sukumaran RK, Elyas KK, Chandrasekaran M. Lipase from marine Aspergillus awamori BTMFW032: production, partial purification and application in oil effluent treatment. New Biotechnol. 2011:28(6):627-38.

125. de Almeida AF, Tauk-Tornisielo SM, Carmona EC. Acid lipase from Candida viswanathii: production, biochemical properties, and potential application. Bio Med Res Int. 2013;435818:1-10

126. Neugnot V, Moulin G, Dubreucq E, Bigey F. The lipase/acyltransferase from Candida parapsilosis: molecular cloning and characterization of purified recombinant enzymes. Eur J Biochem. 2002;269(6):1734-45.

127. Godfredson SE, Fogarty WM, Kelly ET. Microbial enzymes and biotechnology, vol. 10. Amsterdam: Elsevier; 1990. p. 255-73.

128. Chandra P, Enespa. Mycoremediation of environmental pollutants from contaminated soil. In: Mycorrhizosphere and pedogenesis. Singapore: Springer; 2019b, p. 239-74.

129. Chandra P, Enespa E. Fungal enzymes for bioremediation of contaminated soil. In: Recent advancement in white biotechnology through fungi. Cham: Springer; 2019a, p. 189-215

130. Nagarajan S. New tools for exploring "old friends-microbial lipases". Appl Biochem Biotech. 2012;168(5):1163-96.

131. Koutinas AA, Wang R, Webb $C$. Restructuring upstream bioprocessing: technological and economic aspects for production of a generic microbial feedstock from wheat. Biotechnol Bioeng. 2004;85(5):524-38.

132. Chen P, Min M, Chen Y, Wang L, Li Y, Chen Q, Deng S. Review of biological and engineering aspects of algae to fuels approach. Int J Agric Biol Eng. 2010;2(4):1-30

133. Rekhif N, Atrih A, Lefebvre G. Characterization and partial purification of plantaricin LC74, a bacteriocin produced by Lactobacillus plantarum LC74. Biotechnol Lett. 1994;16(8):771-6.

134. Saxena RK, Sheoran A, Giri B, Davidson WS. Purification strategies for microbial lipases. J Microbiol Method. 2003;52(1):1-18.

135. Kuczewski M, Fraud N, Faber R, Zarbis-Papastoitsis G. Development of a polishing step using a hydrophobic interaction membrane adsorber with a PER. $C 6^{\circledR}$-derived recombinant antibody. Biotechnol Bioeng. 2010;105(2):296-305.

136. Ghose S, Tao Y, Conley L, Cecchini D. Purification of monoclonal antibodies by hydrophobic interaction chromatography under no-salt conditions. MAbs. 2013:5(5):795-800
137. Passarinha LA Bonifácio MJ Soares-da-Silva P Queiroz JA A new approach on the purification of recombinant human soluble catecholO-methyltransferase from an Escherichia coli extract using hydrophobic interaction chromatography. J Chromatogr A. 2008;1177(2):287-96.

138. Diogo MM, Queiroz JA, Monteiro GA, Martins SAM, Ferreira GNM, Prazeres DMF. Purification of a cystic fibrosis plasmid vector for gene therapy using hydrophobic interaction chromatography. Biotechnol Bioeng. 2000;68(5):576-83.

139. Kuroyama H, Tsutsui $\mathrm{N}$, Hashimoto $Y$, Tsumuraya $Y$. Purification and characterization of a $\beta$-glucuronidase from Aspergillus niger. Carbohyd Res. 2001;333(1):27-39.

140. Hari Krishna S, Karanth NG. Lipases and lipase-catalyzed esterification reactions in nonaqueous media. Catal Rev. 2002;44(4):499-591.

141. Ghanem A. Lipase-catalyzed kinetic resolution of racemates: a versatile method for the separation of enantiomers. In: Enantiomer separation. Springer, Dordrecht; 2004, p. 193-230.

142. Harris RK, Becker ED, De Menezes SMC, Granger P, Hoffman RE, Zilm KW. Further conventions for NMR shielding and chemical shifts (IUPAC Recommendations. Pure Appl Chem. 2008;80(1):59-84.

143. Zhang Y, Füssel S, Reimer U, Schutkowski M, Fischer G. Substrate-based design of reversible Pin1 inhibitors. Biochemistry. 2002;41(39):11868-77.

144. Gilham D, Lehner R. Techniques to measure lipase and esterase activity in vitro. Methods. 2005;36(2):139-47.

145. Azevedo HS, Reis RL. Understanding the enzymatic degradation of biodegradable polymers and strategies to control their degradation rate. In: Biodegrad Syst Tissue Eng Regen Med. 2005, p. 177-201.

146. Stoytcheva M, Montero G, Zlatev R, Leon JA, Gochev V. Analytical methods for lipases activity determination: a review. Curr Anal Chem. 2012:8(3):400-7.

147. Deeth HC, Touch V. Methods for detecting lipase activity in milk and milk products. Aust J Dairy Technol. 2000;55(3):153-68.

148. Sri Kaja B, Lumor S, Besong S, Taylor B, Ozbay G. Investigating enzyme activity of immobilized Candida rugosa lipase. J Food Qual. 2018;1618085:1-9.

149. Prim N, Sánchez M, Ruiz C, Pastor FJ, Diaz P. Use of methylumbeliferylderivative substrates for lipase activity characterization. J Mol Catalysis B: Enzym. 2003;22(5-6):339-46.

150. Singh AK, Mukhopadhyay M. Overview of fungal lipase: a review. Appl Biochem Biotech. 2012;166(2):486-520.

151. Jaeger KE, Ransac S, Dijkstra BW, Colson C, van Heuvel M, Misset O. Bacterial lipases. FEMS Microbiol Rev. 1994;15(1):29-63.

152. El Soda M, Law J, Tsakalidou E, Kalantzopoulos G. Lipolytic activity of cheese related microorganisms and its impact on cheese flavour. Dev Food Sci. 1995;37:1823-47.

153. Ramnath L, Sithole B, Govinden R. Identification of lipolytic enzymes isolated from bacteria indigenous to Eucalyptus wood species for application in the pulping industry. Biotechnol Rep. 2017;15:114-24.

154. Britton J, Majumdar S, Weiss GA. Continuous flow biocatalysis. Chem Soc Rev. 2018:47(15):5891-918.

155. Gonçalves Filho D, Silva AG, Guidini CZ. Lipases: sources, immobilization methods, and industrial applications. Appl Microb Biotechnol. 2019;103(18):7399-423.

156. Girelli AM Astolfi ML, Scuto FR. Agro-industrial wastes as potential carriers for enzyme immobilization: a Rev. Chemosphere. 2020;244:125368.

157. Jesionowski T, Zdarta J, Krajewska B. Enzyme immobilization by adsorption: A Rev. Adsorption. 2014;20(5-6):801-21.

158. Mohamad NR, Marzuki NH, Buang NA, Huyop F, Wahab RA. An overview of technologies for immobilization of enzymes and surface analysis techniques for immobilized enzymes. Biotechnol Biotechnol Equip. 2015:29(2):205-20.

159. López-Gallego F, Fernandez-Lorente G, Rocha-Martín J, Bolivar JM, Mateo C, Guisan JM. Multi-point covalent immobilization of enzymes on glyoxyl agarose with minimal physico-chemical modification: stabilization of industrial enzymes. In: Immobilization of enzymes and cells. Humana, New York, NY; 2020. p. 93-107.

160. Nguyen $\mathrm{HH}$, Kim M. An overview of techniques in enzyme immobilization. Appl Sci Converg Technol. 2017;26(6):157-63.

161. Ashworth CT, Stembridge VA, Sanders E. Lipid absorption, transport and hepatic assimilation studied with electron microscopy. J Phyl-Legacy Cont. 1960;198(6):1326-8. 
162. Pang SM, Le S, Kwiatkowski AV, Yan J. Mechanical stability of aT-catenin and its activation by force for vinculin binding. Mol Biol Cell. 2019:30(16):1930-7.

163. Hanefeld U, Cao L, Magner E. Enzyme immobilisation: fundamentals and application. Chem Soc Rev. 2013;42(15):6211-2.

164. Zdarta J, Meyer AS, Jesionowski T, Pinelo M. A general overview of support materials for enzyme immobilization: characteristics, properties, practical utility. Catalysts. 2018;8(2):92.

165. Turner AP, Pickup JC. Diabetes mellitus: biosensors for research and management. Biosensor. 1985;1(1):85-115.

166. Somerset VS, Klink MJ, Sekota MM, Baker PG, Iwuoha El. Polyanilinemercaptobenzothiazole biosensor for organophosphate and carbamate pesticides. Anal Lett. 2006;39(8):1683-98.

167. Hartmann M, Kostrov X. Immobilization of enzymes on porous silicasbenefits and challenges. Chem Soc Rev. 2013;42(15):6277-89.

168. Guo Z, Bai S, Sun Y. Preparation and characterization of immobilized lipase on magnetic hydrophobic microspheres. Enzym Microb Technol. 2003;32(7):776-82.

169. Shiraki K, Nishikawa K, Goto Y. Trifluoroethanol-induced stabilization of the a-helical structure of $\beta$-lactoglobulin: implication for non-hierarchical protein folding. J Mol Biol. 1995;245(2):180-94.

170. Choi JM, Han SS, Kim HS. Industrial applications of enzyme biocatalysis: current status and future aspects. Biotechnol Adv. 2015;33(7):1443-54.

171. Zucca P, Sanjust E. Inorganic materials as supports for covalent enzyme immobilization: methods and mechanisms. Molecules. 2014;19(9):14139-94.

172. Gürsoy M, Karaman M. Surface treatments for biological, chemical and physical applications. Hoboken: Wiley; 2017.

173. Wahab RA, Elias N, Abdullah F, Ghoshal SK. On the taught new tricks of enzymes immobilization: an all-inclusive overview. React Funct Poly. 2020; 10461.

174. Talekar S, Joshi A, Joshi G, Kamat P, Haripurkar R, Kambale S. Parameters in preparation and characterization of cross linked enzyme aggregates (CLEAs). RSC Adv. 2013;3(31):12485-511.

175. Xu MQ, Wang SS, Li LN, Gao J, Zhang YW. Combined cross-linked enzyme aggregates as biocatalysts. Catalysts. 2018;8(10):460.

176. Vršanská M, Voběrková S, Jimenez Jimenez AM, Strmiska V, Adam V. Preparation and optimisation of cross-linked enzyme aggregates using native isolate white rot fungi Trametes versicolor and Fomes fomentarius for the decolourisation of synthetic dyes. Int J Environ Res Public Health. 2018;15(1):23

177. Ferrer-Miralles N, Domingo-Espín J, Corchero JL, Vázquez E, Villaverde A Microbial factories for recombinant pharmaceuticals. Microb Cell Fact. 2009:8(1):17.

178. Stead D. Microbial lipases: their characteristics, role in food spoilage and industrial uses. J Dairy Res. 1986;53(3):481-505.

179. Torres MD, Foresti ML, Ferreira ML. Cross-linked enzyme aggregates (CLEAs) of selected lipases: a procedure for the proper calculation of their recovered activity. AMB Express. 2013:3(1):25.

180. Osbon Y, Kumar M. Biocatalysis and strategies for enzyme improvement. In: Biophysical chemistry-advance applications. 2019. Intech Open. https://doi.org/10.5772/intechopen.85018

181. Reis CL, Sousa EY, Serpa JD, Oliveira RC, Santos JC. Design of immobilized enzyme biocatalysts: drawbacks and opportunities. Química Nova. 2019:42(7):768

182. Facin BR, Melchiors MS, Valério A, Oliveira JV, Oliveira DD. Driving immobilized lipases as biocatalysts: 10 years state of the art and future prospects. Ind Eng Chem Res. 2019;58(14):5358-78.

183. Sharifi M, Karim AY, Mustafa Qadir Nanakali N, Salihi A, Aziz FM, Hong J, Khan RH, Saboury AA, Hasan A, Abou-Zied OK, Falahati M. Strategies of enzyme immobilization on nanomatrix supports and their intracellular delivery. J Biomol Struct Dyn. 2020;38(9):2746-62.

184. Nguyen HD, Liu HY, Hudson BN, Lin CC. Enzymatic cross-linking of dynamic thiol-norbornene click hydrogels. ACS Biomater Sci Eng. 2019;5(3):1247-56.

185. Ye J, Chu T, Chu J, Gao B, He B. A versatile approach for enzyme immobilization using chemically modified 3D-printed scaffolds. ACS Sust Chem Eng. 2019;7(21):18048-54.

186. Diaz-Vidal T, Armenta-Perez VP, Rosales-Rivera LC, Mateos-Díaz JC, Rodríguez JA. Cross-linked enzyme aggregates of recombinant Candida antarctica lipase $B$ for the efficient synthesis of olvanil, a nonpungent capsaicin analogue. Biotechnol Prog. 2019;35(4):e2807.

187. Velasco-Lozano S. Immobilization of enzymes as cross-linked enzyme aggregates: general strategy to obtain robust biocatalysts. In: Immobilization of enzymes and cells. Humana, New York, NY; 2020, p. 345-61.

188. Chvatal A, Ambrus R, Party P, Katona G, Jójárt-Laczkovich O, SzabóRévész P, Fattal E, Tsapis N. Formulation and comparison of spray dried non-porous and large porous particles containing meloxicam for pulmonary drug delivery. Int J Pharma. 2019:559:68-75.

189. Balcao VM, Malcata FX. Lipase catalyzed modification of milk fat. Biotechnol Adv. 1998;16(2):309-41.

190. Ray A. Application of lipase in industry. Asian J Pharma Technol. 2012;2(2):33-7

191. Hamdy S, Hamdy Shaaban HS, Mahmoud KA, Farouk A. Preparation of Ras cheese flavour concentrate using lipolyzed cream and skim milk curd. Science. 2017:12(4):275-81.

192. Wolf IV, Meinardi CA, Zalazar CA. Production of flavour compounds from fat during cheese ripening by action of lipases and esterases. Prot Peptide Lett. 2009;16(10):1235-43

193. Li S, Yang X, Yang S, Zhu M, Wang X. Technology prospecting on enzymes: application, marketing and engineering. Comput Struct Biotechnol J. 2012;2(3):e201209017.

194. Herrington BL. Lipase: a review. J Dairy Sci. 1954;37(7):775-89.

195. Law BA. Cheese ripening and cheese flavour technology. In: Technology cheesemaking; 1999, p. 163-92.

196. Kilcawley KN, Wilkinson MG, Fox PF. Enzyme-modified cheese. Int Dairy J. 1998:8(1):1-10.

197. Chandan RC. Dairy processing and quality assurance: an overview. Dairy Process Quality Assur; 2008, p. 1-40.

198. Priebe S, Linde J, Albrecht D, Guthke R, Brakhage AA. Fungi Fun: a webbased application for functional categorization of fungal genes and proteins. Fungal Gen Biol. 2011;48(4):353-8.

199. Esser K, Mohr G. Integrative transformation of filamentous fungi with respect to biotechnological application. Process Bioch. 1986;21:153-9.

200. Turner C, Persson M, Mathiasson L, Adlercreutz P, King JW. Lipasecatalyzed reactions in organic and supercritical solvents: application to fat-soluble vitamin determination in milk powder and infant formula. Enzym Microb Technol. 2001:29(2-3):111-21.

201. Kirchner G, Scollar MP, Klibanov AM. Resolution of racemic mixtures via lipase catalysis in organic solvents. J Am Chem Soc. 1985;107(24):7072-6.

202. Ghanem A, Aboul-Enein HY. Lipase-mediated chiral resolution of racemates in organic solvents. Tetrahed Asymmet. 2004;15(21):3331-51.

203. Aravindan $R$, Anbumathi $P$, Viruthagiri T. Lipase applications in food industry. Indian J Biotechnol. 2007;6:141-58.

204. Omar KA, Gounga ME, Liu R, Mlyuka E. Wang X (2016) Effects of microbial lipases on hydrolyzed milk fat at different time intervals in flavour development and oxidative stability. J Food Sci Technol. 2016:53(2):1035-46.

205. Christen P, López-Munguía A. Enzymes and food flavor-a review. Food Biotechnol. 1994:8(2-3):167-90.

206. Karami M, Ehsani MR, Mousavi SM, Rezaei K, Safari M. Microstructural properties of fat during the accelerated ripening of ultrafiltered-Feta cheese. Food Chem. 2009;113(2):424-34.

207. Fox PF. Acceleration of cheese ripening. Food Biotechnol. 1988;2(2):133-85

208. Kondyli E, Massouras T, Katsiari MC, Voutsinas LP. Free fatty acids and volatile compounds in low-fat Kefalograviera-type cheese made with commercial adjunct cultures. Int Dairy J. 2003;13(1):47-54.

209. Avsar YK, Karagul-Yuceer Y, Drake MA, Singh TK, Yoon Y, Cadwallade KR. Characterization of nutty flavor in Cheddar cheese. J Dairy Sci. 2004:87(7):1999-2010.

210. De Wit M, Osthoff G, Viljoen BC, Hugo A. A comparative study of lipolysis and proteolysis in Cheddar cheese and yeast-inoculated Cheddar cheeses during ripening. Enzym Microbial Technol. 2005;37(6):606-16.

211. Grummer J, Bobowski N, Karalus M, Vickers Z, Schoenfuss T. Use of potassium chloride and flavor enhancers in low sodium Cheddar cheese. J Dairy Sci. 2013;96(3):1401-18.

212. McSweeney PL, Sousa MJ. Biochemical pathways for the production of flavour compounds in cheeses during ripening: a review. Le Lait. 2000:80(3):293-324. 
213. Yang SF, Hoffman NE. Ethylene biosynthesis and its regulation in higher plants. Ann Rev Plant Physiol. 1984;35(1):155-89.

214. Alkhalaf W, Piard JC, El-Soda M, Gripon JC, Desmazeaud M, Vassal L. Liposomes as proteinase carriers for the accelerated ripening of SaintPaulin type cheese. J Food Sci. 1988;53(6):1674-9.

215. Schilling EA, Kamholz AE, Yager P. Cell lysis and protein extraction in a microfluidic device with detection by a fluorogenic enzyme assay. Anal Chem. 2002;74(8):1798-804.

216. Nongonierma AB, Abrlova M, Kilcawley KN. Encapsulation of a lactic acid bacteria cell-free extract in liposomes and use in Cheddar cheese ripening. Food. 2013;2(1):100-19.

217. Soda ME, Pannell L, Olson N. Microencapsulated enzyme systems for the acceleration of cheese ripening. J Microencapsul. 1989;6(3):319-26.

218. Fraga JL, Penha AC, Pereira DS, Silva KA, Akil E, Torres AG, Amaral PF. Use of Yarrowia lipolytica Lipase immobilized in cell debris for the production of lipolyzed milk fat (LMF). Int J Mol Sci. 2018;19(11):3413.

219. Kailasapathy K, Lam SH. Application of encapsulated enzymes to accelerate cheese ripening. Int Dairy J. 2005;15(6-9):929-39.

220. Chávez R, Fierro F, García-Rico RO, Laich F. Mold-fermented foods: Penicillium spp. as ripening agents in the elaboration of cheese and meat products Mycofactories. Emirate of Sharjah: Bentham Sci Publisher; 2011. p. 73-98.

221. Lessard MH, Bélanger G, St-Gelais D, Labrie S. The composition of Camembert cheese-ripening cultures modulates both mycelial growth and appearance. Appl Environ Microbiol. 2012;78(6):1813-9.

222. Woo AH, Lindsay RC. Concentrations of major free fatty acids and flavor development in Italian cheese varieties. J Dairy Sci. 1984;67(5):960-8.

223. Moskowitz GJ, Noelck SS. Enzyme-modified cheese technology. J Dairy Sci. 1987;70(8):1761-9.

224. Marr AG, Ingraham JL. Effect of temperature on the composition of fatty acids in Escherichia coli. J Bacteriol. 1962:84(6):1260-7.

225. Fábregas J, García D, Morales E, Domínguez A, Otero A. Renewal rate of semicontinuous cultures of the microalga Porphyridium cruentum modifies phycoerythrin, exopolysaccharide and fatty acid productivity. J Ferment Bioeng. 1998;86(5):477-81.

226. Harzevili FD. Yarrowia lipolytica in biotechnological applications. In: Biotechnological applications of the yeast Yarrowia lipolytica. Cham: Springer; 2014, p. 17-74

227. Law BA. Controlled and accelerated cheese ripening: the research base for new technology. Int Dairy J. 2001;11(4-7):383-98.

228. Azarnia S, Robert N, Lee B. Biotechnological methods to accelerate Cheddar cheese ripening. Crit Rev Biotechnol. 2006;26(3):121-43.

229. Stanley G. Cheeses. In: Microbiology of fermented foods. Boston: Springer; 1998, p. 263-307.

230. Dekker PJ, Koenders D, Bruins MJ. Lactose-free dairy products: market developments, production, nutrition and health benefits. Nutrient. 2019;11(3):551.

231. Harju M, Kallioinen $\mathrm{H}$, Tossavainen O. Lactose hydrolysis and other conversions in dairy products: technological aspects. Int Dairy J. 2012;22(2):104-9.

232. Titus D, Samuel EJJ, Roopan SM. Importance of food science and technology-way to future. In: Bioorganic phase in natural food: an overview. Cham: Springer; 2018, p. 11-23.

233. Floros JD, Newsome R, Fisher W, Barbosa-Cánovas GV, Chen H, Dunne CP, Knabel SJ. Feeding the world today and tomorrow: the importance of food science and technology: an IFT scientific review. Comp Rev Food Sci Food Saf. 2010:9(5):572-99.

234. Otzen D. Protein-surfactant interactions: a tale of many states. Biochimica et Biophysica Acta. 2011;1814(5):562-91.

235. Damude HG, Zhu QQ. U.S. Patent No. 8,119,860. Washington, DC: U.S. Patent and Trademark Office; 2012

236. Mukherjee KD. Lipase-catalyzed reactions for modification of fats and other lipids. Biocatalysis. 1990;3(4):277-93.

237. Gunstone FD. Enzymes as biocatalysts in the modification of natura lipids. J Sci Food Agric. 1999;79(12):1535-49.

238. Cobb RE, Chao R, Zhao H. Directed evolution: past, present, and future. AIChE J. 2013;59(5):1432-40

239. Wandrey C, Liese A, Kihumbu D. Industrial biocatalysis: past, present, and future. Organ Process Res Dev. 2000;4(4):286-90.
240. Malcata FX Hill CG Ir Amundson CH. Use of a lipase immobilized in a membrane reactor to hydrolyze the glycerides of butteroil. Biotechnol Bioeng. 1991;38(8):853-68.

241. Giorno L, Drioli E. Biocatalytic membrane reactors: applications and perspectives. Trends Bioethanol. 2000;18(8):339-49.

242. Singhania T, Sinha H, Das P, Kumar Mukherjee A. Efficient degumming of rice bran oil by immobilized PLA1 from Thermomyces lanuginosus. Food Technol Biotechnol. 2015;53(1):91-5.

243. Cerminati S, Eberhardt F, Elena CE, Peirú S, Castelli ME, Menzella HG. Development of a highly efficient oil degumming process using a novel phosphatidylinositol-specific phospholipase C enzyme. Appl Microb Biotechnol. 2017:101(11):4471-9.

244. Ibrahim NA, Guo Z, Xu X. Enzymatic interesterification of palm stearin and coconut oil by a dual lipase system. J Am Oil Chem Soc. 2008;85(1):37-45

245. Holm HC, Cowan D. The evolution of enzymatic interesterification in the oils and fats industry. Eur J Lipid Sci Technol. 2008;10(8):679-91.

246. Yang T, Xu X, He C, Li L. Lipase-catalyzed modification of lard to produce human milk fat substitutes. Food Chem. 2003;80(4):473-81.

247. Rønne TH, Pedersen LS, Xu X. Triglyceride selectivity of immobilized Thermomyces lanuginosa lipase in interesterification. J Am Oil Chem Soc. 2005;2(10):737-43.

248. Joseph B, Ramteke PW, Thomas G, Shrivastava N. Standard review cold-active microbial lipases: a versatile tool for industrial applications. Biotechnol Mol Biol Rev. 2007:2(2):39-48.

249. Murty VR, Bhat J, Muniswaran PKA. Hydrolysis of oils by using immobilized lipase enzyme: a review. Biotechnol Bioprocess Eng. 2002;7(2):57-66

250. Benjamin S, Pandey A. Candida rugosa lipases: molecular biology and versatility in biotechnology. Yeast. 1998;14(12):1069-87.

251. Rumble T, Wallace A, Deeps C, McVay K, Curran M, Allen J, O'Sullivan A. New food labelling initiatives in Australia and New Zealand. Food Control. 2003;14(6):417-27.

252. Criado M, Hernández-Martín E, López-Hernández A, Otero C. Enzymatic interesterification of extra virgin olive oil with a fully hydrogenated fat: characterization of the reaction and its products. J Am Oil Chem Soc. 2007;84(8):717-26.

253. De Clercq N, Danthine S, Nguyen MT, Gibon V, Dewettinck K. Enzymatic interesterification of palm oil and fractions: monitoring the degree of interesterification using different methods. J Am Oil Chem Soc. 2012;89(2):219-29.

254. Mu H, Xu X, Høy CE. Production of specific-structured triacylglycerols by lipase-catalyzed interesterification in a laboratory-scale continuous reactor. J Am Oil Chem Soc. 1998;75(9):1187-93.

255. Haraldsson GG, Höskuldsson PA, Sigurdsson ST, Thorsteinsson F, Gudbjarnason S. The preparation of triglycerides highly enriched with $\omega-3$ polyunsaturated fatty acids via lipase catalyzed interesterification. Tetrahed Lett. 1989;30(13):1671-4.

256. Khodadadi M. Optimization of lipase-catalyzed synthesis of flaxseed oil-based structured lipids in non-conventional media. Canada: McGill University; 2012

257. de Araújo MEMB, Campos PRB, Alberto TG, Contesini FJ, de Oliveira Carvalho P. Synthesis of structured triacylglycerols enriched in n-3 fatty acids by immobilized microbial lipase. Brazil J Microbiol. 2016:47(4):1006-13.

258. Clausen K. Enzymatic oil-degumming by a novel microbial phospholipase. Eur J Lipid Sci Technol. 2001;103(6):333-40.

259. Xiaoyang S, Shaojun T, Lifen Z, Jianchun X. Effect of Phospholipase A1-catalyzed degumming on oryzanol, tocopherols, and tocotrienols of dewaxed rice bran oil. 2019:2019:1-8. Article ID 1608750.

260. Guo Z, Xu X. New opportunity for enzymatic modification of fats and oils with industrial potentials. Organ Biomol Chem. 2005;3(14):2615-9.

261. Meher LC, Sagar DV, Naik SN. Technical aspects of biodiesel production by transesterification- a review. Renew Sustain Energy Rev. 2006:10(3):248-68.

262. Willis WM, Lencki RW, Marangoni AG. Lipid modification strategies in the production of nutritionally functional fats and oils. Crit Rev Food Sci Nutri. 1998:38(8):639-74. 
263. Zaharudin NA, Rashid R, Esivan SMM, Othman N, Idris A. Review on the potential use of waste cooking palm oil in the production of high oleic palm oil via enzymatic acidolysis. J Teknol. 2016:78:6-12.

264. Farfán M, Álvarez A, Gárate A, Bouchon P. Comparison of chemical and enzymatic interesterification of fully hydrogenated soybean oil and walnut oil to produce a fat base with adequate nutritional and physical characteristics. Food Technol Biotechnol. 2015:53(3):361-6.

265. Bornscheuer UT. Enzymes in lipid modification. Ann Rev Food Sci Technol. 2018:9:85-103.

266. Osborn HT, Akoh CC. Structured lipids-novel fats with medical, nutraceutical, and food applications. Compr Rev Food Sci Food Saf. 2002;1(3):110-20.

267. Osório NM, Ferreira-Dias S, Gusmão JH, Da Fonseca MMR. Response surface modelling of the production of $\omega-3$ polyunsaturated fatty acids-enriched fats by a commercial immobilized lipase. J Mol Catal B: Enzym. 2001;11(4-6):677-86.

268. Feltes MM, de Oliveira Pitol L, Correia JG, Grimaldi R, Block JM, Ninow $J \mathrm{~L}$. Incorporation of medium chain fatty acids into fish oil triglycerides by chemical and enzymatic interesterification. Grasas y Aceites. 2009:60(2):168-76.

269. Arvanitoyannis IS, Vlachos A. Implementation of physicochemical and sensory analysis in conjunction with multivariate analysis towards assessing olive oil authentication/adulteration. Crit Rev Food Sci Nutr. 2007;47(5):441-98.

270. Aparicio R, Conte LS, Fiebig HJ. Olive oil authentication. In: Handbook of olive oil. Boston: Springer; 2013, p. 589-653.

271. Çiftçi ON, Fadiloğlu S, Kowalski B, Göğüş F. Synthesis of cocoa butter triacylglycerols using a model acidolysis system. Grasasy Aceites. 2008:59(4):316-20.

272. Salihu A, Alam MZ, Alam MZ. Production and applications of microbial lipases: a review. Sci Res Essay. 2012;7:2667-77.

273. Alberghina $L$, editor. Protein engineering for industrial biotechnology. London: CRC Press; 2000.

274. Minifie BW. Science and Technology of chocolate and confectionery. In:Chocolate, cocoa and confectionery: science and technology. Springer, Dordrecht; 1989, p. 639-74.

275. Brody AL, Sacharow S. Flexible packaging of foods. Crit Rev Food Sci Nutr. 1970:1(1):71-155.

276. Favre T, Kos H, Bhaggan K, Fages S. Process for making a triglyceride composition. 2010; WO, 130395, 2010.

277. Prathumpai W, Flitter SJ, McIntyre M, Nielsen J. Lipase production by recombinant strains of Aspergillus niger expressing a lipase-encoding gene from Thermomyces lanuginosus. Appl Microbiol Biotechnol. 2004:65(6):714-9.

278. El-Batal Al, Farrag AA, Elsayed MA, El-Khawaga AM. Biodiesel production by Aspergillus niger lipase immobilized on barium ferrite magnetic nanoparticles. Bioengineering. 2016:3(2):14

279. Xu X. Production of specific-structured triacylglycerols by lipase-cataIyzed reactions: a review. Eur J Lipid Sci Technol. 2000;102(4):287-303.

280. Schmid RD, Verger R. Lipases: interfacial enzymes with attractive applications. Angewand Cheme Int Edit. 1998:37(12):1608-33.

281. Łopaciuk A, Łoboda M. Global beauty industry trends in the 21 st century. In: Management, knowledge and learning international conference; 2013, p. 19-21.

282. Hennigs N, Karampournioti E, Wiedmann KP. Do as you would be done by: the importance of animal welfare in the global beauty care industry. In: Green fashion. Singapore: Springer; 2016, p. 109-125.

283. Fiume MM, Belsito DV, Hill RA, Klaassen CD, Liebler D, Marks JG Jr, Heldreth B. Amended safety assessment of alkyl esters as used in cosmetics. Washington, DC: Cosmetic Ingred Rev; 2013. p. 1-82.

284. Longo MA, Sanromán MA. Production of food aroma compounds: microbial and enzymatic methodologies. Food Technol Biotechnol. 2006;44(3):335-53.

285. Knezevic Z, Milosavic N, Bezbradica D, Jakovljevic Z, Prodanovic R. Immobilization of lipase from Candida rugosa on Eupergit ${ }^{\circledR} \mathrm{C}$ supports by covalent attachment. Biochem Eng J. 2006:30(3):269-78.

286. Lehtinen T, Efimova E, Santala S, Santala V. Improved fatty aldehyde and wax ester production by overexpression of fatty acyl-CoA reductases. Microb Cell Fact. 2018;17(1):19.
287. Zasada M, Budzisz E. Retinoids: active molecules influencing skin structure formation in cosmetic and dermatological treatments. Adv Dermatol Allergol/Postępy Dermatologii i Alergologii. 2019:36(4):392.

288. Bryce GF, Bogdan NJ, Brown CC. Retinoic acids promote the repair of the dermal damage and the effacement of wrinkles in the UVB-irradiated hairles mouse. J Invest Dermatol. 1988;91(2):175-80.

289. Cho S, Lowe L, Hamilton TA, Fisher GJ, Voorhees JJ, Kang S. Longterm treatment of photoaged human skin with topical retinoic acid improves epidermal cell atypia and thickens the collagen band in papillary dermis. J Am Acad Dermatol. 2005;53(5):769-74.

290. Safford B, Api AM, Barratt C, Comiskey D, Daly EJ, Ellis G, Thomas R. Use of an aggregate exposure model to estimate consumer exposure to fragrance ingredients in personal care and cosmetic products. Regul Toxicol Pharma. 2015;72(3):673-82.

291. Nohynek GJ, Antignac E, Re T, Toutain H. Safety assessment of personal care products/cosmetics and their ingredients. Toxicol Appl Pharmacol. 2010;243(2):239-59

292. Seino H, Uchibori T, Nishitani T, Inamasu S. Enzymatic synthesis of carbohydrate esters of fatty acid (I) esterification of sucrose, glucose, fructose and sorbitol. J Am Oil Chem Soc. 1984:61(11):1761-5.

293. Goldsmith HA. Polyhydric alcohol esters of fatty acids. Their preparation, properties, and uses. Chem Rev. 1943;33(3):257-349.

294. Vadgama RN, Odaneth AA, Lali AM. Green synthesis of isopropyl myristate in novel single phase medium part I: batch optimization studies. Biotechnol Rep. 2015:8:133-7.

295. Anderson EM, Larsson KM, Kirk O. One biocatalyst-many applications: the use of Candida antarctica B-lipase in organic synthesis. Biocatal Biotransform. 1998;16(3):181-204

296. Gramza A, Korczak J, Amarowicz R. Tea polyphenols-their antioxidant properties and biological activity-a review. Pol J Food Nutrit Sci. 2005;14(3):219.

297. Takeo T, Mahanta PK. Comparison of black tea aromas of orthodox and CTC tea and of black teas made from different varieties. J Sci Food Agric. 1983;34(3):307-10.

298. Calkins CR, Hodgen JM. A fresh look at meat flavor. Meat Sci. 2007:77(1):63-80.

299. Bakker J, Clarke RJ. Wine: flavour chemistry. Hoboken: Wiley; 2011.

300. Clough PM. Specialty vegetable oils containing $y$-linolenic acid and stearidonic acid. Struct Modif Lipid. 2001;4:75-107.

301. Haghi AK, editor. Food science: research and technology. Boca Raton: CRC Press; 2011

302. Xu X, Ying Y. Microbial biosensors for environmental monitoring and food analysis. Food Rev Int. 2011;27(3):300-29.

303. Wolf B, Kraus $M$, Brischwein $M$, Ehret R, Baumann W, Lehmann $M$. Biofunctional hybrid structures-cell-silicon hybrids for applications in biomedicine and bioinformatics. Bioelectrochem Bioenergy. 1998:46(2):215-25.

304. Chahinian H, Ali YB, Abousalham A, Petry S, Mandrich L, Manco G, Canaan S, Sarda L. Substrate specificity and kinetic properties of enzymes belonging to the hormone-sensitive lipase family: comparison with non-lipolytic and lipolytic carboxylesterases. Biochimica et Biophysica Acta. 2005;1738(1-3):29-36.

305. Esteban-Torres M, Reverón I, Santamaría L, Mancheño JM, de las Rivas B, Muñoz R. The Lp_3561 and Lp_3562 enzymes support a functional divergence process in the lipase/esterase toolkit from Lactobacillus plantarum. Front Microbiol. 2016;7:1118

306. Zehani N, Dzyadevych SV, Kherrat R, Jaffrezic-Renault NJ. Sensitive impedimetric biosensor for direct detection of diazinon based on lipases. Front Chem. 2014;2:44

307. He W, Barak Y, Hevener A, Olson P, Liao D, Le J, Evans RM. Adiposespecific peroxisome proliferator-activated receptor $\gamma$ knockout causes insulin resistance in fat and liver but not in muscle. Proc Natl Acad Sci. 2003;100(26):15712-7.

308. Després JP, Ross R, Boka G, Alméras N, Lemieux I. Effect of rimonabant on the high-triglyceride/low-HDL-cholesterol dyslipidemia, intraabdominal adiposity, and liver fat: the ADAGIO-Lipids trial. Arterioscl Thromb Vasc Biol. 2009;29(3):416-23.

309. Maki KC, Beiseigel JM, Jonnalagadda SS, Gugger CK, Reeves MS, Farmer MV, Rains TM. Whole-grain ready-to-eat oat cereal, as part of a dietary program for weight loss, reduces low-density lipoprotein cholesterol 
in adults with overweight and obesity more than a dietary program including low-fiber control foods. J Am Diet Assoc. 2010;110(2):205-14.

310. Bantscheff M, Lemeer S, Savitski MM, Kuster B. Quantitative mass spectrometry in proteomics: critical review update from 2007 to the present. Analyt Bioanal Chem. 2012;404(4):939-65.

311. Maier NM, Lindner W. Chiral recognition applications of molecularly imprinted polymers: a critical review. Anal Bioanal Chem. 2007;389(2):377-97.

312. Koesukwiwat U, Sanguankaew K, Leepipatpiboon N. Rapid determination of phenoxy acid residues in rice by modified QuEChERS extraction and liquid chromatography-tandem mass spectrometry. Analytica Chim Acta. 2008;626(1):10-20.

313. Weng S, Zhu W, Dong R, Zheng L, Wang F. Rapid detection of pesticide residues in paddy water using surface-enhanced Raman spectroscopy. Sensor. 2019;19(3):506.

314. Kartal F, Kilin ÇA, Timur S. Lipase biosensor for tributyrin and pesticide detection. Int J Environ Anal Chem. 2007;87(10-11):715-22.

315. Barrios CA, Canalejas-Tejero V, Herranz S, Moreno-Bondi MC, Avella-Oliver M, Puchades R, Maquieira A. Aluminum nanohole arrays fabricated on polycarbonate for compact disc-based label-free optical biosensing. Plasmonics. 2014;9(3):645-9.

316. Arreguín-Espinosa R, Arreguín B, González C. Purification and properties of a lipase from Cephaloleia presignis (Coleoptera, Chrysomelidae). Biotechnol Appl Biochem. 2000;31(3):239-44.

317. Pohanka M. Biosensors and bioassays based on lipases, principles and applications, a review. Molecule. 2019;24(3):616.

318. Sarker SD, Nahar L. An introduction to natural products isolation. In: Natural products isolation. Humana press; 2012. p. 1-25.

319. Li H, Liu S, Dai Z, Bao J, Yang X. Applications of nanomaterials in electrochemical enzyme biosensors. Sensor. 2009;9(11):8547-61.

320. Holzinger M, Le Goff A, Cosnier S. Nanomaterials for biosensing applications: a review. Front Chem. 2014;2:63.

321. Hou S, Zhang A, Su M. Nanomaterials for bio sensing applications. Nanomaterial. 2016;6(4):58.

322. Abu-Salah KM, Alrokyan SA, Khan MN, Ansari AA. Nanomaterials as analytical tools for genosensors. Sensors. 2010;10(1):963-93.

323. Zhang Y, Chen X. Nanotechnology and nanomaterial-based no-wash electrochemical biosensors: from design to application. Nanoscale. 2019;11(41):19105-18

324. Khan I, Saeed K, Khan I. Nanoparticles: properties, applications and toxicities. Arab J Chem. 2019;12(7):908-31.

325. Haes AJ, Zou S, Schatz GC, Van Duyne RP. Nanoscale optical biosensor: short range distance dependence of the localized surface plasmon resonance of noble metal nanoparticles. J Phys Chem B. 2004;108(22):6961-8.

326. Unser S, Bruzas I, He J, Sagle L. Localized surface plasmon resonance biosensing: current challenges and approaches. Sensor. 2015;15(7):15684-716

327. Abarrategi A, Gutierrez MC, Moreno-Vicente C, Hortigüela MJ, Ramos V, Lopez-Lacomba JL, del Monte F. Multiwall carbon nanotube scaffolds for tissue engineering purposes. Biomaterial. 2008;29(1):94-102.

328. Venkatesan J, Ryu B, Sudha PN, Kim SK. Preparation and characterization of chitosan-carbon nanotube scaffolds for bone tissue engineering. Int J Biol Macromol. 2012;50(2):393-402.

329. Merlo R, Del Prete S, Valenti A, Mattossovich R, Carginale V, Supuran CT, Capasso C, Perugino G. An AGT-based protein-tag system for the labelling and surface immobilization of enzymes on E. coli outer membrane. J Enzym Inhibit Med Chem. 2019;34(1):490-9.

330. Farris PK. Topical vitamin C: a useful agent for treating photoaging and other dermatologic conditions. Dermatol Surg. 2005;31:814-8.

331. Antunes $L M G$, Darin JDAC, Bianchi MDLP. Protective effects of vitamin C against cisplatin-induced nephrotoxicity and lipid peroxidation in adult rats: a dose-dependent study. Pharmacol Res. 2000;41(4):405-11.

332. Reyes-Duarte D, Lopez-Cortes N, Torres P, Comelles F, Parra JL, Peña S, Plou FJ. Synthesis and properties of ascorbyl esters catalyzed by lipozyme TL IM using triglycerides as acyl donors. J Am Oil Chem Soc. 2011;88(1):57-64

333. Schröder H, Navarro E, Mora J, Galiano D, Tramullas A. Effects of a-tocopherol, $\beta$-carotene and ascorbic acid on oxidative, hormonal and enzymatic exercise stress markers in habitual training activity of professional basketball players. Eur J Nutr. 2001;40(4):178-84.
334. Javidipour I, Tüfenk R, Baştürk A. Effect of ascorbyl palmitate on oxidative stability of chemically interesterified cottonseed and olive oils. J Food Sci Technol. 2015:52(2):876-84

335. Ortiz C, Ferreira ML, Barbosa O, dos Santos JC, Rodrigues RC, BerenguerMurcia Á, Fernandez-Lafuente R. Novozym 435: the "perfect" lipase immobilized biocatalyst? Catal Sci Technol. 2019;9(10):2380-420.

336. Nartey ET, Ofosuhene M, Kudzi W, Agbale CM. Antioxidant and gastric cytoprotective prostaglandins properties of Cassia sieberiana roots bark extract as an anti-ulcerogenic agent. BMC Complement Alternat Med. 2012;12(1):1-10.

337. Barbosa O, Ortiz C, Berenguer-Murcia Á, Torres R, Rodrigues RC. Fernandez-Lafuente R Strategies for the one-step immobilizationpurification of enzymes as industrial biocatalysts. Biotechnol Adv. 2015;33(5):435-56.

338. Sheldon RA. Characteristic features and biotechnological applications of cross-linked enzyme aggregates (CLEAs). Appl Microbiol Biotechnol. 2011;92(3):467-77.

339. Tufiño C, Bernal C, Ottone C, Romero O, Illanes A, Wilson L. Synthesis with immobilized lipases and downstream processing of ascorbyl palmitate. Mol. 2019;24(18):3227.

340. Yadav P, Maharjan J, Korpole S, Prasad GS, Sahni G, Bhattarai T, Sreerama L. Production, Purification, and Characterization of Thermostable Alkaline Xylanase From Anoxybacillus kamchatkensis NASTPD13. Front Bioeng Biotechnol. 2018;6:65.

341. Kamerlin SC, Warshel A. At the dawn of the 21st century: is dynamics the missing link for understanding enzyme catalysis. Proteins Struct Funct Bioinf. 2010;78(6):1339-75.

342. Tan T, Lu J, Nie K, Deng L, Wang F. Biodiesel production with immobilized lipase: a review. Biotechnol Adv. 2010;28(5):628-34.

343. Sahin N, Akoh CC, Karaali A. Lipase-catalyzed acidolysis of tripalmitin with hazelnut oil fatty acids and stearic acid to produce human milk fat substitutes. J Agric Food Chem. 2005;53(14):5779-83.

344. Basso A, Serban S. Industrial applications of immobilized enzymes-a review. Mol Catal. 2019;479:110607.

345. Yang T, Fruekilde MB, Xu X. Applications of immobilized Thermomyces lanuginosa lipase in interesterification. J Am Oil Chem Soc. 2003:80(9):881-7.

346. Huang J, Zhao Q, Bu W, Zhang C, Yang Z, Zhang X, Zhang K. Ultrasoundassisted hydrolysis of lard for free fatty acids catalyzed by combined two lipases in aqueous medium. Bioengineering. 2020:11(1):241-50

347. Mine Y. Recent advances in egg protein functionality in the food system. World Poul Sci J. 2002:58(1):31-9.

348. Kiosseoglou V. Egg yolk protein gels and emulsions. Curr Opin Coll Interface Sci. 2003:8(4-5):365-70.

349. Mirzanajafi-Zanjani M, Yousefi M, Ehsani A. Challenges and approaches for production of a healthy and functional mayonnaise sauce. Food Sci Nutr. 2019;7(8):2471-84.

350. Motta-Romero H, Zhang Z, Tien Nguyen A, Schlegel V, Zhang Y. Isolation of egg yolk granules as low-cholesterol emulsifying agent in mayonnaise. J Food Sci. 2017;82(7):1588-93.

351. Scholten B. US organic dairy politics: animals, pasture, people, and agribusiness. Berlin: Springer; 2014.

352. Lin CSK, Koutinas AA, Stamatelatou K, Mubofu EB, Matharu AS, Kopsahelis N, Luque R. Current and future trends in food waste valorization for the production of chemicals, materials and fuels: a global perspective. Biofuel, Bioprod Bioref. 2014;8(5):686-715.

353. Lovett PN. Shea butter: Properties and processing for use in food. In: Specialty oils and fats in food and nutrition. Wood head Publish. 2015. p. $125-58$

354. Tamilvanan S. Oil-in-water lipid emulsions: implications for parenteral and ocular delivering systems. Prog Lipid Res. 2004;43(6):489-533.

355. Hur SJ, Decker EA, McClements DJ. Influence of initial emulsifier type on microstructural changes occurring in emulsified lipids during in vitro digestion. Food Chem. 2009;1 14(1):253-62.

356. Jooyandeh H, Amarjeet K, Minhas KS. Lipases in dairy industry: a review. J Food Sci Technol (Mysore). 2009:46(3):181-9.

357. Collins YF, McSweeney PL, Wilkinson MG. Lipolysis and free fatty acid catabolism in cheese: a review of current knowledge. Int Dairy J. 2003;13(11):841-66. 
358. Liu KJ, Cheng HM, Chang RC, Shaw JF. Synthesis of cocoa butter equivalent by lipase-catalyzed interesterification in supercritical carbon dioxide. J Am Oil Chem Soc. 1997;74(11):1477-82

359. Tavaria FK, Ferreira AS, Malcata FX. Volatile free fatty acids as ripening indicators for Serra da Estrela cheese. J Dairy Sci. 2004;87(12):4064-72.

360. Langsrud T, Reinbold GW. Flavor development and microbiology of Swiss cheese-a review: III. Ripening and flavor production. J Milk Food Technol. 1973;36(12):593-609.

361. Yu AQ, Pratomo Juwono NK, Leong SSJ, Chang MW. Production of fatty acid-derived valuable chemicals in synthetic microbes. Front Bioeng Biotechnol. 2014;2:78

362. Huang HT, Dooley JG. Enhancement of cheese flavors with microbial esterases. Biotechnol Bioeng. 1976;18(7):909-19.

363. Ellaiah P, Adinarayana K, Bhavani Y, Padmaja P, Srinivasulu B. Optimization of process parameters for glucoamylase production under solid state fermentation by a newly isolated Aspergillus sp. Process Biochem. 2002;38(4):615-20.

364. Yang WZ, Beauchemin KA, Rode LM. Effects of an enzyme feed additive on extent of digestion and milk production of lactating dairy cows. J Dairy Sci. 1999:82(2):391-403.

365. Seitz EW. Microbial and enzyme-induced flavors in dairy foods. J Dairy Sci. 1990;73(12):3664-91.

366. Kinsella JE, Hwang DH, Dwivedi B. Enzymes of Penicillium roqueforti involved in the biosynthesis of cheese flavor. Crit Rev Food Sci Nutr. 1976;8(2):191-228.

367. Larios A, García HS, Oliart RM, Valerio-Alfaro G. Synthesis of flavor and fragrance esters using Candida antarctica lipase. Appl Microbiol Biotechnol. 2004;65(4):373-6

368. De Souza MCM, Dos Santos KP, Freire RM, Barreto ACH, Fechine PBA, Gonçalves LRB. Production of flavor esters catalyzed by lipase B from Candida antarctica immobilized on magnetic nanoparticles. Brazil J Chem Eng. 2017;34(3):681-90

369. Foda MS, El-Naggar MR, Haroun BM. Production of Candida utilis on slop by-product of fermentation industries. Zentralblatt für Bakteriologie, Parasitenkunde, Infektionskrankheiten und Hygiene. Zweite Naturwissenschaftliche Abteilung: Allgemeine, Landwirtschaftliche und Technische Mikrobiologie. 1976;131(6):512-6.

370. Hasan F, Shah AA, Hameed A. Industrial applications of microbial lipases. Enzym Microbial Technol. 2006;39(2):235-51.

371. Shamim S, Liaqat U, Rehman A. Microbial lipases and their applicationsa review. AJ Life Sci. 2018;1(2):54-76.

372. Sato K, Goto S, Yonemura S, Sekine K, Okuma E, Takagi Y, Saiki T. Effect of yeast extract and vitamin B12 on ethanol production from cellulose by Clostridium thermocellum I-1-B. Appl Environ Microbiol. 1992;58(2):734-6

373. Laopaiboon L, Nuanpeng S, Srinophakun P, Klanrit P, Laopaiboon P. Ethanol production from sweet sorghum juice using very high gravity technology: effects of carbon and nitrogen supplementations. Biores Technol. 2009:100(18):4176-82.

374. Sumby KM, Grbin PR, Jiranek V. Microbial modulation of aromatic esters in wine: current knowledge and future prospects. Food Chem. 2010;121(1):1-16.

375. Lambrechts MG, Pretorius IS. Yeast and its importance to wine aroma-a review. South Afr J Enol Viticul. 2000;21(1):97-129.

376. Teodosiu C, Gabur I, Cotea V, Peinado RA, López de Lerma N. Evaluation of aroma compounds in the process of wine ageing with oak chips. Foods. 2019;8(12):662

377. Petruzzi L, Capozzi V, Berbegal C, Corbo MR, Bevilacqua A, Spano G, Sinigaglia M. Microbial resources and enological significance: opportunities and benefits. Front Microbiol. 2017:8:995

378. Caven-Quantrill DJ, Buglass AJ. Analysis of volatile components of varietal english wines using stir bar sorptive extraction/gas chromatography-mass spectrometry. Beverages. 2017;3(4):62.

379. Charpentier C. Ageing on lees (sur lies) and the use of specialty inactive yeasts during wine fermentation. In: Manag Wine Qual. Woodhead Publish: 2010, p. 164-87.

380. Mingorance-Cazorla L, Clemente-Jiménez JM, Martínez-Rodríguez S, Las Heras-Vázquez FJ, Rodríguez-Vico F. Contribution of different natural yeasts to the aroma of two alcoholic beverages. World J Microbiol Biotechnol. 2003;19(3):297-304.
381. McEvily AJ, lyengar R, Otwell WS. Inhibition of enzymatic browning in foods and beverages. Crit Rev Food Sci Nutr. 1992;32(3):253-73.

382. Esteban-Torres M, Barcenilla JM, Mancheño JM, de las Rivas B, Munoz R. Characterization of a versatile arylesterase from Lactobacillus plantarum active on wine esters. J Agric Food Chem. 2014;62(22):5118-25.

383. Esteban-Torres M, Landete JM, Reverón I, Santamaría L, de las Rivas B, Muñoz AR. Lactobacillus plantarum esterase active on a broad range of phenolic esters. Appl Environ Microbiol. 2015;81(9):3235-42.

384. Barros M, Fleuri LF, Macedo GA. Seed lipases: sources, applications and properties-a review. Brazil J Chem Eng. 2010;27(1):15-29.

385. Belda I, Ruiz J, Esteban-Fernández A, Navascués E, Marquina D, Santos A, Moreno-Arribas M. Microbial contribution to wine aroma and its intended use for wine quality improvement. Molecules. 2017;22(2):189.

386. Claus H. Microbial enzymes: relevance for winemaking. In: Biology of microorganisms on grapes, in must and in wine. Cham: Springer; 2017, p. 315-38.

387. Jagtap UB, Bapat VA. Wines from fruits other than grapes: current status. Fut Prosp Food Biosci. 2015:9:80-96.

388. Lindley MG. Fat replacer ingredients and the markets for fat-reduced foods. In: Low-calorie foods and food ingredients. Boston: Springer: 1993, p. 77-105.

389. Akoh CC. Lipid-based synthetic fat substitutes. In: Food lipids. CRC Press; 2002, p. 712-45.

390. Lim J, Inglett GE, Lee S. Response to consumer demand for reduced-fat foods; multi-functional fat replacers. Japan J Food Eng. 2010;11(4):147-52.

391. Sargent JR, Bell JG, Bell MV, Henderson RJ, Tocher DR. Requirement criteria for essential fatty acids. J Appl Ichthyol. 1995;11(3-4):183-98

392. Müllner H, Daum G. Dynamics of neutral lipid storage in yeast. Acta Biochimica Polonica. 2004;51(2):323-47.

393. Lee KT, Foglia TA, Lee JH. Low-calorie fat substitutes: synthesis and analysis. Handb Ind Biocatal. 2005;16:1-19.

394. Watanabe Y, Sato S, Asada M, Arishima T, lida Y, Imagi J, Sato C. Enzymatic analysis of positional fatty acid distributions in triacylglycerols by 1 (3)-selective transesterification with Candida antarctica lipase B: a collaborative study. J Oleo Sci. 2015:64(11):1193-205.

395. Gudmundsdottir AV, Hansen KA, Magnusson CD, Haraldsson GG. Synthesis of reversed structured triacylglycerols possessing EPA and DHA at their terminal positions. Tetrahedron. 2015;71(45):8544-50.

396. Fernandez-Lafuente R. Lipase from Thermomyces lanuginosus: uses and prospects as an industrial biocatalyst. J Mol Catal B: Enzym. 2010:62(3-4):197-212.

397. Foresti ML, Ferreira ML. Lipase-catalyzed acidolysis of tripalmitin with capric acid in organic solvent medium: analysis of the effect of experimental conditions through factorial design and analysis of multiple responses. Enzym Microb Technol. 2010;46(6):419-29.

398. Bistrian BR. Novel lipid sources in parenteral and enteral nutrition. Proc Nutr Soc. 1997;56(1B):471-7.

399. Ramırez M, Amate L, Gil A. Absorption and distribution of dietary fatty acids from different sources. Early Hum Dev. 2001;65:S95-101.

400. Straarup EM, Lauritzen L, Faerk J, Høy CE, Michaelsen KF. The stereospecific triacylglycerol structures and fatty acid profiles of human milk and infant formulas. J Pediat Gastroenterol Nutrit. 2006:42(3):293-9.

401. Teichert SA, Akoh CC. Modifications of stearidonic acid soybean oil by enzymatic acidolysis for the production of human milk fat analogues. J Agric Food Chem. 2011;59(24):13300-10.

402. Zou XQ, Huang JH, Jin QZ, Liu YF, Song ZH, Wang XG. Lipase-catalyzed preparation of human milk fat substitutes from palm stearin in a solvent-free system. J Agric Food Chem. 2011;59(11):6055-63.

403. Zhang H, Xu X, Mu H, Nilsson J, Adler-Nissen J, Høy CE. Lipozyme IMcatalyzed interesterification for the production of margarine fats in a $1 \mathrm{~kg}$ scale stirred tank reactor. Eur J Lipid Sci Technol. 2000;102(6):411-8.

404. Isaacs CE, Litov RE, Marie P, Thormar H. Addition of lipases to infant formulas produces antiviral and antibacterial activity. J Nutr Biochem. 1992;3(6):304-8.

405. Isaacs CE, Thormar H. The role of milk-derived antimicrobial lipids as antiviral and antibacterial agents. In: Immunology of milk and the neonate. Boston: Springer; 1991, p. 159-65.

406. Xiao F, Li Z, Pan L. Application of microbial lipase and its research progress. Prog Appl Microbiol. 2017; 8-14. 
407. Yan J, Liu S, Hu J, Gui X, Wang G, Yan Y. Enzymatic enrichment of polyunsaturated fatty acids using novel lipase preparations modified by combination of immobilization and fish oil treatment. Biores Technol. 2011;102(14):7154-8.

408. Peng Q, Wang X, Shang M, Huang J, Guan G, Li Y, Shi B. Isolation of a novel alkaline-stable lipase from a metagenomic library and its specific application for milkfat flavor production. Microb Cell Fact. 2014;13(1):1-9.

409. Esakkiraj P, Usha R, Palavesam A, Immanuel G. Solid-state production of esterase using fish processing wastes by Bacillus altitudinis AP-MSU. Food Bioprod Process. 2012;90(3):370-6.

410. Rebah FB, Miled N. Fish processing wastes for microbial enzyme production: a review. 3 Biotech. 2013;3(4):255-65.

411. Wickramasinghe NN, Ravensdale J, Coorey R, Chandry SP, Dykes GA. The predominance of psychrotrophic pseudomonads on aerobically stored chilled red meat. Comp Rev Food Sci Food Safety. 2019;18(5):1622-35.

412. Ribeiro JS, Santos MJ, Silva LK, Pereira LC, Santos IA, da Silva Lannes SC, da Silva MV. Natural antioxidants used in meat products: a brief review. Meat Sci. 2019;148:181-8.

413. Yang A, Mottillo EP, Mladenovic-Lucas L, Zhou L, Granneman JG. Dynamic interactions of $A B H D 5$ with PNPLA3 regulate triacylglycerol metabolism in brown adipocytes. Nat Metabol. 2019;1(5):560-9.

414. Gligor O, Mocan A, Moldovan C, Locatelli M, Crișan G, Ferreira IC Enzyme-assisted extractions of polyphenols-A comprehensive review. Trend Food Sci Technol. 2019;88:302-15.

415. Zhou CY, Pan DD, Bai Y, Li CB, Xu XL, Zhou GH, Cao JX. Evaluating endogenous protease of salting exudates during the salting process of Jinhua ham. LWT. 2019;101:76-82.

416. Lee HJ, Choe J, Kim M, Kim HC, Yoon JW, Oh SW, Jo C. Role of moisture evaporation in the taste attributes of dry-and wet-aged beef determined by chemical and electronic tongue analyses. Meat Sci. 2019;151:82-8.

417. Toldrá F, Flores M. The role of muscle proteases and lipases in flavor development during the processing of dry-cured ham. Crit Rev Food Sci. 1998;38(4):331-52

418. Vestergaard CS, Schivazappa C, Virgili R. Lipolysis in dry-cured ham maturation. Meat Sci. 2000;55(1):1-5

419. Toldrá F. The role of muscle enzymes in dry-cured meat products with different drying conditions. Trends Food Sci Technol. 2006;17(4):164-8.

420. Guillén M, Benaiges MD, Valero F. Biosynthesis of ethyl butyrate by immobilized recombinant Rhizopus oryzae lipase expressed in Pichia pastoris. Biochem Eng J. 2012;65:1-9.

421. Ahmed EH, Raghavendra T, Madamwar D. An alkaline lipase from organic solvent tolerant Acinetobacter sp. EH28: application for ethyl caprylate synthesis. Biotechnology. 2010;101(10):3628-34.

422. Chen Y, Cheong LZ, Zhao J, Panpipat W, Wang Z, Li Y, Su X. Lipase-catalyzed selective enrichment of omega-3 polyunsaturated fatty acids in acylglycerols of cod liver and linseed oils: modeling the binding affinity of lipases and fatty acids. Int J Biol Macromol. 2019;2019(123):261-8.

423. Sherwani SI, Arif IA, Khan HA. Modes of action of different classes of herbicides. In: Price A, Kelton J, Sarunaite L, editors. Herbicides, physiology of action, and safety. London: IntechOpen; 2015. https://doi. org/10.5772/61779.

424. Dekkers HP, Emeis CA, Oosterhoff LJ. Measurement of optical activity in racemic mixtures. J Am Chem Soc. 1969:91(16):4589-90.

425. Suzuki T, Kotsuki H, Isobe K, Moriya N, Nakagawa Y, Ochi M. Drastic structural change in silver (I) complexes with alteration of the optical activity of a pyridine derivative ligand: helical arrays with extended structure and an optically inactive dinuclear complex. Inorgan Chem. 1995;34(3):530-1.

426. Wu Q, Liu C, Yang J, Guan A. Ma HDesign, synthesis, and herbicidal activity of novel quaternary ammonium salt derivatives. Pest Biochem Physiol. 2017;143:246-51.

427. Thayer AM. Biocatalysis helps reach a resolution. Chem Eng News. 2006;84(33):29-31.

428. Wainer I, editor. Drug stereochemistry: analytical methods and pharmacology, vol. 18. Boca Raton: CRC Press; 1993.

429. PhD JC. The importance of stereochemistry in drug action and disposition. J Clin Pharma. 1992;32(10):925-9.

430. Brooks HW, Guida CW, Daniel GK. The significance of chirality in drug design and development. Curr Top Med Chem. 2011;11(7):760-70.
431. Mittersteiner M, Machado TM, Jesus PCD, Brondani PB, Scharf DR, Wendhausen $\mathrm{R}$ Jr. Easy and simple $\mathrm{SiO}_{2}$ immobilization of lipozyme CaLB-L: its use as a catalyst in acylation reactions and comparison with other lipases. J Brazil Chem Soci. 2017;28(7):1185-92.

432. Zhang Q, Han Y, Xiao H. Microbial a-amylase: a biomolecular overview. Process Biochem. 2017;53:88-101.

433. Ren Y, Rivera JG, He L, Kulkarni H, Lee DK, Messersmith PB. Facile, high efficiency immobilization of lipase enzyme on magnetic iron oxide nanoparticles via a biomimetic coating. BMC Biotechnol. 2011:11(1):63.

434. Basso A, Serban S. Overview of immobilized enzymes'applications in pharmaceutical, chemical, and food industry. In: Immobilization of enzymes and cells. New York: Humana; 2020; p. 27-63.

435. Samer M. Biological and chemical wastewater treatment processes. Wastewater Treat Eng. 2015; 1-50.

436. Yadav AN, Singh S, Mishra S, Gupta A, editors. Recent advancement in white biotechnology through fungi, vol. 3., Perspective for sustainable environmentsBerlin: Springer; 2019.

437. Agobo KU, Arazu VA, Uzo K, Igwe CN. Microbial lipases: a prospect for biotechnological industrial catalysis for green products: a review. Ferment Technol. 2017;6(144):2.

438. Porwal HJ, Mane AV, Velhal SG. Biodegradation of dairy effluent by using microbial isolates obtained from activated sludge. Water Resour Ind. 2015:9:1-15.

439. Bera P, Hegde MS. Recent advances in auto exhaust catalysis. J Indian Inst Sci. 2012:90(2):299-325.

440. Scarfato P, Di Maio L, Incarnato L. Recent advances and migration issues in biodegradable polymers from renewable sources for food packaging. J Appl Polym Sci. 2015;132(48):1-11.

441. Ribeiro C, Sencadas V, Costa CM, Ribelles JLG, Lanceros-Méndez S. Tailoring the morphology and crystallinity of poly (L-lactide acid) electrospun membranes. Sci Technol Adv Mater. 2011:12(1):015001.

442. Nzila A, Razzak SA, Zhu J. Bioaugmentation: an emerging strategy of industrial wastewater treatment for reuse and discharge. Int J Env Res Pub Health. 2016;13(9):846.

443. Lailaja VP. Alkaline lipase production by marine Bacillus smithii BTMS 2007; 11 .

444. MacLean E, Broger T, Yerlikaya S, Fernandez-Carballo BL, Pai M, Denkinger CM. A systematic review of biomarkers to detect active tuberculosis. Nat Microb. 2019;4(5):748-58.

445. Behera AR, Veluppal A, Dutta K. Optimization of physical parameters for enhanced production of lipase from Staphylococcus hominis using response surface methodology. Env Sci Pollut Res. 2019;26(33):34277-84

446. Olusesan AT, Azura LK, Abubakar F, Hamid NS, Radu S, Saari N. Phenotypic and molecular identification of a novel thermophilic Anoxybacillus sp.: a lipase-producing bacterium isolated from a Malaysian hotspring. World J Microbiol Biotechnol. 2009;25(11):1981-8.

447. Gao LL, Lu YC, Zhang JL, Li J, Zhang JD. Biotreatment of restaurant wastewater with an oily high concentration by newly isolated bacteria from oily sludge. World J Microbiol Biotechnol. 2019;35(11):179.

448. Chandra P, Singh DP. Removal of $\mathrm{Cr}(\mathrm{VI})$ by a halotolerant bacterium Halomonas sp. CSB 5 isolated from sāmbhar salt lake Rajastha (India). Cell Mol Biol. 2014:60(5):64-72.

449. Chandra P, Rawat AP, Singh DP. Isolation of alkaliphilic bacterium Citricoccus alkalitolerans CSB1: an efficient biosorbent for bioremediation of tannery waste water. Cell Mol Biol. 2016;62(3):135.

450. Azhdarpoor A, Mortazavi B, Moussavi G. Oily wastewaters treatment using Pseudomonas sp. isolated from the compost fertilizer. J Environ Health Sci Eng. 2014;12(1):77.

451. Martini VP, Glogauer A, Müller-Santos M, lulek J, de Souza EM, Mitchell DA, Pedrosa FO, Krieger N. First co-expression of a lipase and its specific foldase obtained by metagenomics. Microb Cell Fact. 2014:13(1):171.

452. Tsuji M, Kudoh S, Tanabe Y, Hoshino T. Basidiomycetous yeast of the genus Mrakia. In: Fungi in extreme environments: ecological role and biotechnological significance. Cham: Springer; 2019, p. 145-56.

453. Quyen T, Vu C, Le GT. Enhancing functional production of a chaperonedependent lipase in Escherichia coli using the dual expression cassette plasmid. Microb Cell Fact. 2012;11(1):29.

454. Zhang H, Li M, Li J, Wang G, Liu Y. Purification and properties of a novel quizalofop-p-ethyl-hydrolyzing esterase involved in quizalofop-p-ethyl degradation by Pseudomonas sp. J-2. Microb Cell Fact. 2017;16(1):1 . 
455. Margesin R, Labbe D, Schinner F, Greer CW, Whyte LG. Characterization of hydrocarbon-degrading microbial populations in contaminated and pristine alpine soils. Appl Environ Microbiol. 2003;69(6):3085-92.

456. Amoroso MJ, Benimeli CS, Cuozzo SA, editors. Actinobacteria: application in bioremediation and production of industrial enzymes. Boca Raton: CRC Press; 2013.

457. Ferraz LR, de Oliveira DDS, Silva MF, Rigo E, Di Luccio M, Oliveira JV, Treichel $\mathrm{H}$. Production and partial characterization of multifunctional lipases by Sporobolomyces ruberrimus using soybean meal, rice meal and sugarcane bagasse as substrates. Biocatal Agric Biotechnol. 2012;1(3):243-52

458. Vasileva-Tonkova E, Galabova D. Hydrolytic enzymes and surfactants of bacterial isolates from lubricant-contaminated wastewater. Zeitschrift für Naturforschung C. 2003;58(1-2):87-92.

459. HS AEG. Oil and grease removal from industrial wastewater using new utility approach. Adv Environ Chem. 2014: 1-6.

460. Gurung N, Ray S, Bose S, Rai V. A broader view: microbial enzymes and their relevance in industries, medicine, and beyond. BioMed Res Int. 2013;1-18: Article ID 329121. https://doi.org/10.1155/2013/329121

461. Gavrilescu M, Chisti Y. Biotechnology- a sustainable alternative for chemical industry. Biotechnol Adv. 2005;23(7-8):471-99.

462. Demuner BJ, Pereira Junior N, Antunes A. Technology prospecting on enzymes for the pulp and paper industry. J Technol Manag Innov. 2011;6(3):148-58

463. Kawamori Y, Monno S, Hashiguchi Y, Inoue Y, Hamada M. U.S. Patent No. 5,158,697. Washington, DC: U.S. Patent and Trademark Office; 1992.

464. Kirk TK, Jeffries TW. Roles for microbial enzymes in pulp and paper processing; 1996.

465. Beena PS, Basheer SM, Bhat SG, Chandrasekaran M. Garcina cambogia leaf and seawater for tannase production by marine Aspergillus awamori BTMFW032 under slurry state fermentation. Nat Prod Comm. 2011;6(12):1934578X1100601236.

466. Anastas PT, Lankey RL. Life cycle assessment and green chemistry: the yin and yang of industrial ecology. Green Chem. 2000;2(6):289-95.

467. Thanikaivelan P, Rao JR, Nair BU, Ramasami T. Progress and recent trends in biotechnological methods for leather processing. TRENDS Biotechnol. 2004;22(4):181-8.

468. Virtanen S, Chowreddy RR, Irmak S, Honkapää K, Isom L. Food industry co-streams: potential raw materials for biodegradable mulch film applications. J Polym Environ. 2017;25(4):1110-30.

469. Lusas EW, Riaz MN, Alam MS, Clough R. Animal and vegetable fats, oils, and waxes. In: Handbook of Industrial Chemistry and Biotechnology. Cham: Springer; 2017, p. 823-932.

470. Fickers P, Benetti PH, Waché Y, Marty A, Mauersberger S, Smit MS, Nicaud JM. Hydrophobic substrate utilisation by the yeast Yarrowia lipolytica, and its potential applications. FEMS Yeast Res. 2005;5(6-7):527-43.

471. Smythe CV. Microbiological production of enzymes and their industrial applications. Ecol Bot. 1951;5(2):126-44.

472. Lobedanz S, Damhus T, Borchert TV, Hansen TT, Lund H, Lai W, Kirk O. Enzymes in industrial biotechnology. Kirk Othmer Encycl Chem Technol. 2000; 1-73.

473. Sowbhagya HB, Chitra VN. Enzyme-assisted extraction of flavorings and colorants from plant materials. Crit Rev Food Sci Nutr. 2010;50(2):146-61.

474. Afsar A, Cetinkaya F. Studies on the degreasing of skin by using enzyme in liming process. 2008;15(5):507-10.

475. Kanwar SS, Verma ML. Lipases. Encyclopedia of industrial biotechnology: bioprocess, bioseparation, Cell Tech. 2009; 1-16.

476. Palivan CG, Goers R, Najer A, Zhang X, Car A, Meier W. Bioinspired polymer vesicles and membranes for biological and medical applications. Chem Soc Rev. 2016:45(2):377-411.

477. Manzo G. Hot water treatment for degreasing sheepskins. Leather Int. 2003:205(9):14-8

478. Galante YM, Formantici C. Enzyme applications in detergency and in manufacturing industries. Curr Organ Chem. 2003;7(13):1399-422.

479. Chang WJ, Horiuchi S, Takahashi K, Yamasaki M, Yamada Y. The structure and function of acid proteases. J Biochem. 1976:80(5):975-81.

480. Takahashi K, Chang WJ, Arima K. The structure and function of acid proteases: IV. Inactivation of the acid protease from Mucor pusillus by acid protease-specific inhibitors. J Biochem. 1976:80(1):61-7.
481. George N, Sondhi S, Soni SK, Gupta N. Lime and sulphide-free dehairing of animal skin using collagenase-free alkaline protease from Vibrio metschnikovii NG155. Ind J Microbiol. 2014;54(2):139-42.

482. Saran S, Chib S, Saxena RK. Biotechnology of leather: an alternative to conventional leather processing. High Value Ferment Prod Hum Welf. 2019;2:23-47

483. De Souza FR, Gutterres M. Application of enzymes in leather processing: a comparison between chemical and coenzymatic processes. Brazil J Chem Eng. 2012:29(3):473-82.

484. Tünay $\mathrm{O}$, Kabdasli I, Orhon D, Ates E. Characterization and pollution profile of leather tanning industry in Turkey. Water Sci Technol. 1995:32(12):1-9.

485. Ebrahiem MA, Turki IY, Haroun HE. The effect of breed on skin/leather quality of Sudan desert sheep. J Afr Leath Prod Adv. 2014;1(1):45-53.

486. Song JH, Murphy RJ, Narayan R, Davies GBH. Biodegradable and compostable alternatives to conventional plastics. Philosophical transac tions of the royal society B: Biol Sci. 2009;364(1526):2127-39.

487. North EJ, Halden RU. Plastics and environmental health: the road ahead. Rev Environ Health. 2013;28(1):1-8.

488. Abdel-Motaal FF, El-Sayed MA, El-Zayat SA, Ito SI. Biodegradation of poly ( $\varepsilon$-caprolactone) (PCL) film and foam plastic by Pseudozyma japonica sp. nov, a novel cutinolytic ustilaginomycetous yeast species. 3 Biotech. 2014;4(5):507-12

489. Chandra P, Enespa, Singh DP. Microplastic degradation by bacteria in aquatic ecosystem. In: Microorganisms for sustainable environment and health. Elsevier; 2020, p. 490-515.

490. Danso D, Chow J, Streit WR. Plastics: environmental and biotechnological perspectives on microbial degradation. Appl Environ Microbiol. 2019:85:e01095-19.

491. Restrepo-Flórez JM, Bassi A, Thompson MR. Microbial degradation and deterioration of polyethylene - a review. Internat Biodet Biodegrad. 2014;88:83-90

492. Wilkes RA, Aristilde L. Degradation and metabolism of synthetic plastics and associated products by Pseudomonas sp.: capabilities and challenges. J Appl Microbiol. 2017;123(3):582-93.

493. Branco RV, Estrada Gutarra ML, Freire DMG, Almeida RV (2010) Immobilization and characterization of a recombinant thermostable lipase (Pf2001) from Pyrococcus furiosus on supports with different degrees of hydrophobicity. Enzym Res. 2010; Article ID 180418.

494. Cesarini S, Infanzón B, Pastor FJ, Diaz P. Fast and economic immobilization methods described for non-commercial Pseudomonas lipases. BMC Biotechnol. 2014;14(27):1-9.

495. Durand E, Lecomte J, Villeneuve P. Deep eutectic solvents: synthesis, application, and focus on lipase-catalyzed reactions. Eur J Lipid Sci Technol. 2013;115(4):379-85.

496. Shirke AN, Basore D, Butterfoss GL, Bonneau R, Bystroff C, Gross RA. Toward rational thermostabilization of Aspergillus oryzae cutinase: insights into catalytic and structural stability. Proteins Struct Funct Bioinformat. 2016:84(1):60-72.

497. Chattopadhyay S, Sivalingam G, Madras G. Lipase specificity for the hydrolysis of poly (vinyl acetate). Polym Degrad Stabil. 2003;80(3):477-83.

498. DiCosimo R, McAuliffe J, Poulose AJ, Bohlmann G. Industrial use of immobilized enzymes. Chem Soc Rev. 2013;42(15):6437-74.

499. Noraini MY, Ong HC, Badrul MJ, Chong WT. A review on potential enzymatic reaction for biofuel production from algae. Renew Energy Rev. 2014:39:24-34.

500. Azócar L, Heipieper HJ, Navia R. Biotechnological processes for biodiesel production using alternative oils. Appl Microbiol Biotechnol. 2010;88(3):621-36.

501. Sivalingam G, Madras G. Dynamics of lipase catalyzed enzymatic degradation of poly (bisphenol-A carbonate). J Appl Polym Sci. 2004;91(4):2391-6.

502. Eberl A, Heumann S, Brückner T, Araujo R, Cavaco-Paulo A, Kaufmann F, Guebitz GM. Enzymatic surface hydrolysis of poly (ethylene terephthalate) and bis (benzoyloxyethyl) terephthalate by lipase and cutinase in the presence of surface active molecules. J Biotechnol. 2009;143(3):207-12.

503. Zumstein MT, Kohler HPE, McNeill K, Sander M. High-throughput analysis of enzymatic hydrolysis of biodegradable polyesters by monitoring 
cohydrolysis of a polyester-embedded fluorogenic probe. Environ Sci Technol. 2017;51(8):4358-67.

504. Gamerith C, Vastano M, Ghorbanpour SM, Zitzenbacher S, Ribitsch D, Zumstein MT, Guebitz GM. Enzymatic degradation of aromatic and aliphatic polyesters by P. pastoris expressed cutinase 1 from Thermobifida cellulosilytica. Front Microbiol. 2017;8:938.

505. Stroud JL, Paton Gl, Semple KT. Microbe-aliphatic hydrocarbon interactions in soil: implications for biodegradation and bioremediation. J Appl Microbiol. 2007:102(5):1239-53.

506. McGenity T, Van Meer JR, de Lorenzo V. Handbook of hydrocarbon and lipid microbiology. Berlin: Springer; 2010. p. 4716.

507. Bardach J, Fujiya M, Holl A. Investigations of external chemoreceptors of fishes. In: Olfaction and Taste II. Pergamon; 1967, p. 647-65.

508. Pettersson A, Adamsson M, Dave G. Toxicity and detoxification of Swedish detergents and softener products. Chemosphere. 2000;41(10):1611-20.

509. Lailaja VP, Chandrasekaran M. Detergent compatible alkaline lipase produced by marine Bacillus smithii BTMS 11. World J Microbiol Biotechnol. 2013;29(8):1349-60

510. Jaeger KE, Reetz MT. Microbial lipases form versatile tools for biotechnology. Trend Biotechnol. 1998;16(9):396-403.

511. Dey A, Chattopadhyay A, Mukhopadhyay SK, Saha P, Chatterjee S, Maiti TK, Roy P. Production, partial purification and characterization of an extracellular psychrotrophic lipase from Pseudomonas sp. ADT3. J Bioremed Biodegred. 2014;5(6):242.

512. Fujii T, Tatara T, Minagawa M. Studies on applications of lipolytic enzyme in detergency I. Effect of lipase from Candida cylindracea on removal of olive oil from cotton fabric. J Am Oil Chem Soc. 1986;63(6):796-9.

513. Nerurkar M, Vaidyanathan J, Adivarekar R, Langdana ZB. Use of a natural dye from Serratia marcescens subspecies Marcescens in dyeing of textile fabrics. Octa J Environ Res. 2013:1(2):129-35.

514. LiY, Li J, Li W, Du H. A state-of-the-art review on magnetorheological elastomer devices. Smart Mat Struct. 2014:23(12):123001.

515. Unni KN, Priji P, Sajith S, Faisal PA, Benjamin S. Pseudomonas aeruginosa strain BUP2, a novel bacterium inhabiting the rumen of Malabari goat, produces an efficient lipase. Biologia. 2016;71(4):378-87.

516. Niyonzima FN, More SS. Coproduction of detergent compatible bacterial enzymes and stain removal evaluation. J Basic Microbiol. 2015;55(10):1149-58.

517. Iqbal SA, Rehman A. Characterization of lipase from Bacillus subtilis I-4 and its potential use in oil contaminated wastewater. Brazil Arch Biol Tech. 2015:58(5):789-97.

518. Bacha AB, Al-Assaf A, Moubayed NM, Abid I. Evaluation of a novel thermo-alkaline Staphylococcus aureus lipase for application in detergent formulations. Saudi J Biol Sci. 2018;25(3):409-17.

519. Zhang C, Kim SK. Research and application of marine microbial enzymes: status and prospects. Mar Drug. 2010;8(6):1920-34.

520. Parra LP, Reyes F, Acevedo JP, Salazar O, Andrews BA, Asenjo JA. Cloning and fusion expression of a cold-active lipase from marine Antarctic origin. Enzym Microbial Technol. 2008;42(4):371-7.

521. Chesson A. Effects of sodium hydroxide on cereal straws in relation to the enhanced degradation of structural polysaccharides by rumen microorganisms. J Sci Food Agric. 1981:32(8):745-58.

522. Ogierman MA, Fallarino A, Riess T, Williams SG, Attridge SR, Manning PA. Characterization of the Vibrio cholerae El Tor lipase operon lipAB and a protease gene downstream of the hly region. J Bacteriol. 1997:179(22):7072-80.

523. Bacchiocchi E, Montobbio F. International knowledge diffusion and home-bias effect: do USPTO and EPO patent citations tell the same story. Scand J Econ. 2010;112(3):441-70.

524. Berka RM, Boominathan KC, Sandal T. U.S. Patent No. 5,821,102. Washington, DC: U.S. Patent and Trademark Office; 1998.

525. Trono D. Recombinant enzymes in the food and pharmaceutical industries. In: Advances in enzyme technology. Elsevier; 2019, p. 349-87.

526. Contesini FJ, Lopes DB, Macedo GA, da Graça Nascimento M, de Oliveira Carvalho P. Aspergillus sp. lipase: potential biocatalyst for industrial use. J Mol Catal B Enzym. 2010;67(3-4):163-71.

527. Lo Giudice A, Michaud L, De Pascale D, De Domenico M, Di Prisco G, Fani R, Bruni V. Lipolytic activity of Antarctic cold-adapted marine bacteria (Terra Nova Bay, Ross Sea). J Appl Microbiol. 2006;101(5):1039-48,
528. Moustafa GA, Kasama K, Higashio K, Akai S. Base-promoted lipasecatalyzed kinetic resolution of atropisomeric 1, 1'-biaryl-2, 2'-diols. RSC Adv. 2019:9(3):1165-75.

529. Aguillón AR, Avelar MN, Gotardo LE, de Souza SP, Leão RA, Itabaiana I Jr, de Souza RO. Immobilized lipase screening towards continuous-flow kinetic resolution of ( \pm )-1, 2-propanediol. Mol Catal. 2019;467:128-34.

530. Spelmezan CG, Bencze LC, Katona G, Irimie FD, Paizs C, Tosa MI. Efficient and stable magnetic chitosan-lipase B from Candida antarctica bioconjugates in the enzymatic kinetic resolution of racemic heteroarylethanols. Molecule. 2020;25(2):350.

531. Faber K. Non-sequential processes for the transformation of a racemate into a single stereo isomeric product: proposal for stereo chemical classification. Chem Eur J. 2001;7(23):5004-10.

532. Dröge MJ, Bos R, Woerdenbag HJ, Quax WJ. Chiral gas chromatography for the determination of 1, 2-O-isopropylidene-sn-glycerol stereoisomers. J Sep Sci. 2003;26(9-10):771-6.

533. Han DQ, Yao ZP. Chiral mass spectrometry: an overview. TrAC Trends in Analytical Chemistry. 2019; 115763.

534. Röttig A, Wenning L, Bröker D, Steinbüchel A. Fatty acid alkyl esters: perspectives for production of alternative biofuels. Appl Microbiol Biotechnol. 2010;85(6):1713-33.

535. Klein-Júnior LC, Mangelings D, Vander Heyden Y. Experimental design methodologies for the optimization of chiral separations: an overview. In: Separations Chiral, editor. Humana. New York: NY; 2019. p. $453-78$.

536. Borowiecki P, Paprocki D, Dranka M. First chemoenzymatic stereo divergent synthesis of both enantiomers of promethazine and ethopropazine. Beilstein J Org Chem. 2014;10(1):3038-55.

537. Ingenbosch KN, Rousek A, Wunschik DS, Hoffmann-Jacobsen K. A fluorescence-based activity assay for immobilized lipases in nonnative media. Anal Biochem. 2019:569:22-7.

538. Arana-Peña S, Lokha Y, Fernández-Lafuente R. Immobilization on octyl-agarose beads and some catalytic features of commercial preparations of lipase a from Candida antarctica (Novocor ADL): comparison with immobilized lipase B from Candida antarctica. Biotechnol Prog. 2019;35(1):e2735.

539. Muralidhar RV, Chirumamilla RR, Ramachandran VN, Marchant R, Nigam P. Racemic resolution of RS-baclofen using lipase from Candida cylindracea. Mededelingen (Rijksuniversiteit te Gent. Fakulteit van de Landbouwkundige en Toegepaste Biologische Wetenschappen). 2001;66(3a):227-32.

540. Patel RN. Microbial/enzymatic synthesis of chiral pharmaceutical intermediates. Curr Opin Drug Discov Dev. 2003;6(6):902-20.

541. Baran PS, Maimone TJ, Richter JM. Total synthesis of marine natural products without using protecting groups. Nature. 2007:446(7134):404-8.

542. Ghislieri D, Turner NJ. Biocatalytic approaches to the synthesis of enantiomerically pure chiral amines. Top Catal. 2014;57(5):284-300

543. Panke S, Wubbolts M. Advances in biocatalytic synthesis of pharmaceutical intermediates. Curr Opin Chem Biol. 2005;9(2):188-94.

544. Sharma M, Sharma R. Drugs and drug intermediates from fungi: striving for greener processes. Crit Rev Microbiol. 2016;42(2):322-38.

545. Arnold FH. Engineering enzymes for non-aqueous solvents. Trend Biotechnol. 1990;8:244-9.

546. Dong H, Gao S, Han SP, Cao SG. Purification and characterization of a Pseudomonas sp. lipase and its properties in non-aqueous media. Biotechnol Appl Biochem. 1999;30(3):251-6.

547. Huang X, Garcia-Borràs M, Miao K, Kan SJ, Zutshi A, Houk KN, Arnold FH. A biocatalytic platform for synthesis of chiral a-trifluoromethylated organoborons. ACS Central Sci. 2019:5(2):270-6.

548. Zhang Q, Wu ZM, Hao CL, Tang XL, Zheng RC, Zheng YG. Highly regioand enantioselective synthesis of chiral intermediate for pregabalin using one-pot bienzymatic cascade of nitrilase and amidase. Appl Microbiol Biotechnol. 2019:103(14):5617-26.

549. Urban MJ, Shen C, Kong XT, Zhu C, Govorov AO, Wang Q, Liu N. Chiral plasmonic nanostructures enabled by bottom-up approaches. Ann Rev Phys Chem. 2019;70:275-99.

550. Ahanger FA, Malik SM, Wani N, Sahay S, Jain K. Organic Solvent Tolerant (OST) Lipases, Sources and Industrial Applications. Res Rev: J Life Sci. 2019:9(1):32-42. 
551. Seco JM, Quiñoá E, Riguera R. Assignment of the absolute configuration of polyfunctional compounds by NMR using chiral derivatizing agents. Chem Rev. 2012;112(8):4603-41.

552. Mamo T, Moseman EA, Kolishetti N, Salvador-Morales C, Shi J, Kuritzkes DR, Farokhzad OC. Emerging nanotechnology approaches for HIV/AIDS treatment and prevention. Nanomedicine. 2010;5(2):269-85.

553. Norjannah B, Ong HC, Masjuki HH, Juan JC, Chong WT. Enzymatic transesterification for biodiesel production: a comprehensive review. RSC Adv. 2016:6(65):60034-55.

554. Rachmadona N, Amoah J, Quayson E, Hama S, Yoshida A, Kondo A, Ogino C. Lipase-catalyzed ethanolysis for biodiesel production of untreated palm oil mill effluent in water-containing system. Sustain Energy Fuel. 2020;4:1105-11.

555. Baldo F, Nguyen QL, Pham DM. U.S. Patent Application No. 12/919,371; 2011.

556. Gherardini J, Wegner J, Chéret J, Ghatak S, Lehmann J, Alam M, Ward C Transepidermal UV radiation of scalp skin ex vivo induces hair follicle damage that is alleviated by the topical treatment with caffeine. Int J Cosmetic Sci. 2019;41(2):164-82.

557. Kauffmann I, Schmidt-Dannert C. Conversion of Bacillus thermocatenulatus lipase into an efficient phospholipase with increased activity towards long-chain fatty acyl substrates by directed evolution and rational design. Protein Eng. 2001;14(11):919-28.

558. Guncheva M, Zhiryakova D. Catalytic properties and potential applications of Bacillus lipases. J Mol Catal B Enzym. 2011;68(1):1-21.

559. Horchani H, Aissa I, Ouertani S, Zarai Z, Gargouri Y, Sayari A. Staphylococcal lipases: biotechnological applications. J Mol Catal B Enzym. 2012;76:125-32

560. Brust B, Lecoufle M, Tuaillon E, Dedieu L, Canaan S, Valverde V, Kremer L. Mycobacterium tuberculosis lipolytic enzymes as potential biomarkers for the diagnosis of active tuberculosis. PLoS ONE. 2011;6(9):e25078.

561. Suzuki M, Sai JK, Shimizu T. Acute pancreatitis in children and adolescents. World J Gastrointestinal Pathophysiol. 2014;5(4):416.

562. Lerner A. Acute pancreatitis in children and adolescents. In: Textbook of gastroenterology and nutrition in infancy. New York: Raven Press; 1989, p. 897-906.

563. Chabot JA, Tsai WY, Fine RL, Chen C, Kumah CK, Antman KA, Grann VR. Pancreatic proteolytic enzyme therapy compared with gemcitabinebased chemotherapy for the treatment of pancreatic cancer. J Clin Oncol. 2010;28(12):2058.

564. Tietz NW, Shuey DF. Lipase in serum-the elusive enzyme: an overview. Clin Chem. 1993:39(5):746-56

565. Shibatani T, Matsumae H, Tosa T. Asymmetric hydrolysis of phenylgIycidate ester by esterase from serratia marcescens. In: Biochemical Engineering for 2001. Springer, Tokyo; 1992. p. 92-5

566. Furutani T, Imashiro R, Hatsuda M, Seki M. A practical procedure for the large-scale preparation of methyl (2 R, 3 S)-3-(4-Methoxyphenyl) glycidate, a key intermediate for diltiazem. J Organ Chem. 2002;67(13):4599-601.

567. Gotor-Fernández V, Vicente G. Use of lipases in organic synthesis. In: Industrial enzymes. Dordrecht: Springer; 2007, p. 301-15.

568. Idris A, Bukhari A. Immobilized Candida antarctica lipase B: hydration, stripping off and application in ring opening polyester synthesis. Biotechnol Adv. 2012;30(3):550-63.

569. Adlercreutz P. Immobilization and application of lipases in organic media. Chem. Soci. Rev. 2013;42(15):6406-36.

570. Bilal M, Asgher M, Cheng $H$, Yan Y, labal HM. Multi-point enzyme immobilization, surface chemistry, and novel platforms: a paradigm shift in biocatalyst design. Crit Rev Biotechnol. 2019;39(2):202-19.

571. Zerbini CA, McClung MR. Odanacatib in postmenopausal women with low bone mineral density: a review of current clinical evidence. Ther Adv Musculoskeletal Dis. 2013:5(4):199-209.

572. Chapurlat RD. Odanacatib: a review of its potential in the management of osteoporosis in postmenopausal women. Ther Adv Musculoskeletal Dis. 2015;7(3):103-9.

573. Laquièvre A, Allaway NS, Lyskawa J, Woisel P, Lefebvre JM, Fournier D. Highly efficient ring-opening reaction of azlactone-based copolymer platforms for the design of functionalized materials. Macromol Rapid Commun. 2012;33(9):848-55.

574. Prince RC. Biodegradation of methyl tertiary-butyl ether (MTBE) and other fuel oxygenates. Crit Rev Microbiol. 2000;26(3):163-78.
575. Okeke BC, Frankenberger WT Jr. Biodegradation of methyl tertiary butyl ether (MTBE) by a bacterial enrichment consortia and its monoculture isolates. Microbiol Res. 2003:158(2):99-106.

576. Cantone S, Ferrario V, Corici L, Ebert C, Fattor D, Spizzo P, Gardossi L. Efficient immobilisation of industrial biocatalysts: criteria and constraints for the selection of organic polymeric carriers and immobilisation methods. Chem Soc Rev. 2013:42(15):6262-76.

577. dos Santos JC, Bonazza HL, de Matos LJ, Carneiro EA, Barbosa O, Fernandez-Lafuente R, Santiago-Aguiar RS. Immobilization of CALB on activated chitosan: application to enzymatic synthesis in supercritical and near-critical carbon dioxide. Biotechnol Rep. 2017;14:16-26.

578. Serrano-Arnaldos M, Bastida J, Máximo F, Ortega-Requena S, Montiel C. One-step solvent-free production of a spermaceti analogue using commercial immobilized lipases. Chem Select. 2018;3(2):748-52.

579. Chen B, Hu J, Miller EM, Xie W, Cai M, Gross RA. Candida antarctica lipase $B$ chemically immobilized on epoxy-activated micro-and nanobeads: catalysts for polyester synthesis. Biomacromolecules. 2008:9(2):463-71.

580. Itoh T. Ionic liquids as tool to improve enzymatic organic synthesis. Chem Rev. 2017:117(15):10567-607.

581. Moradpour D, Penin F, Rice CM. Replication of hepatitis C virus. Nat Rev Microbiol. 2007:5(6):453-63.

582. de Oliveria Andrade LJ, D'Oliveira A, Junior RCM, De Souza EC, Silva CAC, Parana R. Association between hepatitis $C$ and hepatocellular carcinoma. J Global Infect Dis. 2009;1 1):33.

583. Ha S, Totten S, Pogany L, Wu J, Gale-Rowe M. Infectious Disease as Chronic Disease: hepatitis C in Canada and the importance of riskbased screening. Can Commun Dis Rep. 2016;42(3):57.

584. Nusrat S, Khan MS, Fazili J, Madhoun MF Cirrhosis and its complications: evidence based treatment. World J Gastroenterol: WJG. 2014:20(18):5442.

585. Habu D, Shiomi S, Tamori A, Takeda T, Tanaka T, Kubo S, Nishiguchi S. Role of vitamin $\mathrm{K} 2$ in the development of hepatocellular carcinoma in women with viral cirrhosis of the liver. JAMA. 2004;292(3):358-61.

586. Bagaglio S, Uberti-Foppa C, Morsica G. Resistance mechanisms in hepatitis $C$ virus: implications for direct-acting antiviral use. Drugs. 2017;77(10):1043-55

587. de María PD, de Gonzalo G, Alcántara AR. Biocatalysis as useful tool in asymmetric synthesis: an assessment of recently granted patents (2014-2019). Catalysts. 2019;9(10):802.

588. Hinckley G, Mozhaev VV, Budde C, Khmelnitsky YL. Oxidative enzymes possess catalytic activity in systems with ionic liquids. Biotechnol Lett. 2002;24(24):2083-7.

589. Tang $\mathrm{S}$, Jones $\mathrm{CL}$, Zhao H. Glymes as new solvents for lipase activation and biodiesel preparation. Bioresour Technol. 2013;129:667-71.

590. Cabrera-Padilla RY, Melo EB, Pereira MM, Figueiredo RT, Fricks AT, Franceschi E. Soares CM Use of ionic liquids as additives for the immobilization of lipase from Bacillus sp. J Chem Technol Biotechnol. 2015:90(7):1308-16.

591. Wenk MR. The emerging field of lipidomics. Nat Rev Drug Discov. 2005:4(7):594-610.

592. Jeong CY, Han YD, Yoon JH, Yoon HC. Bioelectrocatalytic sensor for triglycerides in human skin sebum based on enzymatic cascade reaction of lipase, glycerol kinase and glycerophosphate oxidase. J Biotechnol. 2014:175:7-14.

593. Vissers RJ, Abu-Laban RB, McHugh DF. Amylase and lipase in the emergency department evaluation of acute pancreatitis. J Emerg Med. 1999:17(6):1027-37.

594. Munoz A, Katerndahl DA. Diagnosis and managment of acute pancreatitis. Am Fam Phys. 2000;62(1):164-74.

595. Sikkens EC, Cahen DL, Kuipers EJ, Bruno MJ. Pancreatic enzyme replacement therapy in chronic pancreatitis. Res Clinic Gastroent. 2010;24(3):337-47.

596. Steiner JM, Rutz GM, Williams DA. Serum lipase activities and pancreatic lipase immunoreactivity concentrations in dogs with exocrine pancreatic insufficiency. Am J Vet Res. 2006;67(1):84-7.

597. Mylonakis ME, Xenoulis PG, Theodorou K, Siarkou VI, Steiner JM, Harrus $S$, Koutinas AF. Serum canine pancreatic lipase immunoreactivity in experimentally induced and naturally occurring canine monocytic ehrlichiosis (Ehrlichia canis). Vet Microbiol. 2014;169(3-4):198-202. 
598. Sen K, Rodgers M. Distribution of six virulence factors in Aeromonas species isolated from US drinking water utilities: PCR identification. J Appl Microbiol. 2004;97(5):1077-86.

599. Sun J, Zhang X, Gao X, Jiang Q, Wen Y, Lin L. Characterization of virulence properties of Aeromonas veronii isolated from diseased Gibel Carp (Carassius gibelio). Int J Mol Sci. 2016;17(4):496.

600. Higaki S, Morohashi M. Propionibacterium acnes lipase in seborrheic dermatitis and other skin diseases and Unsei-in. Drugs Exp Clin Res. 2003:29(4):157-9.

601. Garg N, Luzzatto-Knaan T, Melnik AV, Caraballo-Rodríguez AM, Floros DJ, Petras D, Phelan W. Natural products as mediators of disease. Nat Prod Rep. 2017:34(2):194-219.

602. Tan MW, Rahme LG, Sternberg JA, Tompkins RG, Ausubel FM. Pseudomonas aeruginosa killing of Caenorhabditis elegans used to identify $P$. aeruginosa virulence factors. Proc Natl Acad Sci. 1999;96(5):2408-13.

603. Dougherty JM, McCulley JP, Silvany RE, Meyer DR. The role of tetracycline in chronic blepharitis. Inhibition of lipase production in staphylococci. Invest Ophthal Vis Sci. 1991;32(11):2970-5.

604. Frühbeck G. Overview of adipose tissue and its role in obesity and metabolic disorders. In: Adipose tissue protocols. Humana Press; 2008, p. $1-22$

605. Harris WS. Fish oils and plasma lipid and lipoprotein metabolism in humans: a critical review. J Lipid Res. 1989;30(6):785-807.

606. Guilherme A, Virbasius JV, Puri V, Czech MP. Adipocyte dysfunctions linking obesity to insulin resistance and type 2 diabetes. Nat Rev Mol Cell Biol. 2008;9(5):367-77

607. Sears B, Perry M. The role of fatty acids in insulin resistance. Lipid Health Dis. 2015;14(1):121.

608. Rasouli N, Molavi B, Elbein SC, Kern PA. Ectopic fat accumulation and metabolic syndrome. Diab Obes Metabol. 2007;9(1):1-10.

609. Clee SM, Kastelein JJ, van Dam M, Marcil M, Roomp K, Zwarts KY, Suda T. Age and residual cholesterol efflux affect HDL cholesterol levels and coronary artery disease in ABCA1 heterozygotes. J Clin Invest. 2000;106(10):1263-70.

610. Takahashi M, Yagyu H, Tazoe F, Nagashima S, Ohshiro T, Okada K, Ishibashi S. Macrophage lipoprotein lipase modulates the development of atherosclerosis but not adiposity. J Lipid Res. 2013;54(4):1124-34.

611. Laplante M, Sell H, MacNaul KL, Richard D, Berger JP, Deshaies Y. PPAR-Y activation mediates adipose depot specific effects on gene expression and lipoprotein lipase activity: mechanisms for modulation of postprandial lipemia and differential adipose accretion. Diabetes. 2003:52(2):291-9.

612. Tansey J, Sztalryd C, Hlavin E, Kimmel A, Londos C. The central role of perilipin a in lipid metabolism and adipocyte lipolysis. IUBMB Life 2004;56(7):379-85.

613. Duncan RE, Ahmadian M, Jaworski K, Sarkadi-Nagy E, Sul HS. Regulation of lipolysis in adipocytes. Annu Rev Nutr. 2007:27:79-101.

614. Ahmadian M, Wang Y, Sul HS. Lipolysis in adipocytes. Int J Biochem Cell Biol. 2010:42(5):555-9.

615. Geldenhuys WJ, Lin L, Darvesh AS, Sadana P. Emerging strategies of targeting lipoprotein lipase for metabolic and cardiovascular diseases. Drug Discov Today. 2017;22(2):352-65

616. Raposo HF, Paiva AA, Kato LS, de Oliveira HC. Apolipoprotein CIII overexpression exacerbates diet-induced obesity due to adipose tissue higher exogenous lipid uptake and retention and lower lipolysis rates. Nutr Metabol. 2015;12(1):61.

617. McClave SA, Lowen CC, Kleber MJ, McConnell JW, Jung LY, Goldsmith $\sqcup$. Clinical use of the respiratory quotient obtained from indirect calorimetry. J Parent Enteral Nutr. 2003;27(1):21-6.

618. Bey L, Hamilton MT. Suppression of skeletal muscle lipoprotein lipase activity during physical inactivity: a molecular reason to maintain daily low-intensity activity. J Physiol. 2003;551(2):673-82.

619. Ferraro RT, Eckel RH, Larson DE, Fontvieille AM, Rising R, Jensen DR, Ravussin E. Relationship between skeletal muscle lipoprotein lipase activity and 24-hour macronutrient oxidation. J Clinic Invest. 1993:92(1):441-5

620. Yin W, Tsutsumi K, Yuan Z, Yang B. Effects of the lipoprotein lipase activator NO-1886 as a suppressor agent of atherosclerosis in aorta of mild diabetic rabbits. Arzneimittelforschung. 2002;52(08):610-4.

621. Kusunoki M, Kawasima M, Nishikawa H, Morimoto K, Hayami T, Hontsu S, Kawai T. Protein adsorption on patterned hydroxyapatite thin films fabricated by pulsed laser deposition. Japan J Appl Phys. 2005;44(2L):L326

622. Hasan F, Shah A, Hameed A. Purification and characterization of a mesophilic lipase from Bacillus subtilis FH5 stable at high temperature and $\mathrm{pH}$. Acta Biologica Hungarica. 2007:58(1):115-32.

623. Wang H, Eckel RH. Lipoprotein lipase: from gene to obesity. Ameri J Physiol-Endocrinol Metabol. 2009;297(2):E271-88.

624. Kushi LH, Doyle C, McCullough M, Rock CL, Demark-Wahnefried W, Bandera EV, American Cancer Society 2010 Nutrition and Physical Activity Guidelines Advisory Committee. American Cancer Society Guidelines on nutrition and physical activity for cancer prevention: reducing the risk of cancer with healthy food choices and physical activity. CA Cance J Clin. 2012;62(1):30-67.

625. Takasu S, Mutoh M, Takahashi M, Nakagama H. Lipoprotein lipase as a candidate target for cancer prevention/therapy. Biochem Res Int. 2011; 2012. Article ID 398697, 1-8.

626. Kim SJ, Park S, Kim HK. Characterization of organic solvent-tolerant lipoIytic enzyme from Marinobacter lipolyticus isolated from the Antarctic Ocean. Appl Biochem Biotechnol. 2019;187(3):1046-60.

627. Seitz EW. Industrial application of microbial lipases: a review. J Am Oil Chem Soc. 1974;51(2):12-6.

628. Barrett JC. Mechanisms of multistep carcinogenesis and carcinogen risk assessment. Environ Health Perspect. 1993;100:9-20.

629. Das SK, Hoefler G. The role of triglyceride lipases in cancer associated cachexia. Trend Mol Med. 2013:19(5):292-301.

630. Petruzzelli M, Wagner EF. Mechanisms of metabolic dysfunction in cancer-associated cachexia. Gene Dev. 2016:30(5):489-501.

631. Zaidi N, Lupien L, Kuemmerle NB, Kinlaw WB, Swinnen JV, Smans K. Lipogenesis and lipolysis: the pathways exploited by the cancer cells to acquire fatty acids. Prog Lipid Res. 2013;52(4):585-9.

632. Peretti N, Marcil V, Drouin E, Levy E. Mechanisms of lipid malabsorption in Cystic Fibrosis: the impact of essential fatty acids deficiency. Nutrit Metabol. 2005:2(1):11.

633. Anthony H, Collins CE, Davidson G, Mews C, Robinson P, Shepherd R, Stapleton D. Pancreatic enzyme replacement therapy in cystic fibrosis: Australian guidelines. J Paedia Child Health. 1999;35(2):125-9.

634. Erskine JM, Lingard CD, Sontag MK, Accurso FJ. Enteral nutrition for patients with cystic fibrosis: comparison of a semi-elemental and nonelemental formula. J Pediat. 1998;132(2):265-9.

635. Hemmerich J, Adelantado N, Barrigón JM, Ponte X, Hörmann A, Ferrer $P$, Kensy F, Valero F. Comprehensive clone screening and evaluation of fed-batch strategies in a microbioreactor and lab scale stirred tank bioreactor system: application on Pichia pastoris producing Rhizopus oryzae lipase. Microb Cell Fact. 2014;13(1):36.

636. Devery J, Milborrow BV. B-Carotene-15, 15'-dioxygenase (EC 1.13. 11.21) isolation reaction mechanism and an improved assay procedure. Br J Nutr. 1994:72(3):397-414

637. Klek S. Omega-3 fatty acids in modern parenteral nutrition: a review of the current evidence. J Clin Med. 2016:5(3):34.

638. Dauvergne P, Neville KJ. The changing north-south and south-south political economy of biofuels. Third World Quart. 2009;30(6):1087-102.

639. Hafid HS, Shah UKM, Baharuddin AS, Ariff AB. Feasibility of using kitchen waste as future substrate for bioethanol production: a review. Renew Sustain Energy Rev. 2017;74:671-86

640. Pariza MW, Johnson EA. Evaluating the safety of microbial enzyme preparations used in food processing: update for a new century. Regul Toxicol Pharmacol. 2001;33(2):173-86.

641. Stefanovic E, Kilcawley KN, Roces C, Rea MC, O'sullivan M, Sheehan JJ, McAuliffe O. Evaluation of the potential of Lactobacillus paracasei adjuncts for flavor compounds development and diversification in short-aged cheddar cheese. Front Microbiol. 2018;9:1506

642. EFSA CEP Panel (European Food Safety Authority Panel on Food Contact Materials, Triacylglycerol lipases and Processing Aids), Silano V, Barat Baviera JM, Bolognesi C, Cocconcelli PS, Crebelli R, Gott DM, Grob K, Lampi E, Mortensen A, Riviere G, Steffensen I-L, Tlustos C, Van Loveren $H$, Vernis L, Zorn H, Glandorf B, Herman L, Aguilera J, Arcella D, Maia J, Liu Y, Rainieri S, Andrew C. Scientific Opinion on the safety evaluation of the food enzyme triacylglycerol lipase from Trichoderma reesei (strain RF10625). EFSA J. 2019;17(10):5837. https://doi.org/10.2903/j. efsa.2019.5837. 
643. Talon R, Montel MC, Berdague JL. Production of flavor esters by lipases of Staphylococcus warneri and Staphylococcus xylosus. Enzy Microb Technol. 1996;19(8):620-2.

644. Oliveira ACD, Fernandes ML, Mariano AB. Production and characterization of an extracellular lipase from Candida guilliermondii. Brazil J Microbiol. 2014;45(4):1503-11.

645. Ghaly AE, Dave D, Brooks MS, Budge S. Production of biodiesel by enzymatic transesterification. American J Biochem Biotechnol. 2010;6(2):54-76.

646. Arumugam A, Ponnusami V. Production of biodiesel by enzymatic transesterification of waste sardine oil and evaluation of its engine performance. Heliyon. 2017;3(12):e00486.

647. Cai YJ, Wang L, Liao XR, Ding YR, Sun J. Purification and partial characterization of two new cold-adapted lipases from mesophilic Geotrichum sp. SYBC WU-3. Process Biochem. 2009;4:786-90.

648. Bastida A, Sabuquillo P, Armisen P, Fernández-Lafuente R, Huguet J, Guisán JM. A single step purification, immobilization, and hyper activation of lipases via interfacial adsorption on strongly hydrophobic supports. Biotechnol Bioeng. 1998;58(5):486-93.

649. Nguyen TH, Nguyen VD. Characterization and applications of marine microbial enzymes in biotechnology and probiotics for animal health. Adv Food Nutr Res. 2017:80:37-74.

650. Souza LT, Oliveira JS, Rodrigues MQ, dos Santos VL, Pessela BC, Resende RR. Macaúba (Acrocomia aculeata) cake from biodiesel processing: a low-cost substrate to produce lipases from Moniliella spathulata R25L270 with potential application in the oleochemical industry. Microb Cell Fact. 2015;14(1):87.

651. Kawakami Z, Ikarashi Y, Kase Y. Isoliquiritigenin is a novel NMDA receptor antagonist in kampo medicine yokukansan. Cell Mol Neurobiol. 2011;31(8):1203-12.

652. Yoshida Y, Wada H, Izumi K, Tokito S. Highly conductive metal interconnects on three-dimensional objects fabricated with omnidirectional ink jet printing technology. Jpn J Appl Phys. 2017;56(5):1.

653. Akoh CC, Chang SW, Lee GC, Shaw JF. Enzymatic approach to biodiesel production. J Agric Food Chem. 2007:55(22):8995-9005.

654. Uddin F. Introductory chapter: textile manufacturing processes. In: Textile manufacturing process. Intech Open; 2019.

655. Al-Zuhair S, Taher H. Supercritical fluids technology in lipase catalyzed processes. Boca Raton: CRC Press; 2016.

656. Agyei D, Shanbhag BK, He L. Enzymes for food waste remediation and valorisation. In: Improving and tailoring enzymes for food quality and functionality. Woodhead Publish; 2015, p. 123-45.

657. Shen J. Enzymatic treatment of wool and silk fibers. In: Advances in textile biotechnology. Woodhead Publish; 2019, p. 77-105.

658. Kalantzi I, Shimmield TM, Pergantis SA, Papageorgiou N, Black KD. Karakassis I Heavy metals, trace elements and sediment geochemistry at four Mediterranean fish farms. Sci Total Environ. 2013;444:128-37.

659. Xu F. Applications of oxidoreductases: recent progress. Ind Biotechnol. 2005; 1(1):38-50

660. Aguilera J, Gomes AR, Olaru I. Principles for the risk assessment of genetically modified microorganisms and their food products in the European Union. Int J Food Microbiol. 2013;167(1):2-7.

661. Magnuson B, Munro I, Abbot P, Baldwin N, Lopez-Garcia R, Ly K, Socolovsky $S$. Review of the regulation and safety assessment of food substances in various countries and jurisdictions. Food Add Contam Part A. 2013;30(7):1147-220

662. Ifeoma O, Oluwakanyinsola S. Screening of herbal medicines for potential toxicities. In: New insight toxi drug testing; 2013, p. 63-88.

663. Pariza MW, Foster EM. Determining the safety of enzymes used in food processing. J Food Protect. 1983;46(5):453-68.

664. Coenen C, Lomax TL. Auxin-cytokinin interactions in higher plants: old problems and new tools. Trend Plant Sci. 1997;2(9):351-6.

665. Flood MT, Kondo M. Safety evaluation of lipase produced from Rhizopus oryzae: summary of toxicological data. Regul Toxicol Pharmacol. 2003:37(2):293-304.

666. Maduko CO, Akoh CC, Park YW. Enzymatic interesterification of tripalmitin with vegetable oil blends for formulation of caprine milk infant formula analogs. J Dairy Sci. 2007;90(2):594-601.

667. Zhang M, Yu XW, Swapna GV, Xiao R, Zheng H, Sha C, Xu Y, Montelione GT. Efficient production of $2 \mathrm{H}, 13 \mathrm{C}, 15 \mathrm{~N}$-enriched industrial enzyme
Rhizopus chinensis lipase with native disulfide bonds. Microb Cell Fact. 2016;15(1):1-2.

668. Selvin J, Kennedy J, Lejon DP, Kiran GS, Dobson AD. Isolation identification and biochemical characterization of a novel halo-tolerant lipase from the metagenome of the marine sponge Haliclona simulans. Microb Cell Fact. 2012;11(1):72.

669. Daimer K, Kulozik U. Oil-in-water emulsion properties of egg yolk: effect of enzymatic modification by phospholipase A2. Food Hydrocolloid. 2009:23(5):1366-73.

670. Sarmah N, Revathi D, Sheelu G, Yamuna Rani K, Sridhar S, Mehtab V, Sumana C. Recent advances on sources and industrial applications of lipases. Biotechnol Prog. 2018;34(1):5-28.

671. Celligoi M, Baldo C, de Melo MR, Gasparin F, Marques T, BarrosLipase M. Properties, functions and food applications. In: Ray RC, Rosell CM, editors. Microbial enzyme technology in food applications. Boca Raton: CRC Press; 2017. p. 214-40.

672. Khumalo LW, Majoko L, Read JS, Ncube I. Characterisation of some underutilised vegetable oils and their evaluation as starting materials for lipase-catalysed production of cocoa butter equivalents. Ind Crop Prod. 2002;16(3):237-44.

673. Woodley JM. New opportunities for biocatalysis: making pharmaceutical processes greener. Trend Biotechnol. 2008;26(6):321-7.

674. Andualema B, Gessesse A. Microbial lipases and their industrial applications. Biotechnology. 2012;11(3):100.

675. Tecelão C, Guillén M, Valero F, Ferreira-Dias S. Immobilized heterologous Rhizopus oryzae lipase: a feasible biocatalyst for the production of human milk fat substitutes. Biochem Eng J. 2012;67:104-10.

676. Glogauer A, Martini VP, Faoro H, Couto GH, Müller-Santos M, Monteiro RA, Mitchell DA, de Souza EM, Pedrosa FO, Krieger N. Identification and characterization of a new true lipase isolated through metagenomic approach. Microb Cell Fact. 2011;10(1):54.

677. Yamaguchi S, Mase T. High-yield synthesis of monoglyceride by monoand diacylglycerol lipase from Penicillium camembertii U-150. J Ferment Bioeng. 1991;72(3):162-7.

678. Rabie AM. Acceleration of blue cheese ripening by cheese slurry and extracellular enzymes of Penicillium roqueforti. Le Lait. 1989;69(4):305-14.

679. Uhlig H, editor. Industrial enzymes and their applications. Hoboken: Wiley; 1998.

680. Knob A, Izidoro SC, Lacerda LT, Rodrigues A, de Lima VA. A novel lipolytic yeast Meyerozyma guilliermondii: efficient and low-cost production of acid and promising feed lipase using cheese whey. Biocat Agr Biotechnol. 2020. https://doi.org/10.1016/j.bcab.2020.101565.

681. Cai D, Klinman JP. Copper amine oxidase: heterologous expression, purification, and characterization of an active enzyme in Saccharomyces cerevisiae. Biochem. 1994;33(24):7647-53.

682. Skagerlind P, Gibson K, Wenger K, Hatzack F, Nilsson LD, Salmon S, Pedersen $\mathrm{S}$, Heldt-Hansen HP, Poulsen PB, Lund H, Oxenbøll KM. Industrial enzymes. White. Biotechnology. 2007;105:59.

683. Houde A, Kademi A, Leblanc D. Lipases and their industrial applications. Appl Biochem Biotechnol. 2004;118(1-3):155-70.

684. Undurraga D, Markovits A, Erazo S. Cocoa butter equivalent through enzymic interesterification of palm oil midfraction. Proc Biochem. 2001;36(10):933-9.

685. Farag S, Soliman NA. Biodegradation of crude petroleum oil and environmental pollutants by Candida tropicalis strain. Brazil Arch Biol Tech. 2011;54(4):821-30.

686. Li N, Zong MH. Lipases from the genus Penicillium: production, purification, characterization and applications. J Mol Catalysis B: Enzym. 2010;66(1-2):43-54

687. Khambhaty Y. Applications of enzymes in leather processing. Environ Chem Lett. 2020;18:747-69.

688. Gonçalves C, Lopes M, Ferreira JP, Belo I. Biological treatment of olive mill wastewater by non-conventional yeasts. Biol Technol. 2009;100(15):3759-63.

689. Chinedu SN, Okochi VI, Omidiji O. Cellulase production by wild strains of Aspergillus niger, Penicillium chrysogenum and Trichoderma harzianum grown on waste cellulosic materials. Ife J Sci. 2011;13(1):57-62.

690. Ten Brink HB, Flöter E, Lawrence CF, Huizinga H, Zuiderwijk MA, inventors; Conopco Inc, assignee. Enzymatic modification of triglyceride fats. United States patent US 8,431,370; 2013 . 
691. Akacha NB, Gargouri M. Microbial and enzymatic technologies used for the production of natural aroma compounds: synthesis, recovery modeling, and bioprocesses. Food Bioprod Proc. 2015;94:675-706.

692. Vaysse L, Dubreucq E, Pirat JL, Galzy P. Fatty hydroxamic acid biosynthesis in aqueous medium in the presence of the lipase-acyltransferase from Candida parapsilosis. J Biotechnol. 1997;53(1):41-6.

693. Rozalen M, Huertas FJ, Brady PV. Experimental study of the effect of $\mathrm{pH}$ and temperature on the kinetics of montmorillonite dissolution. Geochimica et Cosmochimica Acta. 2009;73(13):3752-66

694. Prieto SF, Smets J, Gil BE, Celades JF, Carda VJ, inventors; Procter, Gamble $\mathrm{Co}$, assignee. Fluid detergent compositions comprising a di-amido gellant, and processes for making. United States patent US 8,168,579; 2012

695. Kiamarsi Z, Soleimani M, Nezami A, Kafi M. Biodegradation of n-alkanes and polycyclic aromatic hydrocarbons using novel indigenous bacteria isolated from contaminated soils. Int J Environ Sci Technol. 2019;16(11):6805-16.

696. Aleu J, Bustillo AJ, Hernandez-Galan R, Collado IG. Biocatalysis applied to the synthesis of agrochemicals. Curr Organ Chem. 2006;10(16):2037-54.

697. Ghori MI, labal MJ, Hameed A. Characterization of a novel lipase from Bacillus sp. isolated from tannery wastes. Brazil J Microb. 2011;42(1):22-9.

698. Nakamura T, Nagasawa T, Yu F, Watanabe I, Yamada H. Characterization of a novel enantioselective halohydrin hydrogen-halide-lyase. Appl Environ Microbiol. 1994;60(4):1297-301.

699. Zarinviarsagh M, Ebrahimipour G, Sadeghi H. Lipase and biosurfactant from Ochrobactrum intermedium strain MZV101 isolated by washing powder for detergent application. Lipid Health Dis. 2017;16(1):177.

700. Li X, Yu HY. Characterization of an organic solvent-tolerant lipase from Haloarcula sp. G41 and its application for biodiesel production. Folia Microbiol. 2014:59(6):455-63.

701. Mnif I, Besbes S, Ellouze R, Ellouze-Chaabouni S, Ghribi D. Improvement of bread quality and bread shelf-life by Bacillus subtilis biosurfactant addition. Food Sci Biotech. 2012;21(4):1105-12.

702. Dror A, Shemesh E, Dayan N, Fishman A. Protein engineering by random mutagenesis and structure-guided consensus of Geobacillus stearothermophilus lipase T6 for enhanced stability in methanol. Appl Environ Microbiol. 2014;80(4):1515-27.

703. Nitschke M, Costa SG, Haddad R, Gonçalves LAG, Eberlin MN. Contiero J Oil wastes as unconventional substrates for rhamnolipid biosurfactant production by Pseudomonas aeruginosa LBI. Biotechnol Prog. 2005;21(5):1562-6.

704. Gerritse G, Hommes RW, Quax WJ. Development of a lipase fermentation process that uses a recombinant Pseudomonas alcaligenes strain. Appl Env Microbiol. 1998;64(7):2644-51.

705. Cardenas F, De Castro MS, Sanchez-Montero JM, Sinisterra JV, Valmaseda M, Elson SW, Alvarez E. Novel microbial lipases: catalytic activity in reactions in organic media. Enzy Microbial Technol. 2001;28(2-3):145-54.

706. Hasan F, Shah AA, Javed S, Hameed A. Enzymes used in detergents: lipases. Afr J Biotechnol. 2010;9(31):4836-44.

707. Wakelin NG, Forster CF. An investigation into microbial removal of fats, oils and greases. Biores Technol. 1997;59(1):37-43.

708. Yukselen O, Timucin E, Sezerman U. Predicting the impact of mutations on the specific activity of Bacillus thermocatenulatus lipase using a combined approach of Odocking and molecular dynamics. J Mol Recogn. 2016;29(10):466-75.

709. Toelstede S, Hofmann T. Kokumi-active glutamyl peptides in cheeses and their biogeneration by Penicillium roquefortii. J Agric Food Chem. 2009;57(9):3738-48

710. Montel MC, Masson F, Talon R. Bacterial role in flavour development. Meat Sci. 1998;49:S111-23.

711. Fukuda $\mathrm{H}$, Kondo A, Noda H. Biodiesel fuel production by transesterification of oils. J Biosci Bioeng. 2001;92(5):405-16.

712. Pérez MM, Gonçalves EC, Vici AC, Salgado JC, de Moraes MD. Fungal lipases: versatile tools for white biotechnology. In: Recent advancement in white biotechnology through fungi. Cham: Springer; 2019, p. 361-404.

713. Yeo SH, Nihira T, Yamada Y. Screening and identification of a novel lipase from Burkholderia sp. YY62 which hydrolyzes t-butyl esters effectively. J Gen Appl Microbiol. 1998;44(2):147-52.

714. Wei W, Wang R, Nie L, Yao S. Enzymatic determination of organophosphorus pesticides with a surface acoustic wave impedance sensor. Instrument Sci Technol. 1997;25(2):157-67.

715. Wang J, Meng G, Tao K, Feng M, Zhao X, Li Z, Lu JR. Immobilization of lipases on alkyl silane modified magnetic nanoparticles: effect of alkyl chain length on enzyme activity. PLoS ONE. 2012;7(8):e43478.

716. Reddy KG, Madhavi G, Swamy B, Reddy S, Reddy AV, Medhavi V. Electrochemical investigations of lipase enzyme activity inhibition by methyl parathion pesticide: voltammetric studies. J Mol Liq. 2003;180:26-30.

717. Pliego J, Mateos JC, Rodriguez J, Valero F, Baeza M, Femat R, Camacho R, Sandoval G, Herrera-Lopez EJ. Monitoring lipase/esterase activity by stopped flow in a sequential injection analysis system using p-nitrophenyl butyrate. Sensor. 2015;15:2798-811.

718. Jegannathan KR, Leong J-Y, Eng-Seng C, Pogaku R. Production of biodiesel from palm oil using liquid core lipase encapsulated in k-carrageenan. Fuel. 2010;89(9):2272-7.

\section{Publisher's Note}

Springer Nature remains neutral with regard to jurisdictional claims in published maps and institutional affiliations.
Ready to submit your research? Choose BMC and benefit from:

- fast, convenient online submission

- thorough peer review by experienced researchers in your field

- rapid publication on acceptance

- support for research data, including large and complex data types

- gold Open Access which fosters wider collaboration and increased citations

- maximum visibility for your research: over $100 \mathrm{M}$ website views per year

At BMC, research is always in progress.

Learn more biomedcentral.com/submissions 